\title{
WYPISY Z AKT KAPITUŁY W ŁOWICZU DO ZAKRYSTII, SKARBCA, BIBLIOTEKI, ARCHIWUM I KANCELARII MIEJSCOWEJ KOLEGIATY I KAPITUŁY$$
\text { Z LAT 1525-1818 }
$$ \\ OPRACOWAE I WYDAE KS. STANISEAW LIBROWSKI
}




\section{Anni 1722 continuatio}

et iuramento super secreto Venerabilis Capituli praestito. Ac tandem assignatum est mihi stallum in parte dextra post canonicos, domus certa ad residentiam cum horto, altaria duo: unum Sacrat. Corporis, alterum S. Crucis in eadem Ecclesia Collegiata, et agri cum pratis in Eowicz, et alia de iure spectantia tradita sunt mihi.

D. 8 sequb. Decembris, in capitulo generali Conceptionis:

[536] s. 770. Inventarium rerum artis musicae. Committitur perilbus Martino Lipnicki ${ }^{213}$ et Matthaeo Witkowski ${ }^{214}$ [canonicis], quatenus inventarium librorum instrumentorumque musicorum curent conscribi per magistrum Capellae et subscribi. Creabuntque mgrum Capellae dnum Urbanum Janczewski ${ }^{215}$, aut potius in eodem officio iam alias constitutum, eundem approbabunt.

\section{3}

Dieb. 18-20 Maii, in capitulo generali Pentecostes:

[537] s. 782. Recapitulatio. Lectis capitulis partialibus, praesens capitulum illa approbat.

[538] s. 782-783. Commodatio rerum ecclesiasticarum. Stando anterioribus decretis et statutis, nunc quoque statuimus et decernimus, ne res ecclesiasticae tam de rebus [s. 783] maioris, quam etiam minoris aestimationis, alias nullae sine consensu partialis capituli, commodentur et ex Ecclesia Collegiata extradantur. Exceptis ecclesiis S. Ioannis et Hospitalis S. Leonardi, quibus pro sollemnitatibus illarum possunt commodari. Semper tamen sub regestro extradentur et iuxta idem recipientur.

[539] s. 783. Adm. rndus Ulicki. Inhaerendo decreto reformationis cels. principis Stanislai in Słupów Szembek archieppi Gnesnensis ${ }^{213}$, adm. rndus Ioannes Ulicki ${ }^{217}$, post assecutam praeposituram Ecclesiae S. Spiritus Łoviciensis ${ }^{218}$, penes officium vicepraepositurae, vicecustodiae et altarium SS. Angelorum Custodum ${ }^{219}$ et S. Rochi ${ }^{220}$ in Ecclesia Collegiata Eoviciensi conservetur, nisi solus quodvis horum velit libere resignare. Et hoc ipsi soli ob merita in hac ecclesia, praesertim officium vice-

${ }^{213}$ Kan. M. Lipnicki-jak przyp. 47.

214 Kan. M. Witkowski-jak przyp. 172.

215 Urban Janczewski kapelmistrz orkiestry kolegiackiej.

${ }_{216}$ Nie znany dekret ref. arcybpa St. Szembeka do zaginionych akt wizytacyjnych archidiakonatu low. $z 1721$ r. (Polnarowskiego).

217 Zakr. ks. Ulicki kolejnym prepoz. par. Sw. Ducha.

218 Zatem ks. Trzeciak byl tylko rok ww. prepozytem.

219 Oliarz Aniołbw Stróźów w kolegiacie.

220 Oltarz Sw. Rocha w kolegiacie. 
praepositurae et vicecustodiae, tenendum et obeundum conceditur.

D. 4 Augusti, in capitulo partiali extraordinario:

[540] s. 789. Sacristianus. Praesens Ven. Capitulum rndo sacristiano dat spatium temporis duarum septimanarum ad recolligendum se, ut hoc officium sponte resignet. Alias post elapsam hanc definitionem temporis, perilris rmus Custos ${ }^{221}$ providebit de alia sufficienti persona.

D. 7 Augusti, in capitulo partiali ordinario:

[541] s. 791. Clavis a Conclavi Capitulari. Decernit praesens Ven. Capitulum, ut clavis a Conclavi Capitulari penes perilrem Procuratorem maneat ex eo, quod nunc repertum aliquas particulas auri ex ecclesia per negligentiam sacellanorum deperiisse.

D. 11 Septembris, in capitulo partiali ordinario:

[542] s. 792. Rndus S. Stominski. Siquidem ilris Ioannes Ulicki praepositus Ecclesiae Parochialis S. Spiritus, vicepraepositus Ecclesiae Collegiatae Łoviciensis, ob receptam praeposituram S. Spiritus Łoviciensis, nequit satisfacere officio vicecustodiae illudque deserit, ideo praesens Ven. Capitulum, ex recommendatione perilris $\mathrm{rmi}$ dni Custodis rndi Stephani Słomiński, huius eccelesiae rorantistae ${ }^{222}$, illum unanimi consensu suscipit et penes idem officium vicecustodiae vult conservare.

D. 14 Octobris, in capituli partiali extraordinario:

[543] s. 795. Domus rndi Sacristiani. Retulit perilris Trewani ${ }^{223}$, quod domus residentialis rndi sacristiani notabiliter indiget reparatione in tectis. Ideo praesens Ven. Capitulum committit perilri Procuratori ${ }^{224}$, ut aliquid contribuat pro his resarciendis tectis.

D. 8-13 Decembris, in capitulo generali Conceptionis:

[544] s. 799. Recapitulatio. Lectis capitulis partialibus, praesens Ven. Capitulum in toto acceptat omnia et singula tam ea, quae in capitulis ordinariis, quam extraordinariis conclusa sunt.

[545] s. 799. Liber fundationum. Ut palam fiat, et praesertim iis, quibus interest, [Capitulum] innotescat, quod omnes et singulae cuiusque diei fundationes absolvantur. Proinde procurabitur liber, in quo quilibet sacerdos, absoluta fundationis missa, tenebitur inscribere diem mensis et proprium cognomen, idque in praesentia rndi vicecustodis.

[546] s. 800. Missale ad osculum. Semper tempestive praeparetur a caeremoniario decorum missaie in mensa, tectum velo, et deferatur ad osculum dominis [praelatis et] canonicis.

[547] s. 800. Oblatum ad Altare Crucis et quorundam veterum conflatio. Immediate ante capitulum generale Conceptionis BVM obtulit pro voto rmus dnus Alexander Działyński Gnesnensis canonicus, Łoviciensis praepositus ${ }^{225}$ sat pretiosum aureum annulum ad Altare Crucifixi in Ecclesia Collegiata, introeundo in ecclesiam in parte sinistra siti $^{226}$. In quo annulo infixus est lapis saphireus, circumcirca adamantibus minutioribus septus. Obtulit simul et holosericum coloris rubri sub

221 Prat. kust. Robertson - jak przyp. 181.

222 Ks. Stefan Slomiński rorantysta, kolejny (po Ulickim) zakrystian czyli wicekustosz.

${ }^{223}$ Karol Trewani poch. wtoskiego, m.in. kanonik towicki w l. 1716-1728.

224 Kan. M. Witkowski - jak przyp. 172.

225 Aleksander Dzialyński $h$. Ogończyk, dr ob. prawa, m.in. prat. prepozyt towicki wl. 1723-1739, od 1737 biskup.

226 Oltarz Ukrzyżcivanego (Šo. Krzyża, Eugowskiego) - jak przyp. 28. 
vota suffigendum. Pro quibus oblatis summas ei gratias egit Venerabile Capitulum et, ut eadem donata in librum inventarii inserantur, praecepit. Uno eodemque decreto dat facultatem rmo dno Kobielski, singularem curam huius altaris hebenti ${ }^{227}$, conflandi quaedam minutiora vota pro cinctura Crucifixo, decora et sufficienti conficienda.

[548] s. 803. Sebum ex Arce Loviciensi. Expostulabitur ilmus Administrator ${ }^{228}$, quatenus pensiones retentas quotannis antehac pro sebo extradi solitis ad Ecclesiam Collegiatam solvi, iubeat ex proventibus Clavis Eoviciensis.

\section{4}

Die 6 Martii, in capitulo partiali extraordinario:

[549] s. 808-809. Deputati ad conscribendum rerum perilris Kobielski. [s. 809] Obtemperando mandatis Cels. ac Rmi Principis ${ }^{229}$, ut plenam possessionem perilris Krajewski ${ }^{230}$ possit sui canonicatus ${ }^{231}$ capere, res quasdam in residentia dicti canonicatus per p. Kobielski ${ }^{2{ }^{2}}$ in hypocaustis obseratas, praesens Ven. Capitulum dominis deputatis, videlicet perilbus Owsiany ${ }^{233}$ et Witkowski ${ }^{234}$ canonicis cum rndo Notario ${ }^{235}$ conscribi et inventarium confici, atque ad Locum Capitularem comportari, ibique sigillo capitulari obsigillari committit.- Nulla inseratur protestatio: A. Dzialyński C.G.P.モ. praesidens ${ }^{238}$.

D. 11 Martii, in capitulo partiali ordinario:

[550] s. 809. Sacristianus. Moneatur Sacristianus ${ }^{237}$, ut diligentior sit in suo munere. Mappas auro tectas nonnisi solis praelatis [et canonicis] ad altaria dabit.

D. 6-20 Iunii, in capitulo generali Pentecostes:

[551] s. 813. Lectio statutorum et capitulorum partialium. Lectis statutis et quibusdam ad tractandum ex iisdem annotatis, ad lectionem capitulorum partialium Domini Capitulares processerunt, ac decreta omnia tam ordinariorum, quam extraordinariorum capitulorum approbaverunt.

[552] s. 814. Petitum rndi Notarii. Habendo respectu in exacta suppletione Divinorum officiorum pro dominis capitularibus rndi Notarii, sicuti in decantatione missarum matutinarum diebus festivis et vesperarum pro dominis capitularibus debilibus et legitime impeditis, et praedicta officia Divina per se absolvere non valentibus, Perillustres Capitulares ex gratia sua decimam manipularem in villa Plyćwia ${ }^{238}$, ad

${ }_{227}$ Franciszek Antoni Kobielski h. Poraj, m.in. kanonik lowicki od $r$. 1723, od 1725 biskup.

${ }_{228}$ Adm. archidiec. gnieźn. Kretkowski - jak przyp. 205.

${ }^{229}$ Teodor Potocki h. Pilawa, arcybiskup gnieźnieński wo l. 1723-1738.

230 Jan Krajewski h. Jasieńczyk, dr ob. prawa, audytor prym. Potockiego (po Robertsonie), m.in. kanonik lowicki w l. 1724-1742.

${ }_{231}$ Kanoniz tz posiadal przed Krajewskim Kobielski.

232 Kan. F. Kobielski - jak przyp. 227.

${ }^{288}$ Kan. A. Rolicz Owsiany - jak przyp. 129.

234 Kan. M. Witkowski - jak przyp. 172.

235 Not. kap. W. Piaggia - jak przyp. 212.

236 Prał. prep. Działyński - jak przyp. 225

237 Ks. Stominski - jak przyp. 222.

238 Plyćwia wieś - jak przyp. 140. 
Capitulum pertinentem, [eidem] donant et dant obligando eundem, ut ab officiis, quoties invitatus fuerit ab aliquo dno capitulari, se non excuset.

[553] s. 816. Inventarium argenteriae. Post conflationem" praesenti anno quorundam votorum argenteorum ex Altari S. Crucis pro cinctum Crucifixi, reliquae argenteriae novum inventarium facient et subscribent librum rerum ecclesiasticarum rmi Custos ${ }^{239}$, Archidiaconus ${ }^{240}$ et Proszewski ${ }^{241}$, qui ad hunc effectum vigore praesentis decreti deputantur.

[554] s. 816-817. Liquidatio anniversariorum. Cum constet, quod multa anniversaria iuxta veterem illorum tabulam reperiantur, quorum plane iam deperdita est fundatio aut per medium provisio recipitur, nihilominus ex massa Capituli iuxta inscriptionem in tabula expressam in toto persolvantur. Proinde novam tabulam anniversariorum committit facere praesens Ven. Capitulum perilri Procuratori ${ }^{242}$ et rndo Notario ita, ut [s. 817] anniversaria de quorum non constat inscriptione, aut de quorum constat et sunt etiam deperditae, gratis absolvantur. A quibus per medium percipitur - per medium; a quibus totum - per totum persolvantur. Dando facultatem partiali capitulo praedictam tabulam ita factam approbandi, praevio tamen consensu Lociordinarii.

[555] s. 817. Accommodatio rerum ecclesiasticarum. Datur facultas accommodandi quorundam apparatuum ecclesiasticorum rndo Sacristiano ad exornationem altarium in plateis Civitatis pro sollemni processione crastina die ${ }^{243}$ per easdem plateas facienda.

[556] s. 821. Sebum ex Arce Eoviciensi. Committitur perilri Procuratori, quatenus privilegium producat ratione sebi huic Collegiatae ex Arce Łoviciensi inscripti, rmo Lipski concellario Suae Celsitudinis Primatialis ${ }^{244}$, postulando cum eodem rmo pro extraditione dicti sebi.

[557] s. 822. Scripta varia in Loco Capitulari iacentia. Ad revidenda componenda scripta, quae dispersa per Locum Capitularem iacent, deputantur rmus Archidiaconus cum rndo Notario, qui in iisdem scriptis obligationem certam perilris Zajączkowski ${ }^{245}$ investigabunt.

D. 19 Augusti, in capitulo partiali:

[558] s. 827. Iura Collegiorum. Collegiis Vicariorum, Psalteristarum et Rorantistarum nuntiabit rndus Notarius, quatenus iura sua adinveniant et parata habeant ad futurum Tribunal Petricoviense.

[559] s. 828. Petitum Promotoris SS. Angelorum Custodum. Ad postulationem rndi Promotoris ${ }^{246}$ SS. Angelorum Custodum ${ }^{247}$, ut sibi ad dispositionem apparatus Altari SS. Angelorum Custodum donati redderentur, Venerabile Capitulum decrevit, quatenus rndus Sacristianus

\footnotetext{
1 conflagrationem akta.

239 Prat. kust. Robertson - jak przyp. 181.

240 Prat. archid. Polnarowski — jak przyp. 183.

241 Kan. A. Proszewski — jak przyp. 12.

242 Kan. M. Witkowski - jak przyp. 172.

243 Boże Cialo - w czwartek 15 czerwca.

244 Jan Aleksander Lipski h. Grabie, dr teol., m.in. kanclerz Kurii prym. Potockiego $i k a n$, lowicki w $l .1724-1725$, pózniejszy biskup i kardynat.

245 Adam Zajaczkowski prep. Kośc. Szpit. Sw. Jana i kan. urodz. low.

2 246 Promotor ten czasowo nie odszukany.

247 Por. przyp. 219.
} 
praedictos omnes apparatus rndo Promotori extradat et regestrum ab eodem receptorum accipiat - -

[560] s. 828. Legata perilris Lipnicki. Coram praesenti Ven. Capitulo comparuerunt ilres et adm. rndi dni Valentinus Majorowski canonicus honorarius ${ }^{248}$ et Stanislaus Drzewiecki vicepraepositus huius Ecclesiae Collegiatae Łoviciensis ${ }^{240}$ cum tapetibus duobus, tobalio uno et alba una, quae omnia uti exsecutores perilris olim Martini Lipnicki canonici Eoviciensis ${ }^{250}$, vigore testamenti eiusdem perillustris, a se recipi et de receptis quietari postularunt. Tum etiam de annulo apud eundem p. Lipnicki per Ven. Capitulum, receptis praefatis legatis, tum etiam annulo suo proprio gratias egit pro legatis dominis exsecutoribus, et secundum voluntatem testatoris illa applicavit: ad Altare Rorantistarum ${ }^{251}$ tapetum unum et tobalium, ad Altare S. Rosaliae ${ }^{252}$ itidem tapetum unum, pro usu dominorum canonicorum ad Sacristiam albam unam. Praenominatos exsecutores quietavit tam de legatis, quam de annulo deposito, vigoreque decreti praesentis quietat.

[561] s. 828. Commodatio baldachini. Datur facultas rndo dno Sacristiano commodandi baldachinum pro imminenti festivitate $\mathrm{S}$. Hyacinthi ${ }^{253}$ Patribus Dominicanis ob respectum, quod Cels. Princeps dominus noster clementissimus apud eosdem pro dicta sollemnitate speretur. Qui Patres post finitam devotionem huius diei tenebuntur quamprimum illud reddere.

D. 8-12 Decembris, in capitulo generali Conceptionis:

[562] s. 835. Hospitale S. Leonardi. Curam Hospitalis S. Leonardi, seu potius pauperum in eodem hospitali degentium, habebit rndus Notarius cum dependentia a perilri Proszewski.

\section{5}

Die 10 Ianuarii, in capitulo partiali extraordinario:

[563] s. 838. Deputantur ad conscribendum inventarium ilris Witkowski. Item deputantur ad conscribendas res rndi Matthaei Witkowski $\mathbf{i}^{254}$, in canonia perilris dni Antonii Krobanowski ${ }^{255}$ exsistentes, perilres dni Antonius Owsiany ${ }^{256}$ et Andreas Paprocki ${ }^{257}$.

D. 20 Ianuarii, in capitulo partiali ordinario:

[564] s. 838. Crux argentea donata. Comparens personaliter ilris et adm. rndus Majorowski canonicus honorarius Ecclesiae Collegiatae Eoviciensis ${ }^{258}$, olim perilris Martini Lipnicki ${ }^{250}$ testamenti exsecutor, obtulit ex mente eiusdem p. Lipnicki canonici Łoviciensis crucem argenteam.

248 Walenty Majorouski kanonik hon. tow.

¿40 Stanistaw Drzewiecki wiceprep. kolegiaty.

2:0 Sp. kan. M. Lipnicki-jak przyp. 47.

${ }_{251}$ Ottarz Rorantystów albo Aniotów Stróźów - zob. przyp. 219.

252 Oltarz $\$$ w. Rozalii - jak przyp. 4.

253 Wówczas jeszcze 26 sierpnia.

${ }^{254} \mathrm{Ks}$. M. Witkowski - jak przyp. 172 - pozbawiony kanonii.

255 Jan Antoni Jaksa Krobanowski h. Gryf, m.in. kanonik towicki (po M. Witkowskim) $\dot{w} l$. 1725-1737.

256 Kan. A. Rolicz Owsiany - jak przyp. 129.

257 Andrzej Paprocki h. Jelita, m.in. kanonik towicki od $1722 r$.

$258 \mathrm{Kan}$. hon. W. Majorowski - jak przyp. 248.

${ }_{259} \mathrm{Sp}$. kan. M. Lipnicki - jak przyp. 47 i 250. 
ponderis marcarum septem et aliquot quadrantium, huic Ecclesiae Collegiatae legatam, Altari Rorantistarum applicandam. Qua cruce recepta et gratiis actis ilri Majorowski pro conflatione et comparatione eiusdem crucis, in librum inventarii huius Ecclesiae Collegiatae inscribendam censuerunt.

D. 22-26 Maii, in capitulo generali Pentecostes:

[565] s. 846. Recapitulatio. Lectis et mature perpensis partialibus capitulis, Domini Capitulares illa approbaverunt, excepto decreto de positione lapidum circa aedes canonicales. Ad meliorem ex actis capitularibus informationem, quae acta, et praesertim in hac materia, legere rndo Notario ${ }^{260}$ commiserunt et diligenter, ad quem praefata positio lapidum pertineat, investigare.

[566] s. 848. Candelabra oppignorata. Summam mille florenorum die 9 Decembris anno 1724 ex Monte Pietatis ${ }^{261}$ pro necessitate Venerabilis Capituli interceptam, Domini Capitulares ex summa superius specificata duorum millium tynfonum de bonis Torunensibus, per dominos deputatos allata, domino praesidi Montis Pietatis enumerandam censuerunt, prout incontinenti enumeraverunt et candelabra sex argentea, in oppignorationem data, receperunt.

D. 6 Octobris, in capitulo partiali ordinario:

[567] s. 853. Crux. Crucem argenteam ilmo et rmo dno Hieronymo Wysocki custodi Gnesnensi, praesidenti Tribunalis Regni ${ }^{262}$, data [est] facultas perilri Procuratori ${ }^{263}$ concedendi.

D. 8-12 Decembris, in capitulo generali Conceptionis:

[568] s. 857-858. Cruces argenteae. Ex Ecclesia Collegiata nostra Eoviciensi accommodatae cruces argen[s. 858]teae, una crux Lublinum, altera Petricoviam ilmis dnis Praesidentibus Tribunalis Regni, ne oblivioni dentur, hic annotantur.

\section{6}

Dieb. 11-22 Iunii, in capitulo generali Pentecostes:

[569] s. 862. Recapitulatio. Quoniam ex nonnullis decretis partialibus quaedam dubia emanarunt, ideo resolutionem et approbationem eorum in aliam [diem] Domini Capitulares ob brevitatem temporis transtulerunt.

[570] s. 865. Recapitulatio decretorum partialium capitulorum. In tractu recapitulationis decretorum capitulorum partialium a capitulo generali Festi Immac. Conceptionis BVM anni 1725 ad hocce tẻmpus Festorum Pentecostes peractorum Domini Capitulares ad decretum reinductionis ilris Witkowski ${ }^{264}$ ad canonicatum Eoviciensem pervenerunt - Reliqua decreta partialium capitulorum in toto approbantur.

[571] s. 866. Cruces argenteae. Cruces argenteae rmis dnis Praesidentibus Tribunalis Regni commodatae: 1-ma ilmo dno Lipski procancellario

260 Not. kap. W. Piaggia - jak przyp. 212.

261 Nowy, zasobniejszy Bank Pobożny (Mons Pietatis) ufundowat $w$ Eowiczu w 1720 r. arcybp St. Szembek.

262 Prat. H. Wysocki - jak przyp. 115.

26s Kan. A. Rolicz Owsiany - jak przyp. 129.

${ }^{264} \mathrm{Ks}$. M. Witkowski -- jak przyp. 172 i 254. 
Regni ${ }^{205}$, altera rmo Wysocki custodi Cinesnensi ${ }^{206}$, ut quamprimum ad Aerarium et ecclesiam restituantur, perilris Procurator ${ }^{267}$ in praefato negotio litteras ad eosdem rmos dominos scribet.

[572] s. 866. De mutuatione rerum ecclesiasticarum. Conformando se antiquis decretis, et praecipue statuto de non mutuatione rerum ecclesiasticarum, [Domini] nunc quoque statuerunt et perenniter observari volunt, ne quisquam audeat tam dominorum praelatorum vel canonicorum, quam etiam cleri, in obsequio huius ecclesiae exsistentis, de rebus ecclesiasticis mutuare sub poena arbitraria a Venerabili Capitulo in contra agentem ferenda.

D. 2 Octobris, in capitulo partiali extraordinario:

[573] s. 871-872. Conflagratio civitatis Eowicz et aedium ecclesiasticarum [30 Septembris].

D. 5 Octobris, in capitulo partiali ordinario:

[574] s. 873. Provideatur securitas ecclesiae. Quandoquidem post nupernam grandem Civitatis conflagrationem nova quotidie in eadem $\mathrm{Ci}$ vitate conspiciunt incendia, et signanter die hesterna circa horam 8-vam vespertinam aliquot denuo flamma consumpsit domos. Proinde, ne repentinum aliquod (quod Deus avertat) in ecclesia et eius turres ab igne veniat periculum, decernit praesens Ven. Capitulum, quatenus perilris Procurator subditis villae Strzelczew ${ }^{268}$ serio inculcet et demandet, ut ad custodiendam ecclesiam et eius turres per sex vigiles pro excubiis nocturnis cum securibus et instrumentis ad aquam portandam ordinent et mittant sub poenis gravibus a p. Procuratore in negligentes et pro tempore ferendis. Ut autem aqua prius sit, ad ecclesiam vasa maiora, alias przykadki, in coemeterium comportentur, similiter et ad fenestras turrium. Et ibidem, aqua infusa, impleta, maneant et conserventur. Fenestrae turrium bene obserantur et occludantur, ut omnem impetum ventorum et ignis sustinere possint. Argentum, si quod adhuc in ecclesiae altaribus reperitur, collocatum cum alio argento in Loco Capitulari, iam alias locato, asservetur et ponatur.

D. 8-11 Decembris, in capitulo generali Conceptionis:

[575] s. 876. Exornatio ecclesice. Ecclesia instante flammae calamitate de decore suo, praecipue ex argenteria altaria, denudata, ut nunc pro Festis imminentibus Natalis Christi exornentur, committitur perilri Procuratori.

[576] s. 876. Inventarium rerum et librorum ecclesiasticorum. Ad confrontationem inventarii rerum ecclesiasticorum, tum etiam Bibliothecae et reliquae supellectilis ecclesiae deputantur perilres Krajewski ${ }^{269}$ et Cyboni ${ }^{270}$ canonici.

[577] s. 876. Sacristianus. Moneat servitores ecclesiae, et praecipue sacellanum, ut diligentiam habeat sacrarii ${ }^{\text {, }}$ et praesertim ubi domini praelati et canonici se ad Divina solent exornare.

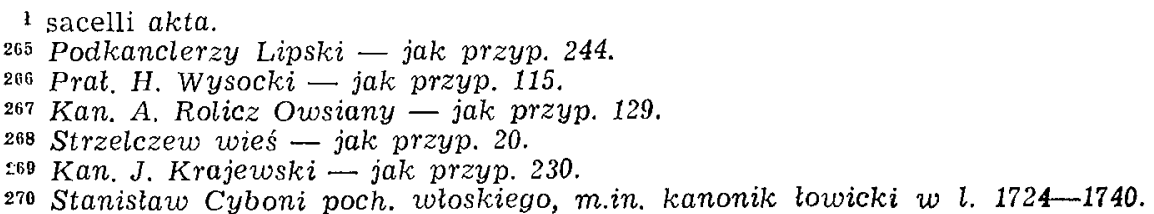


[578] s. 876. Cruces argenteae. Cruces argenteae, commodatae rmis Praesidentibus Tribunalis Regni, sunt repositae et redditae, prout perilris Procurator retulit.

[579] s. 877. Litterae ad Cels. Principem ratione litterarum ad Dominos Torunenses ${ }^{271}$ et ratione rndi Notarii. Litterae ad Celsissimum Principem ${ }^{272}$ capitulariter scribendas Domini Capitulares censuerunt postulando, ut dignetur - - Necnon recommendando merita rndi Notarii nostri Capituli ${ }^{273}$, et praesertim grassante igne singularem eius activitatem. Cuius opera residuae domus canonicales liberae et intactae ab igne permanserunt. Ut dignetur eundem quamprimum gremialis coetus canonicorum annumerare.

\section{7}

Dieb. 3 Iunii - 20 Iulii, in capitulo generali Pentecostes:

[580] s. 882. Lectio statutorum et approbatio partialium capitulorum. Post lectionem statutorum capitularium, ad recapitulationem capitulorum partialium Domini processerunt. Qua peracta recapitulatione, decreta capitulorum partialium approbaverunt et is robur generalis capituli addiderunt, et praecipue ratione Montis Pietatis.

[581] s. 887. Inventarium ecclesiae. Ad conscribendum et verificandum inventarium rerum ecclesiasticarum, videlicet apparatuum, librorum et totius supellectilis ecclesiae deputantur perilres Krajewski ${ }^{\mathbf{2 7 4}}$ et $\mathrm{Cy}$ boni ${ }^{275}$.

\section{KSIĘGA DZIESIĄTA}

\section{OPIS}

Skrócony tytuł nadany (przeze mnie, tu) - Liber X: Acta actorum Venerabilis Capituli Insignis Collegiatae Koviciensis 1727-1746.

Księga nie posiada tytułu, który przypuszczalnie miał być umieszczony na $1 \mathrm{k}$. ochr. A może nie zamierzano go redagować, albowiem od str. 1 kontynuuje sie tu akta kapituły gen. Pentecostes, z której sprawozdanie zaczęto pisać na końcu poprzedniej księgi.

W opracowanym na przeł. XVIII/XIX w. przez notariusza Śladeckiego ${ }^{1}$ spisie zawartości tej jednostki aktowej posiada ona następujący nagłówek: Index decretorum capitularium Insignis Collegiatae Łoviciensis libri septimi, a die 1 Iulii anni 1727 (s. 110).

Sygnatury:

Not. Sladeckiego umieszczona na $1 \mathrm{k}$. ochr. wysoko: Liber Actorum $7^{\mathrm{mus}}$. Dla niego była to rzeczywiście siódma $\mathrm{z}$ kolei zachowana (realna) jednostka. $\mathrm{Na}$ s. 1, w lewym górnym rogu, dodał on: [liber] $7^{\text {mus }}$.

271 Magistrat Toruński.

272 Arcybiskup Potocki - jak przyp. 229.

a73 Not. kap. W. Piaggia - jak przyp, 212.

27 Kan. J. Krajewski - jak przyp. 230.

275 Kan. St. Cyboni - jak przyp. 270.

1 Piotr Sladecki, m.in. notariusz kapituly w latach 1796-1809. 
Sygn. późniejsza, z przeł. XIX/XX stulecia, idealna, znajdująca się na tejże k. ochr. w gónnym prawym rogu: A. 1. 9 [powinno być: 10].

Sygn. aktual. (moja, tutaj): AKE, ks. ideal. 10, real. 6.

Sygn. mikr. Ośrodka ABMK: 3522.

Księga in folio, stron 586, język łaciński i rzadko polski. Oprawa współcz. w skórę. Stan zachowania dobry. Ze str. 533 przeskok na s. 544 , ze s. 549 na 560 .

\section{WYPISY}

\section{Anni 1727 continuatio}

Die 18 Iulii, contin. capituli generalis Pentecostes:

[582] str. 2. Crux accommodatur. Rmo archidiacono, Tribunalis Regni praesidenti ${ }^{2}$ crux accommodatur argentea. Pro qua seorsivum scriptum $a b$ eodem praesidente scriptum intercedet.

D. 27 Septembris, in capitulo partiali ordinario:

[583] s. 10. Litterae innotescentiales in ordine ad visitationem. In praesenti capitulo productum est publicum edictum celmi et rmi principis Theodori Potocki Dei et Apostolicae Sedis gratia archiepiscopi Gnesnensis - - manu eius propria in Arce Eoviciensi die 26 mensis Septembris anno praesenti subscriptum et sigillo maiori communitum, in ordine ad peragendam visitationem [generalem] huius Ecclesiae Collegiatae Łoviciensis. Quod publicum edictum in capitulo lectum Dominis Capitularibus, valvis Loci Capitularis affigere decreverunt, cunctaque omnia pro eadem visitatione facienda, quod cui ex munere sui incumbit praeparare, praecommiserunt.

D. 8-10 Decembris, in capitulo generali Immac. Conceptionis BMV:

[584] s. 13. Approbatio capitulorum partialium. Capitulorum a generali capitulo Pentecosten anni praesentis 1727 ad modernum capitulum omnium partialium decreta approbantur et in suo robore conservantur.

[585] s. 15. Postulatum rev. Notarii. Habendo respectum residentiae notarii ${ }^{3}$, post conflagrationem sumptu eiusdem restauratae, eidem triginta sex florenos dandos Ven. Capitulum decrevit.

\section{8}

D. 24 Ianuarii, in capitulo partiali ordinario:

[586] s. 18. Petitum PP. Scholar. Piarum. Comparens personaliter adm. rev. pater Paulus a S. Andrea rector Scholarum Piarum expostulavit, vigore testamenti olim perilris Matthaei Witkowski canonici Łoviciensis, deputationem canonicorum ad extraditionem librorum certorum per praefatum p. Witkowski Collegio suo Łoviciensi legatorum. Et perilres Domini Canonici deputaverunt ad praefatam librorum extraditionem pp. Antonium Owsiany et Stanislaum Cyboni canonicos.

D. 13 Martii, in capitulo partiali ordinario:

2 Maciej Aleksander Soltyk h. wtas,, m.in. prat. archid, towicki w l. 1725-1728, biskup.

s Wojciech Piaggia, w dc. not. kap. 
[587] s. 23. Visitatio celmi Principis imminet. Praefixa visitationis dies per celmum ac rmum Principen _... facienda Ecclesiae huius Collegiatae foviciensis, videlicet dies sexta Aprilis, ut quantocitius nonnullis innotescere possit Dominis Capitularibus non longe a Łovicio commorantibus, committitur rev. notario, quatenus ad eosdem capitulares dirigat litteras. Ut autem omnia sint parata et suo ordine disposita pro receptione eiusdem celmi Principis ad ecclesiam et visitationem, admoneatur rev. sacristianus ${ }^{4}$ Collegia similiter Vicariorum, Rorantistarum et Psalteristarum, [ut] iura et privilegia sua praeparent celmo Principi producenda.

D. 20 Maii, in capitulo generali Pentecostes:

[588] s. 26. Postulatum PP. Dominicanorum. Cupientes Patres Ordinis S. Dominici imagines Sanctarum Agnetis et Columbae, non adeo pridem canonizatarum Virginum, sollemniter in urbem et suam ecclesiam crastina die recipere, postulaverunt in praesenti capitulo, ut processionem ab hac Ecclesia Collegiata possint instituere et eidem in personis suis Domini Capitulares velint assistere, atque nonnullas res ad exornationem ecclesiae, tum etiam portae triumphalis mutuare. Quorum petitioni annuit Ven. Capitulum, offerendo se assistere eidem processioni et ornamenta, videlicet obicia, dy w n y et alia iuxta certum regestrum mutuare.

D. 24 Maii, itidem in capitulo gen. Pentecostes:

[589] s. 27-28. Receptio Celsissimi Principis in ordine ad visitationem.

D. 2 Octobris, in capitulo partiali ordinario:

[590] s. 44. Workowe et dzwonne. Ad percipiendum calculum a rev. sacristiano wo r k o w e g o et $\mathrm{d} \mathrm{z}$ w o $\mathrm{n}$ n e go deputantur perilres Krajewski et Cyboni [canonici]. Quo recepto, in desiderio suo idem rndus sacristianus, ratione debiti a perilri olim Proszewski [canonici] pro missis ad maius altare absolutis, contentabitur.

[591] s. 44-45. Crux accommodanda. [s. 45] Ilmus ac rmus Trzciński. [decanus] praesidens Tribunalis Regni Petricoviam pro inchoatione iudiciorum tribunalitiorum proficiscens, petiit sibi crucem argenteam, huius Ecclesiae Collegiatae propriam, accommodari. Cuius petitioni Ven. Capitulum satisfaciendo praefatam crucem accomodandam decrevit.

D. 8-9 Decembris. Capitulum generale Conceptionis, s. 45-46. D. 30-31 Dec. Continuatio gen. cap. Conc., s. 46-49:

[592] wklejka pom. s. 46 i 47. Reassumptio gen. cap. Conceptionis: Dispositio et determinatio arearum [post conflagrationem civitatis a. 1726$]$.

[593] s. 48. Decretum reformationis inserendum ${ }^{5}$.

\section{9}

D. 8 Ianuarii, in capitulo partiali ordinario:

[594] s. 50-51. Installatio perilris Piaggia ${ }^{6}$.

- Stefan Stomiński, $w$ dc. zakrystian kolegiaty.

5 Wpisano go dopiero pod r. 1736 (s. 184-188). Do naszego tematu nie ma $w$ nim: niczego.

${ }^{6}$ Wojciech Piaggia, dotychcz, not, kap. i kan, hon. oraz prepoz. par. Gtowno, mian. 2 stycz. 1729 r. kan. grem. 
D. 7 Iunii - 4 Iulii, in capitulo generali Pentecostes:

[595] s. 54. Sepulcra. Abhinc civitatenses non humandi in sepulcris archiepiscopalibus ${ }^{7}$, serio rev. sacristiano inhibet Ven. Capitulum.

[596] s. 56 (11 Iunii). Plenipotentes ad causam rmi Custodis. Rmus custos ${ }^{8}$ de recuperatione sui stalli et praecedentiae querulatus est contra rmum archidiaconum ". Ad procedendum vero in hac causa cum eodem rmo archidiacono suos veros et legitimos in plenipotentes perilres et adm. rndos Ioannem Krajewski, Stanislaum Cyboni et Ludovicum Trwaliński [canonicos] eligit, inscribit et ordinat.

[597] s. 57 (14 Iunii). Organa. Reparatio organi, quoniam indiget magno sumptu et massa capitularis exigua adpraesens est, proinde, ut eorundem reparatio quantocitius effectuari possit, deputantur ad suplicandum Celsissimo Principi - - ut dignetur dare facultatem oppignorandi argenteriam ecclesiasticam, in reparationem praefatorum organorum convertendam, et postea quamprimum restituendam; videlicet deputantur rmus Działyński ${ }^{10}$ et Trwaliński.

[598] s. 57. Dzwonne et workowe. Rev. sacristianus calculum wor$\mathrm{kow}$ e go i d z w o n n e g o reddat perilri procuratori.

[599] s. 58 (18 Iunii). Gratia Ven. Capituli Notario. Ut alacriorem Venerabile Capitulum habeat rev. notarium ${ }^{11}$ ad sua obsequia, dantur ei decimae ex bonis Plyćwia et Swięte ${ }^{12}$.

[600] s. 58 (4 Iulii). Reassumptio capituli generalis. nis:

D. 8 Decembris - 3 Ianuarii a. 1730 , in capitulo generali Conceptio-

[601] s. 63 (2 Ianuarii). Revisio Sacrarii. Ad revisionem Sacrarii deputantur perilres et rndi dni Antonius Owsiany, Adamus Zajączkowski canonici. Insuper committitur iisdem dominis, ut bonum ordinem faciant.

[602] s. 63. Dolium vini [ad Sacristiam]. Quoniam a Celsissimo Principe est declaratum et, ut ad effectum declaratio deducatur, committitur alicui ex perilribus et adm. rndis canonicis, ad Aulam exsistentibus, commemoratio illius.

\section{0}

D. 30 Maii - 3 Iunii, in capitulo generali Pentecostes:

[603] s. 68. Locus tertiae dignitatis. Perilris et rmus Custos ${ }^{13}$ sibi reservat locum tertiae dignitatis.

[604] s. 68. Apparatus a Celmo Principe oblatum. Quoniam Celmi Principis gratia vix non incessanter in nonnullis pro ornamento Ecclesiae Collegiatae apparentiis et apparatibus confluere non desinet, Domini Capitulares non solum pro praeteritis, sed etiam pro praesenti apparatu co-

7 Przypuszcz. chodzito o miejsca na cmentarzu grzebalnym.

${ }^{8}$ Jan Wilhelm Robertson $d r$ ob. prawa, m.in. praz. kustosz low. $w$ l. 1719$-1753$

9 Łukasz Wielowiejski h. Poraj, biskup tyt. Cambisopolitanus, prat. archid. łow. $w l .1728-1742$.

10 Aleksander Dziatyński h. Ogończyk, dr ob. prawa, m.in. pral. prepoz. low. w l. 1723-1739, biskup.

11 Ks. Wloszkiewicz, przelotny not. kap., $z$ którego nie byta ona zadowolona.

12 Płyćwia wieś w par. Godzianów; Swięte w. na terenie par. Maków.

18 Jak przyp. 8. 
loris albi deputarunt de gremio sui pro agendis gratiis Celmo Principi perilrem et rmum dnum Robertson custodem cum perilri Antonio Owsiany canonico.

[605] s. 69. Revisio Sacrarii. Pro revisione Sacrarii et apparamentorum deputantur perilres dni Antonius Owsiany et Adamus Zajączkowski [canonici].

D. 5 Augusti, in capitulo partiali ordinario:

[606] s. 73. Particula reliquiae S. Nicolai Epi donatur. In praesenti capitulo perilris et rmus Alexander Działyński canonicus Gnesnensis, praepositus Eoviciensis, praesentis capituli praesidens obtulit et dono dedit huic Ecclesiae Collegiatae particulam reliquiae Sancti Nicolai Episcopi, patroni huius ecclesiae, argento obvolutam cum authenticis litteris, ex Urbe exportatam. Pro qua Venerabile Capitulum gratias egit et eandem Celmo Principi - - in ordine ad admissionem eiusdem, ut publice exponi populo possit, perilrem Trwaliński [canonicum] deputavit.

D. 5 Octobris, in capitulo partiali extraordinario:

[607] s. 76. Vinum acetosum. Residuitas vini acetosi, non valens ad usum Missae Sacrificii, distribuatur inter praesentes.

D. 8-12 Decembris, in capitulo generali Conceptionis:

[608] s. 79. Loca vacua. Datur facultas partiali capitulo loca decretis capituli generalis Pentecosten, in actis Capituli per ilrem notarium non inducta, inducendi et ad tenorem, prout decisum erat in dicto capitulo, describendi.

\section{1}

D. 2 Ianuarii, in capitulo partiali extraordinario:

[609] s. 82. Rev. Notarius resignat notariatum. Comparens personaliter ilris et adm. rndus Włoszkiewicz ${ }^{14}$ secretarius Capituli gratias egit Dominis Capitularibus pro officio et omnem notariatus hactenus a se tento, unaque altaria ad idem pertinentia resignavit postulando, ut sibi concernens a perilri procuratore per duo quartualia retentum reddatur. Et Perillustres Domini attento eo, quia rndo Sciborowicz ${ }^{15}$, qui duobus quartualibus absolvebat Missae Sacrificia pro dno notario, debentur plus quam quinquaginta floreni, tum quod acta stante notariatu eiusdem dni Włoszkiewicz non sunt connotata et ad mundum descripta, tum quod punctatori ${ }^{18}$ consolatio aliqua debeat dari, qui hocce tempore pro dno notario connotabat praesentias; adeoque centum florenos eidem ilri notario dandos censuerunt, reliquum rndo Ściborowicz et huic, qui describet ad mundum acta, cedet.

D. 13 Ianuarii, in capitulo partiali ordinario:

[610] s. 83. Notarius Capituli. Quoniam Venerabile Capitulum deliberat super subiecto promovendo ad secretariatum Ven. Capituli, ne tantisper obligationes, quae sunt annexae officio notariatus, videlicet missa una ad Altare Sacratissimi Corporis ${ }^{17}$, altera ad Altare Sanctae Crucis ${ }^{18}$

\footnotetext{
14 Por, przyp. 11.

15 Tomasz Sciborowicz kaptan kolegiaty.

16 Not: Wtoszkiewicz nie był punktatorem.

17 Ottarz Bożego Ciała $w$ kolegiacie, objaśniany wyżej.

18 Ottarz Swietego Krzyża, powyżej objaśniany.
} 
quavis septimana absolvendae, ideo perilris procurator aliquem presbyterum substituat, ut praefatas obligationes absolvat.

D. 16 Ianuarii, in capitulo partiali extraordinario:

[611] s. 85. Suscipitur Notarius Capituli. Ad officium secretariatus sui Perillustres et Reverendissimi Domini suprascripti unanimi voto susceperunt adm. rev. Stanislaum Drzewiecki vicepraepositum Ecclesiae Collegiatae Łoviciensis, curatum Bednariensem ${ }^{19}$, incorporando eidem altaria SS. Corporis Christi, alterum S. Crucis, ut obligationibus praefatorum altarium satisfaciat, praevio solito salario. Qui supradictus adm. rndus electus secretarius iuramentum corporale super servandis secretis capitularibus praestabit et installatus erit a per perilres dnos Adalbertum Piaggia et Adamum Zajączkowski canonicos.

D. 15-18 Maii, in capitulo generali Pentecostes:

[612] s. 89. Cappalia. Ad tenorem statutorum Venerabilis Capituli nostri perilri procuratori perillustres domini, qui necdum persolverunt cappalia, solvant, modernum capitulum decrevit.

[613] s. 90 (17 Maii). Negotium cum dna Jaszczewska. Requirat perilris dnus procurator dominam Jaszczewska ${ }^{20}$, post pie defunctum maritum suum cantorem huius Ecclesiae Collegiatae -de manuscriptis musicalibus, quae sunt connotata in regestro.

\section{2}

D. 15 Septembris, in capitulo partiali extraordinario:

[614] s. 112. Particula Ligni Vitae. Ortus est ex certis rationibus scrupulus ratio[ne] particulae Ligni Vitae, acsi aliquo casu, ab immemorabili tempore, eadem particula Ligni Vitae ex hierotheca argentea deaurata, $a^{\mathbf{b}}$ in conservandum praeparata, deperisset? Proinde ad amovendum scrupulum visum est Dominis Capitularibus rmum dnum Suffraganeum ${ }^{21}$, postquam redierit, postulare, ut recepta licentia ilmi dni Lociordinarii, eandem hierothecam revideat et particulam Ligni Vitae (si quae inclusa reperitur) reseret, perrequirat. Interea acta annorum superiorum relegantur, si quid de eodem Ligno Vitae non informabunt, et maxime, si fuerit authenticum?

[615] s. 112. Crux accommodatur. Ilmus dnus suffraganeus Culmensis, praepositus Gnesnensis ${ }^{22}$ petiit in praesenti capitulo crucem aliquam argenteam huius Ecclesiae Collegiatae sibi Petricoviam pro iudiciis generalibus accommodari. Huius Domini Capitulares annuerunt atque unam crucem, praevio ab eodem assecurationis scripto in ordine ad eandem reddendam post feliciter finita iudicia, accommodare decreverunt.

D. 22 Septembris, in capitulo partiali extraordinario:

[616] s. 113. Revisio Sacristiae. Ex casu, quo in hac Ecclesia Collegiata per incuriam rev. sacristiani ${ }^{23}$ nunc est deperditum turibularium,

a est akta.

b ad akta.

19 Ks. Stanistaw Drzewiecki, nowy notariusz kapituty.

20 Jaszczewska wdowa po kantorze kolegiaty.

21 Józef Michat Trzciñski h. Rawicz, dr ob. prawa, m.in. prat. dziekan low. w l. 1719-1738, biskup.

${ }_{22}$ Maciej A. Soltyk - jak przyp. 2.

${ }^{2 s}$ Ks. Stefan Stomiński - jak przyp. 4. 
inante navicula, ideo deputantur ad conscribendum huius ecclesiae supellectilem perilres dni Adalbertus Piaggia et Adamus Zajączkowski canonici. Et praefatum rndum sacristianum moneant, ut habeat meliorem atque diligentiorem attendentiam Sacristiae, faciatque quotidie superiori praelato vel canonico ex praesentibus, in absentia perilris procuratoris, de argenteria ecclesiastica relationem. Et quoniam ex pura et supina negligentia rev. sacristiani hoc damnum factum est, licetsi in hoc capitulo ob illius negligentiam esset amovendus, tamen praesens capitulum paterne. cum illo procedendo, ad futurum generale capitulum hanc amotionem ob spem correctionis distulit. Vigore autem inantecedenti facti decreti generalis capituli ex accidentibus ${ }^{c}$ ecclesiasticis omnino faciat calculationem.

D. 19 Octobris, in capitulo partiali extraordinario:

[617] s. 114. Turibularium. Ad combinationem in solutionem a turibulario deputantur perilres dni Antonius Owsiany, Stanislaus Cyboni, Adalbertus Piaggia et Adamus Zajączkowski canonici. Pro qua iuxta combinationem solutione debent persolvere adm. rndus sacristianus et vicesacristianus atque ministri ecclesiae, id est świąt nicy, qui protunc in servitio ecclesiae fuerunt, ex quo per illorum incuriam factum est hoc damnum.

D. 8-10 Decembris, in capitulo generali Conceptionis:

[618] s. 116 (10 Decembris). Inventarium ecclesiasticum. Comittitur iisdem dominis, qui sunt per partiale capitulum deputati, inchoata revisio ut quam citius perficiatur.

[619] s. 116. Turibularium. Retulit perilris Piaggia procurator, quod turibularium novum, iuxta mentem et dispositionem Venerabilis Capituli, iusserit conficere ponderis ${ }^{24}$.

[620] s. 116. Sacristianus. Reassumitur decretum simul et approbatur partialis capituli sub die 22 Septembris contra rev. sacristianum factum et committitur perilri procuratori hocce decretum ad exsecutionem deducere, una et calculum cum ipso facere.

\section{3}

D. 31 Martii, in capitulo [partiali] extraordinario:

[621] s. 120. Vasa Ecclesiae Meaetropolitanae. Ad requisitionem perilris rmi procuratoris Gnesnensis ${ }^{25}$ Ven. praesens Capitulum vasa stannea extradi mandavit, quae Gnesna p. m. ilmus Mdzewski suffraganeus Gnesnensis ${ }^{20}$ huc Łovicium attulit, salva repetitione minorum vasorum, similiter stanneorum, propriorum Ecclesiae huius Collegiatae Łoviciensis.

D. 26-30 Maii, in capitulo generali Pentecostes:

[622] s. 121 (27 Maii). Medietas Sacellani. Praesens capitulum decrevit medietatem b a $\mathrm{w}$ y detruncare sacellano pro turibulario deperdito ob incuriam illius.

[623] s. 122. Crux canonicalis. Perilris dnus procurator curabit reparationem praefatae crucis ex massa capitulari.

c accidentiis akta.

24 Zalanie urwane.

25 Prokurator kapituly metropolitalnej.

${ }_{26}$ Stefan Antonin Mdzewski h. Dołega, m.in. prat. archid. low. w l. 1703-1716 
[624] s. 122. Inventarium ecclesiasticum et Bibliothecae. Reassumitur decretum inante latum, et deputantur ad conficiendum inventarium ecclesiasticum simul et Bibliothecae perilres dni Krajewski et Piaggia [canonici].

[625] s. 123 (29 Maii). Sacristianus. Auctoritate praesentis capituli commissum perilri dno procuratori faciendi calculum ex accidentibus ${ }^{\mathrm{d}}$ ecclesiasticis cum rndo sacristiano. tionis:

D. 8 Decembris - 18 Ianuarii a. 1734, in capitulo generali Concep-

[626] s. 129 (18 Ianuarii). Inventarium ecclesiasticum. Partiali capitulo datur facultas facere inventarium cum. rev. sacristiano.

\section{4}

D. 15-22 Iunii, in capitulo generali Pentecostes:

[627] s. 132 (19 Iunii). Decima in Płyćwia et Swięte. Venerabile Capitulum, volendo allacriorem sibi reddere ad obsequia ilrem notarium, eidem decimam post villas Płyćwia et Święte ${ }^{27}$, ad Ven. Capitulum spectantes, donat.

D. 3 Augusti, in capitulo [partiali] extraordinario:

[628] s. 135. Residentia pro ilri Notario. Praesens capitulum pro exstruenda residentia rndi notarii ducentos florenos ex massa capitulari extradendos dno procuratori mandavit.

D. 8-11 Decembris, in capitulo generali Conceptionis:

[629] s. 136 (11 Dec.). Lectio statuorum et recapitulatio. Lectis statutis, more solito, praesens capitulum ad recapitulationem praeteriti generalis capituli et partialium accessit.

\section{5}

D. 31 Maii - 3 Iunii, in capitulo generali Pentecostes:

[630] s. 140. Lectio statutorum et recapitulatio. Lectis statutis Domini Capitulares ad normam eorundem ulteriora tractanda in praesenti capitulo decreverunt.

[631] s. 141 (1 Iunii). De testamentis. Statuta et privilegia de testamentis approbandis per Capitulum post fata Dominorum reserantur, tractatus vero commodiori tempore relinquitur.

D. 8--20 Decembris, in capitulo generali Conceptionis:

[632] s. 152 (10 Dec.). Turnus. Praesens Ven. Capitulum decrevit, quatenus dnus notarius Capituli conscribat regestrum dominorum praelatorum et canonicorum tam dignitatis, quam senii in tabella.

[633] s. 155 (19 Dec.). Decreta bina pro parte perilris Zajaczkowski. Compertum est ex actis capitularibus, qualiter ilris secretarius decreta bina generalis unum, aliud partialis capitulorum, favore perilris Zajączkowski ${ }^{28}$ lata, ad protocollum actorum non induxerit. Extractum tamen eorum pro dicto perilri canonico, sigillo Capituli communitum et manu sua subscriptum, in uno folio extradiderit, notariumque exinde suspicio-

d accidentiis akta.

27 Por. przyp. 12.

28 Adam Zajaczkowski h. Zaręba? m.in. kan. low. w l. 1729-1770. 
nis alicuius traxit. Sed quoniam in praesenti capitulo generali ex se plenariam fecit excusationem, quod eadem decreta non in protocollo, sed in chartis manibus perilrium Dominorum correcta sibi data, in multitudine actorum occultata fuisse, moderno in capitulo repererit. Proinde Venerabile Capitulum, inculcata maiori diligentia ilri secretario, liberum ab omni suspicione pronuntiavit. Eadem tamen decreta in acta moderni capituli generalis, ut inducat, demandavit. Et quidem primum prius inducat, post inductionem illius, secundo titulum faciet talem: Decreti secundi sequitur tenor talis. Insertis taliter ambobus, ilmus suffraganeus Gnesnensis, decanus, praesidens protunc capituli manu sua, cum duobus perilribus canonicis ex senio, actum praesentem cum duobus decretis suprascriptis subscribet, praesentis decreti vigore.

\section{6}

D. 22 Maii — 2 Iunii, in capitulo generali Pentecostes:

[634] s. 159. Recapitulatio decretorum. Capitulorum a generali capitulo Conceptionis anni praeteriti 1735-ti ad modernum capitulum omnia partialia decreta approbantur et in suo robore conservantur.

[635] s. 161 (23 Maii). Reliquiae S. Victoriae. Supplicandum censuit praesens generale capitulum Celmo Principi, quatenus deputet aliquem ad obsigillandas reliquias Sanctae Victoriae ${ }^{29}$. Et deputavit in hoc negotio perilres rmos dnos Ioannem Krajewski et Antonium Krobanowski [canonicos].

[636] s. 161 (24 Maii). Psalteristae. Quoniam Collegium Psalteristarum ${ }^{30}$ obligationibus suis non satisfacit, proinde ad videndam erectionem et obligationes eorundem deputantur perilres dni Adalbertus Piaggia et Stanislaus Tarnowski [canonici], ad referendum Venerabili Capitulo.

[637] s. 162. Rorantia. Post fata rev. Stephani Słomiński ${ }^{31}$ confertur rndo Matthiae Dąbrowski beneficium rorantiae, et ad quem de iure instituetur.

[638] s. 162. Vicecustos. Venerabile Capitulum attentis meritis circa Ecclesiam Collegiatam rev. Pauli Tworkowski vicarii Eccl. Coll. Łoviciensis ${ }^{32}$, tum perpensa mente perilris dni Custodis, qui ad vacantern vicecustodiam eidem rndo Tworkowski claves ab ecclesia, Sacristia et Aerario tradidit, eundem circa vicecustodiam et vicariatum conservandum decrevit, praevia submissione, ut utrique officio satisfaciat.

[639] s. 164. Inventarium ecclesiae. Ad conscribendam argenteriam seu totam supellectilem ecclesiasticam deputantur perilres dni Antonius Owsiany et Stanislaus Cyboni [canonici], et hoc negotium stante moderno capitulo generali expediant.

[640] s. 165 (25 Maii). Anniversaria. Ad conscribenda, ordinanda et, quae non sunt in tabula connotata, connotanda anniversaria deputantur perilres dni Adalbertus Piaggia, Stanislaus Tarnowski [canonici] et no-

29 O św. Wiktorii objaśniano wyżej.

80 Kol. Psalterzystów erygowane w $1609 \mathrm{r}$.

31 Zmart rorantysta (i zakrystian) ks. Stomiński.

82 Donoszac o nowym wicekustoszu ( $i$ zakrystianie) ks. Tworkowskim, nawet nie wspomniano o Stomińskim. 
tarius Capituli. Quae anniversaria pro futuro capitulo generali habeant parata.

[641] s. 177 (29 Maii). Inscriptiones bonorum. Circa revisionem iurium capitularium compertum, quod non omnes inscriptiones bonorum et reliqui actus, qui circa inscriptiones peragi solent, in librum inscriptionum Venerabilis Capituli ingrossati sunt. Proinde easdem inscriptiones ilris notarius, et alia documenta ad easdem inscriptiones necessaria, quamprimum in dictum librum inducet et, ut sigillis suorum castrorum et correctis muniantur, curabit.

D. 6 Octobris, in capitulo partiali ordinario:

[642] s. 199. Crux argentea. Ad postulationem nuper ilmi dni Iosephi Trzciński suffraganei Gnesnensis, decani Łoviciensis, praesidentis Tribunalis Regni Petricoviae factam, quatenus Venerabile Capitulum velit ipsi crucem argenteam Wężykovianam cum pastorali atque pontificali commodare ${ }^{\mathrm{a}}$, in quam commodationem crucis, pastoralis et pontificalis Ven. Capitulum consensit.

D. 8-13 Decembris, in capitulo generali Conceptionis:

[643] s. 204-205 (12 Dec.). Inventarium ecclesiae. Ad conscribendum et verificandum inventarium rerumque ecclesiasticorum, videlicet argenteriae, apparatuum, librorum totiusque supellectilis ecclesiasticae deputantur perilres dni Stanislaus Cyboni et Ludovicus Trwaliński [canonici], obligando eosdem [s. 205] perilres dnos deputatos, ut quantocitius hoc negotium expediant.

[644] s. 209 (13 Dec.). Imago Cels. Principis. Perilri dno procuratori ${ }^{35}$ committitur, quatenus imaginem Celsissimi Principis domini nostri ac benefactoris clementissimi ornate depictam et in Capitulari collocandam curet.

D. 22 Decembris, in capitulo partiali ordinario:

[645] s. 211. Reliquiae S. Victoriae. Perilris et rmus dnus [Antonius] Krobanowski decanus et officialis Gnesnensis, canonicus Eoviciensis, ex capitulo generali praeterito ad Celmum Principem dominum clementissimum pro obtinenda licentia ad obsigillationem et conscribendas reliquias Sanctae Victoriae deputatus retulit, quod eundem rmum Krobanowski Sua Celsitudo Primatialis deputavit. Et praesens Ven. Capitulum ad hocce negotium perilrem et rmum dnum Christophorum Dobinski custodem Gnesnensem, canonicum Łoviciensem associavit.

\section{7}

D. 11 Iunii - 6 Iulii, in capitulo generali Pentecostes:

[646] s. 223 (12 Iunii). Recapitulatio. Facta recapitulatione omnium capitulorum partialium a tempore generalis capituli Conceptionis celebratorum, ulteriores tractatus praesens Ven. Capitulum limitavit ad diem crastinam.

[647] s. 224 (13 Iunii). Inventarium ecclesiae. Praeteriti Conceptionis generalis capituli decretum reassumitur et iidem perilres domini ad faciendum praefatum inventarium, scilicet p. Cyboni et Trwaliński, deputantur.

e Lekcja praudopodobna.

83 Wojciech Piaggia - jak przyp. 6. 
D. 8-10 Decembris, in capitulo generali Conceptionis:

[648] s. 242 (9 Dec.). Inventarium ecclesiae. Perilres domini, qui in praeterito capitulo generali Pentecosten anni praesentis fuerunt, iidem perillustres et in moderno ad conscribendum inventarium ecclesiasticum deputantur, scilicet p. dni Stanislaus Cyboni et Ludovicus Trwaliński.

[649] s. 245 (10 Dec.). Capitula partialia. Secundum statuta capitularia et antiquam praxim praesens generale capitulum decernit nunc et in posterum, ut quolibet die sabbativo hebdomadae festo non impedito fiant capitula partialia. In quibus capitulis dnus protunc Praesidens capituli aut primus ex senio, perlectas prius quotidianas praesentias, simul et anniversaria, subscribet.

[650] s. 246. Anniversaria. Multoties perilribus dnis Capitularibus oriuntur dubia, quod anniversaria indebito ordine currunt. Ideo praesens capitulum ad ea revidenda, simul componenda et bene septimanatim per annum in annum ordinanda, deputat perilres dnos Antonium Owsiany, Ludovicum Trwaliński et Adalbertum Piaggia [canonicos], unius absentia non obstante.

\section{8}

D. 11 Ianuarii, in capitulo partiali ordinario:

[651] s. 249. Apparatus ecclesiasticus. Perilri dno [Ludovico] Trwaliński apparatus ecclesiastici destructi committitur reparatio, pro qua reparatione a p. procuratore competentem pecuniam habebit.

D. 25 Ianuarii, in capitulo partiali ordinario:

[652] s. 250. Hypocaustum penes rndum Sacristianum. Pro conservatione in posterum rerum derelictarum, vulgo kolossy, ex funere p. m. ilmi suffraganei Gnesnensis, decani Eoviciensis ${ }^{34}$, tum etiam et aliarum pro commodo ecclesiae inservientium, hypocaustum penes residentiam, in secunda condignatione, rndi vicecustodis Venerabile Capitulum disposuit; lana ${ }^{\mathrm{f}}$ vero p. m. ilmi Suffraganei ad tempus ibidem conservetur.

D. 27 Maii - 17 Iunii, in capitulo generali Pentecostes:

[653] s. 257 (29 Maii). Inventarium ecclesiasticum. Ad conscribendum ecclesiasticum inventarium deputantur perilres dni Antonius Owsiany et Ludovicus Trwaliński [canonici], cum relatione peracti inventarii pro futuro capitulo generali Conceptionis.

[654] s. 277 (14 Iunii). Aurum ecclesiasticum. In reparationem apparatus ecclesiastici perilri dno Trwaliński, ex materiis ảrgento tectis et vetustate destructis, venditio argenti conflati committitur.

[655] s. 279 (17 Iunii). Declaratio perilris Piaggia. Quoniam immutatione temporum immutatae sunt transactiones capitulares ratione originalium summarum, proinde ut secundum modernum statum annotentur et describantur ad tenorem inventarii summarum per perilrem p. $\mathrm{m}$. Alexandrum Proszewski Uniejoviensem archidiaconum, Lanciciensem Łoviciensem canonicum ${ }^{35}$ et in similem formam redigantur, Venerabile Capitulum p. dnum Adalbertum Piaggia, uti gnarum praefatorum nego-

f lasca akta.

84 Józef Michat Trzciński - jak przyp. 21.

35 Aleksander Proszewski kan. tow. w l. 1693-1727. 
tiorum, obligavit. Quam obligationem sponte et libere acceptavit et eidem obligationi pro futuro capitulo generali Pentecosten in anno sequenti 1739 satisfacturum se declaravit.

[656] s. 279. Obligatio perilris futuri Procuratoris. Ut exactius res currant capitulares et Venerabile Capitulum evidentiorem notitiam habere possit debitorum, ex anteactis annis calamitosis contractorum, videlicet quod domini capitulares, tum minorem clerum ac omnes circa ecclesiam inservientes pro suis deservitis concernit; tum etiam, si quid pro interesse Capituli apud mercatores, uti pro cera, vino et aliis necessitatibus debetur. Id totum diligentissime conscribatur et per futurum procuratorem ${ }^{30}$ in capitulo proximo ante vel post festum Assumptionis Beatissimae in Caelum porrigatur.

[657] s. 280. Armarium. In praesenti capitulo Confraternitas Sancti Ioannis Nepomuceni ${ }^{37}$ perilribus dnis praesentibus supplicavit, quatenus Venerabile Capitulum velit exsistens armarium in camera sub turri a parte meridionali pro conservatione rerum supra praetactae confraternitatis designare. Et Ven. Capitulum exauditis postulatis annuit, tamen supra praetacta camera sit semper sub clavi rndi vicecustodis.

[658] s. 281. Bibliotheca. Ad conscribendum Bibliothecae seu librorum exsistentium in conservatorio seorsivo inventarium, alias regestrum, deputantur perilres dni Antonius Owsiany et Stanislaus Cyboni [canonici], cum relatione suae deputationis pro futuro, Deo dante, generali capitulo Conceptionis in hoc anno incidente.

D. 21 Iunii, in capitulo partiali ordinario:

[659] S. 284. Vota Altaris S. Annae. Votorum argenteorum Altaris Sanctae Annae ${ }^{38}$ renovatio permittitur rndo Ioanni Dziewierski. Ad cuius argenteriae ponderationem et connotandum valoris et ponderis dictorum votorum deputatur ilris notarius. Qua connotata argenteria, in regestro eam porriget et in generali regestro Ecclesiae Collegiatae eam inscribet.

D. 3 Iulii, in capitulo partiali extraordinario:

[660] s. 286. Apparatus a magco dno Trzciński. Post fata p. m. ilmi dni Iosephi Trzciński suffraganei Gnesnensis, decani Łoviciensis magcus dnus Felicianus Trzciński pocillator Ravensis apparatum relictum albi coloris cum stola, manipulari, bursa, palla atque cingulo sericeo rubri coloris dono Ecclesiae Collegiatae Łoviciensi obtulit, eundemque statim per ilrem Drzewiecki notarium Capituli ad Sacristiam reddidit.

D. 8-12 Decembris, in capitulo generali Conceptionis:

[661] s. 295 (9 Dec.). Recapitulatio. Ex ratione, quod imminet devotio pro anima p. m. celmi principis Theodori Potocki primatis Regni, die hesterna Varsavia conducti, in hac Ecclesia Collegiata Łoviciensi depositi: cui devotioni, vi obligationis pro multis beneficiis huic Capitulo per Celsissimum supratactum praestitis, Perillustres Domini interesse tenentur; facta solum recapitulatione, ex eaque nonnullis ad tractandum connotatis, praesens capitulum ad diem crastinam limitarunt.

[662] s. 296-297 (10 Dec.). Inventarium ecclesiae. Retulerunt peril-

36 Wtaśnie prokuratorem wybrano ponownie kan. Piaggia.

37 Ottarz Sw. Jana Nepomucena eryg. w r. 1736, a Bractwo w 1737.

s8 Kaplica $i$ Ottarz Sw. Aanny fundowane ok. $1638 \mathrm{r}$. 
res dni deputati, quod revisionem totius supelectilis ecclesiae fecerunt, inventarium conscripserunt et secundum anterius regestrum omnem argenteriam adinvenerunt [s. 297] et noviter accendentem argenteriam, nondum connotatam, connotandam per se declararunt.

[663] s. 297. Imagines. Reparationem imaginum, in Minori Choro in parietibus pendentium, ad futurum generale praesens capitulum remittit.

[664] s. 302 (12 Dec.). Declaratio perilris Piaggia. Quoad conscribendum summarum originalium decretum praeteriti generalis capituli Pentecosten latum reassumitur.

[665] s. 302. Bibliotheca. In praesenti capitulo compertum est, quod perilres dni Owsiany et Cyboni nondum suae deputationis functionem ratione revisionis librorum in seorsivo conservatorio depositorum perfecerunt. Innovatur praeteriti generalis capituli Pentecosten decretum obligando perilres supratactos dominos, quatenus hoc negotium indilate perficiant.

\section{9}

D. 19 Maii - 12 Iunii, in capitulo generali Pentecostes:

[666] s. 306. Lectio statutorum et recapitulatio. Lectis statutis capitularibus, tum quoque facta recapitulatione et ex iisdem connotatis nonnullis tractandis ad capitulationem generalis capituli Conceptionis, tum etiam partialium capitulorum [Domini] processerunt.

[667] s. 309 (21 Maii). Litterae scribendae Romam. Vigore privilegii in libro erectionum exsistentis, ratione approbationis per Venerabile Capitulum testamentorum et dispositionis faciendae intestatorum post de-functos praelatos et canonicos Lovicienses, ad scribendas litteras Romam deputatur perilris dnus Krajewski ${ }^{39}$, ut possit super supratacto privilegio procurare beneplacitum apostolicum.

[668] s. 310. Vinum pro Sacristia. In hodierno capitulo praesentes Domini Capitulares expostularunt cum rmo dno Bratkowski ${ }^{40}$ brevi proficiscente Gedanum, quatenus pro necessitate et commoditate Sacristiae velit conducere Gedano vinum. Et rmus supratactus dominus suam facilitatem in hoc puncto declaravit. Pro quo conducendo et locando vino celarium in archidiaconia Domini Capitulares assignarunt. Dispositionem autem istius vini perilri futuro procuratori ${ }^{41}$ praesens capitulum commisit.

[669] s. 310. Imagines in Choro Minori. Reparationem imaginum in Minori Choro, super stallis in parietibus pendentium, praesens generale capitulum rndo vicecustodi ${ }^{42}$ demandavit.

[670] s. 312 (25 Maii). Inventarium ecclesiasticum. Sicuti in praeterito generali capitulo Conceptionis perilres domini ad conscribendum inventarium ecclesiasticae argenteriae deputati relationem fecerunt, quod non tantum secundum anterius inventarium, immo et augmentum

s9 Jan Krajewski h. Jasieńczyk, dr ob. prawa, m.in. kan. łow. w l. 1724-1742.

40 Józef Bratkowski h. Przegonia, m.in. kan. low. w l. 1737-1745.

11 Pawet Kosicki dr ob. prawa, m.in. kan. low. w l. 1736-1761, prat. dziek. $1762-1778$.

42 Ks. Pawel Tworkowski - jak przyp. 32. 
eiusdem adinvenerunt, hanc solam et in moderno capitulo comprobarunt, quod de novo confectum manibus propriis subscripserunt.

[671] s. 312. Altare SS. Custodum. Ad extradendam argenteriam, seu potius vota ex Archivo Venerabilis Capituli Altare Sanctorum Custodum ${ }^{43}$ concernentia, rndo promotori eiusdem altaris deputatur perilris Trwaliński [canonicus]. Quibus receptis votis et in praesentia supratacti p. deputati praeponderatis, in exornationem imaginis S. Angeli Custodis tenebit rev. promotor, uti se in supplicatorio ad Ven. Capitulum scripto submisit, vestem per aurifabrum comparare.

[672] s. 313 Sebum ex Arce Eoviciensi. Vigore erectionis Venerabile Capitulum ilmos dnos p. m. celmi principis archieppi Gnesnensis Theodori Potocki exsecutores requisivit, quo superstite supratacto Celsissimo per aliquot annos ad Ecclesiam Collegiatam pertinens sebum retentum fuit. Vidente ilmi exsecutores authentico in erectione documento, perlectis in libro rationum probationibus, quod in antecessum pro sebo de anno in annum Ven. Capitulum fuit in exsolutione pecuniaria, excusando defectum Thesauri, compensando reale debitum, peristromata coloris cerulei et flavi partes quinquaginta, vulgo b r e tó w, ad ecclesiam reddiderunt et applicarunt.

[673] s. 315. Declaratio perilris Piaggia. Quoniam p. dnus Piaggia declarationi suae nondum satisfecit in conscribendis summis originalibus ad tenorem inventarii summarum per perilrem p. m. Alexandrum Proszewski archidiaconum Uniejoviensem, Lanciciensem Eoviciensem canonicum, reassumitur decretum in hoc negotio sub tempus generalis capituli Pentecosten anni 1738 die 17 [Iunii] latum, quatenus hoc opus pro futuro generali capitulo Conceptionis dignetur ad effectum deducere.

[674] s. 315. Bibliotheca. Praeteriti generalis capituli Conceptionis decretum reassumitur, et iidem perilres domini inante deputati ad conscribendum inventarium librorum Bibliotecae Capitularis deputantur, videlicet Owsiany et Piaggia [canonici].

D. 12 Septembris, in capitulo partiali ordinario:

[675] s. 325. Visitatio generalis. Quoniam ex innotescentialibus per celmum et ilmum dnum Principem Primatem Regni ${ }^{4.1}$ etc., uti lociordinarium huius Ecclesiae Collegiatae die 15 mensis currentis imminet generalis visitationis terminus, ideo, prout obloquitur Caeremoniale ecclesiasticum, ad suscipiendum eundem Celsissimum per praesens capitulum, cum sermone salutario in ingressu ecclesiae, deputatur perilris Piaggia.

D. 12 Octobris, in capitulo partiali ordinario:

[676] s. 327-328. Praeparatoria pro futura generali visitatione. In praesenti capitulo ex mente celmi Principis domini clementissimi per rmum custodem ${ }^{45}$ repositum, quatenus Venerabile Capitulum pro futura generali visitatione tempestive habeat omnia, quae spectant ad visitationem documenta. Ad quem effectum e medio sui Domini Capitulares perilres dnos Krajewski et Kosicki deputarunt. Qui perilres dni deputati omnium fundorum, fundationum, curiarum, quae sunt reaedi-

${ }^{43}$ Ottarz Aniotów Stróżów z pot. XVII w., objaśniany wyżej.

${ }_{44}$ Krzysztof Antoni Szembek h. wtas., m.in. arcybp gniezn. w l. 1739-1748.

45 Prat. kust. Robertson - jak przyp. 8. 
ficatae sive reparatae aut desolatae, cuius sumptu et cura vel negligentia inventarium conscribere tenebuntur, tum villas ad praelatures et canonicatus pertinentes visitent. Collegia autem omnia et [s. 328] altaristas perilris procurator moneat, ut sua documenta erectionum, fundationum, inscriptionum, obligationum ac residentiarum disitincte, ordinate habeant. Quam deputationem stante actuali revisione perilrium dominorum cum praesentia capitulari praesens capitulum decrevit ${ }^{46}$.

D. 8-14 Decembris, in capitulo generali Conceptionis:

[677] s. 329 (9 Dec.). Recapitulatio et lectio statutorum. Facta recapitulatione tam generalis capituli, quam partialium, et approbatis per praesens generale partialibus, perlectis more antiquo statutis et nonnullis ex iisdem ad tractandum connotatis, Perillustres Domini ulterius processerunt.

[678] s. 335 (12 Dec.). Imagines in Choro Minori. Siquidem cooperatione perilris moderni procuratoris reparatio imaginum iam est effectuata, solum ad has desunt tendicula lignea, vulgo $\mathrm{ramy}$, ob quorum carentiam non possunt esse appensae in parietibus. Ideo recommendatur eidem procuratori, quatenus hoc negotium ad opus perfectum et sua activitate dignetur deducere.

[679] s. 335. Approbatio testamentorum, sebum ex Arce, candelabra oppignorata. Celmo Principi dno clementissimo Venerabile Capitulum per rmum custodem supplicandum esse censuit, et primo ratione per Ven. Capitulum approbationis testamentorum post defunctos praelatos et canonicos Łovicienses testatos sive intestatos, uti inantecessum fuit. Secundo ratione sebi ex Arce Łoviciensi in rem ecclesiae provenientis. Tertio ratione dispensationis super provisione a summa, pro qua per Ven. Capitulum candelabra argentea in Monte Pietatis sunt oppignorata. Et rmus custos, conscribendis per rndum notarium punctis et ad manus habendis, hoc negotium libenter in personam suam favore Ven. Capituli assumpsit.

[680] s. 337 (14 Dec.). Stannum in Sacristia. Repertum, quod a multis annis in Sacristia repositum erat stannum per quem ignotum. Ex quo per incuriam (quia non fuit regestratum) aliqua ablata sunt orbicula, vulgo $\mathrm{misy}$. Proinde ad investigandum eorum deputatur perilris procurator. Qui perillustris curabit eiusdem stanni regestrationem et praeponderationem. Expletis his convertendum esse praesens capitulum in candelabra ecclesiae censuit.

[681] s. 337. Investigatio effractionis carbonae et aliorum. Ex relatione perilris procuratoris praesenti capitulo patuit, quod aliquis ex malevolis hominibus in ecclesia effractionem carbonae fecit et alia ad furtum possibilia signa reliquit. Proinde obviando aliquo subsecuturo periculo, ratione furti in ecclesia, ad investigandum serio huius nefandi criminis deputantur perilres dni Zajączkowski et Kosicki [canonici].

[682] s. 338. Swiatnicy. In praesenti capitulo reposuit perilris dnus procurator, quod ex subditis villae Strzelczew ${ }^{47}$, qui sunt ex antiquo ad obeunda obsequia Ecclesiae Collegiatae dispositi et determinati, nullam habet commoditatem nesciens etiam, quis illis et ad quos usus disponit.

46 Po wizytacji tej nie ma akt ani dekretu reform.

47 Strzelczew wieś wo par. kolegiackiej. 
Et supponitur, quod ad labores pernecessarios advocatiae Strzelczeviensis illos perilris oeconomus convertit, et hoc est in rem Capituli. Proinde committitur perilri dno procuratori, quatenus in locum praefatorum subditorum alios sibi bene visos duos famulos suscipiat, et ex massa capitulari eisdem competentem mercedem persolvat.

[683] s. 339. Regestratio documentorum. Ne in posterum fiat aliqua difficultas in rebus ecclesiae et Capitulo eveniat damnum, perilri dno procuratori committitur, quatenus omnia et singula documenta capitularia transactionum, inscriptionum, compositionum etc. ordine quam optimo in regestro conscribat.

\section{0}

D. $28 \mathrm{Martii}$, in capitulo partiali extraordinario:

[684] s. 346-348. Fundatio Psalteristarum ${ }^{48}$.

D. 7 Iunii ${ }^{8}-5$ Iulii, in capitulo generali Pentecostes:

[685] s. 353 (8 Iunii). Lectio statutorum et recapitulatio. Perlectis statutis et facta recapitulatione, nonnullis ex iisdem ad tractandum connotatis, Perillustres Domini ulterius processerunt.

[686] s. 357 (11 Iunii). Inventarium ecclesiae. Ad conscribendam auctionem argenteriae et aliarum rerum, [quae] post peractam inante revisionern et manibus perilrium deputatorum subscriptionem accesserunt, deputantur iidem p. "domini, scilicet Owsiany et Trwalinski [canonici], cum relatione pro futuro, Deo dante, generali capitulo Conceptionis.

[687] s. 359 (17 Iunni). Libri praesentiarum et anniversariorum. Ad verificanda pro retroactis annis deservita tam praesentiarum, quam anniversariorum deputantur perilres dni Custos et Zajączkowski.

[688] s. 361 (18 Iunii). Petitum ilris Secretarii. Praesens capitulum decrevit, quatenus perilris procurator deservita rndo notario pro anteactis annis, tam pro missis, quam etiam pro obsequiis eius ac consolationes in toto exsolvat.

[689] s. 362. Petitum Sacristae. Sacrista similiter remittitur ad supraspecificatos perilres dnos procuratores.

[690] s. 365 (27 Iunii). Pulsus campanae maioris. Ratione pulsus maioris campanae pro mortuis anteriora decreta reassumuntur, et sine scitu perilris procuratoris numquam rndus vicecustos audeat pulsum facere.

[691] s. 365. Ordinario devotionum in ecclesia [Sacristia]. Repertum est, quod adm. rndi dni vicarii, psalteristae, rorantistae et altaristae habent suas seorsivas et a Venerabili Capitulo independentes fundationes et praecipue anniversaria, videlicet ex censibus a provisionalibus summis hic in Civitate locatis, et absolute nil contribuunt pro vino, cera et apparatu ad massam capitularem. Et Perilres Domini Capitulares videntes per hoc diminutionem massae communis, perilri dno procuratori hoc negotium committuntur, quatenus illos conveniat, dispositionem earundem fundationum faciat, ne frustratur exinde massa capitularis.

[692] s. 367 (5 Iulii). Defuncti superviventia. Siquidem per inadver-

g Maii blęd. akta.

$48 \mathrm{~W}$ tym obcym dla tematu wpisie potwierdzono (na s. 346) fakt odbycia tejże wizytacji przez Szembeka. 
tentiam ilris notarii factum est, quod, iuxta praxim et consuetudinem omnium capitulorum in Regno, refectiones quotidianas et anniversaria post obitum perilris Cyboni canonici et confratris ${ }^{49}$ in libris non connotavit, praesens capitulum decrevit, quatenus statim inchoante semestre, scilicet dominica quarta post Pentecosten, per quattuor septimanas in personam p. m. supratacti perilris Cyboni tam praesentiarum, quam anniversariorum connotationem faciat dnus notarius.

D. 8-12 Decembris, in capitulo generali Conceptionis:

[693] s. 371. Lectio statutorum, recapitulatio ac limitatio. Lectis statutis factaque recapitulatione, et nonnullis ex iisdem ad tractandum connotatis, ad diem crastinam Perilres Domini Capitulares praesens capitulum limitarunt.

[694] s. 372 (9 Dec.). Inventarium ecclesiae. Ad conscribendum inventarium ecclesiae et auctionis in ea deputantur perilres dni Trwaliński et Tarnowski [canonici].

[695] s. 373. Domus canonicales. Ex occasione accensae fuliginis per ignem, quod per incuriam patrisfamilias caminus non fuit expurgatus, ad revisionem omnium curiarum tam praelatorum, quam canonicorum deputantur perilres dni Zajączkowski et Kosicki [canonici].

\section{1}

D. 23 Maii - 7 Iunii, in capitulo generali Pentecostes:

[696] s. 382 (24 Maii). Recapitulatio. Facta praeteritorum tam generalis, quam partialium capitulorum recapitulatione, connotatis nonnullis. ad tractandum, peracta partialium approbatione, ulterius Perillustres Domini praesentes processerunt.

[697] s. 383 (25 Maii). Sacellanus. Quoties acciderit sacellano ${ }^{50}$ in Altari Maiori et Corporis [Christi] candelas accendere, ut superpelliceatus incedat, nomine Capituli per rndum notarium serio moneatur.

[698] s. 387 (29 Maii). Summae originales. Decernitur in praesenti capitulo, ut summae originales omnes, in bonis terrestribus haerentes, pretiis adcitationibus haeredum et possessorum ad iudicia competentia pro exsolvendis iisdem; et quamprimum colligantur, in depositorio capitulari reponantur ad ulteriorem dispositionem Capituli. Cuius dispositionis relinquitur generalis vigor partiali capitulo.

[699] s. 387. Fabrica ecclesiae. Futuro perilri procuratori ${ }^{51}$ committitur, quatenus pro dealbanda ecclesia in Monte Pietatis aut alibi candelabra ecclesiasica argentea in summa centum imperialium oppignoret.

[700] s. 387 (31 Maii). Altare Crucis. Perilri dno Ludovico Trwaliński canonico commendatur, quatenus dignetur curam perficiendae argenteae tabulaturae ad Altare S. Crucis, ex ecclesiastico argento, praeponderato per spectabilem Gruszewicz consulem et aurifabrum in praesentia eiusdem p. Trwaliński, cuius argenti exstant septuagintae marcae et unciae septem.

49 Stanistaw Cyboni, m.in. kan. łow. w l. 1724-1740.

so Kurowski świecki pomocnik ks. zakrystiana. Zob. nr 702.

51 Prokuratorem zostat ponownie kan. Kosicki. 
[701] s. 390 (3 Iunii). Posta. Perilri dno procuratori committitur, quatenus cum dno Lipski postmagistro ${ }^{51 a}$ ratione correspondentiae per postam de pretio conveniat.

[702] s. 390. Sacellanus. In augmentum anterioris salarii sacellano Kurowski decernit praesens capitulum per perilrem procuratorem ex massa communi quolibet quartuali annuatim decem florenos dandos.

D. 1 Iulii, in capitulo partiali hebdomadali:

[703] s. 396. Locus Capitularis. Ex casu noviter emergenti et rationibus capitulariter decisis, praesens capitulum statuit atque rndo notario commisit, quatenus sumptu Capituli mensam rotundam ad Capitulare ac ad

- fores clausuram ferream procurat. A quo Capitulari claves aut clavis semper apud dnum procuratorem aut rev. notarium permaneat, et nemini ex aliis personis concredatur.

D. 5 Augusti, in capitulo partiali hebdomadali:

[704] s. 398. Stemma Celmi Principis. Committitur dno Kiełczewski $^{52}$ dispositio picturae stemmatis Celsissimi Principis domini clementissimi in Ecclesia Collegiata.

D. 16 Septembris, in capitulo partiali ordinario:

[705] s. 400. Revisio curiarum canonicalium. Ad revisionem curiarum canonicalium, tum caminorum deputantur perilris dnus procurator et notarius Capituli.

D. 8-13 Decembris, in capitulo generali Conceptionis:

[706] s. 402. Lectio statutorum et recapitulatio. De praxi antiqua vigore statutorum et consuetudine, perlectis statutis factaque recapitulatione et ex iisdem nonnullis ad tractandum connotatis, Perillustres Domini ulterius processerunt.

[707] s. 406 (12 Dec.). Altare Crucis. Perilri dno Trwaliński faciendae tabulaturae ad Altare S. Crucis committitur attendentio.

[708] s. 409 (13 Dec.). Vigor. Ratione publicandi decreti visitationis ${ }^{53}$ et negotiorum, si quae proponentur a Celsissimo Principe, vigor praesentis generalis capituli partiali immediato relinquitur.

\section{2}

D. 15-31 Maii, in capitulo generali Pentecostes:

[709] s. 417 (16 Maii). Lectio statutorum et recapitulatio. Perlectis statutis factaque recapitulatione praxi antiqua et consuetudine, connotatis ex illis nonnullis ad tractandum in praesenti capitulo Perillustres Domini Capitulares ulterius processerunt.

[710] s. 417. Approbatio capitulorum partialium. Decreta post capitulum generale Conceptionis, in partialibus capitulis statuta, praesenti capitulo generali Pentecosten approbantur et in omnibus punctis [ac] clausulis conservantur.

[711] s. 418. Decreta reformationis. Observando antiquam praxim et consuetudinem Perilres Domini Capitulares statuerunt et decreverunt,

51a Bernard Antoni Lipski h. Grabie, sekretarz i poczmistrz królewski, burmistrz m. Łowicza.

${ }_{52}$ Dominik Kiekczewski h. Pomian, dr teol., m.in. kan. low. w l. 1740-1742, prat. archid. 1742-1743, prat. prepoz. 1743-1776, także biskup.

${ }_{58}$ Dekret reform. Szembeka, jeżeli byt, nie zostal $w$ tych aktach opublikowany. 
quatenus post perlecta statuta et factam recapitulationem, in omnibus in posterum capitulis generalibus per rndum notarium statim legenda sint decreta reformationum.

[712] s. 420 (19 Maii). Anniversarium pro Fratribus. An mentem statuti capitularis Perilres Domini Capitulares in praesenti capitulo statuerunt, quatenus in conclusione capituli generalis pro Fratribus Capitularibus anniversarium trium nocturnorum fiat.

[713] s. 420. Altare in Festo Corporis Christi. Commendatur rndo vicecustodi, quatenus curam altaris in Festo Corporis Christi ipsemet cum ministris ecclesiae curam exornationis habeat, et nemini ex Civitate peristromata accommodet, nisi prius altari capitulari, postea vicariorum, et quid supererit, ad Civitatem accommodet.

[714] s. 421 (21 Maii). Approbatio testamentorum. Ad conscribenda puncta ratione approbationis per Venerabile Capitulum testamentorum deputantur perilres dni Piaggia et Kosicki canonici.

[715] s. 433 (30 Maii). Oblatum perilris Trwaliński. Ex devotione et affectu erga Altare S. Crucis in Ecclesia Collegiata, intrando in ecclesiam a parte sinistra sito, pro solutione aurifabro pro tabulatura elaborato, obtulit $\mathrm{p}$. Trwaliński quindecim hungaricales. Pro hac gratia praestita Perilres Domini praesentes, praevia gratiarum actione eidem p. Trwaliński, acceptarunt. Residuitatem vero solutionis aurifabro ex deservitis p. m. perilris Krajewski [canonici] sescentos assignarunt a supratacta tabulatura.

D. 23 Iulii, in capitulo partiali hebdomadali:

[716] s. 442. Acta sérvanda. Decernunt Perillustres Domini in praesenti capitulo, ut acta in Archivo Capituli abhine serventur ${ }^{54}$.

D. 8-14 Decembris, in capitulo generali Conceptionis:

[717] s. 447. Lectio statutorum et recapitulatio, atque approbatio capitulorum partialium. Lectis statutis, tum decretis reformationum, factaque recapitulatione tum generalis capituli praeteriti, quam partialium Perillustres Domini decreto praesenti approbarunt omnia decreta partialium capitulorum, et his peractis ulterius processerunt.

[718] s. 450 (11 Dec.). Revisio bonorum. Quoad revisionem omnium bonorum Capituli, vigore praesentis generalis capituli, partiali relinquitur ante futurum generale capitulum Pentecosten.

\section{3}

D. 4-22 Iunii, in capitulo generali Pentecostes:

[719] s. 461. Lectio statutorum et approbatio partialium capitulorum. Lectis statutis atque decretis reformationum, factaque recapitulatione tam generalis praeteriti, quam partialium, Perillustres Domini praesentes decreto praesenti omnia capitula partialia approbarunt. His peractis et nonnullis ex iisdem ad tractandum connotatis, ulterius processerunt.

[720] s. 463 (6 Iunii). Acta capitularia. Recommendatur ilri notario, quatenus abhinc nullum instrumentum ex actis capitularibus sine debita aringa praesentiae perillustrium protunc capitularium, sigillo capitulari et subscriptione ilris notarii manu propria extradatur.

$\$ 1$ Niezrozumiale. Chyba miano na myśli akta nowsze. 
[721] s. 464 (7 Iunii). Cappalia et iucundus ingressus. Ad tenorem puncti in statutis de cappaliis et iucundo ingressu praesens capitulum decernit, [ut] qui necdum in his supratactis satisfecerunt, circa solutionem praesentiarum futuro perilri procuratori satisfaciant.

[722] s. 465 (10 Iunii). Bibliotheca. Ad revisionem Bibliothecae et conscribendos libros in regestrum numerice assignantur ilres Stanislaus Drzewiecki secretarius Capituli et Aloysius Dąbrowski concionator substitutus huius ecclesiae.

[723] s. 467 (19 Iunii). Ilmi suffr. Gnesn., decani Łov. oblatum. Ilmus. dnus Christophorus Dobiński episcopus Serrensis, suffraganeus Gnesnensis, decanus Łoviciensis ${ }^{55}$, amore huius ecclesiae et Capituli, obtulit dono ad Altare Corporis [Christi] tapetem, vulgo dywan, pro usu vero perillustrium dominorum capitularium in Loco Capitulari sedilia novem. Et Perilres Dni Capitulares pro praestito beneficio huic ecclesiae et Capitulo summas gratias egerunt eidem ilmo dno episcopo.

[724] s. 471 (22 Iunii). Anniversaria reducenda. Perillustres Domini attento eo, quod anniversaria nonnulla nullum fructum importent Rmo. Capitulo ac quod rndis vicariis pro iisdem solvitur, decreverunt, ut pro reductione eorundem recursio fiat ad Sanctam Sedem Apostolicam. Pro eiusdem vero negotii effectu assignant aureos decem mittendos perilri Szczepański ${ }^{56}$.

D. 17 Augusti in capitulo partiali hebdomadali ordinario:

[725] s. 475-477. Protestatur perilris Custos. Protestatio p. dni Robertson custodis in parata scheda ad praesentia acta porrecta. Cuius copiam ex actis praesens capitulum perilri dno custodi per rndum notarium capitularem extradendum permisit, similiter et aliorum capitulorum inante actorum documentorum.

In solito actu capitulari, quod cadit de more et consuetudine in diem hodiernam decimam septimam Augusti anno currenti 1743, constitutus personaliter Gulielmus Robertson IUD, archidiaconus primus cathedralis Posnaniensis, Metropolitanus Gnesnensis senior canonicus, tum Łoviciensis custos ex antiquo possessus principalis. Occurrendo cuivis praeiudicio iurium suorum custodiaeque suae Łoviciensis, in et coram eodem officio ac actis praesentibus sollemniter, sollemnius ac sollemnissime protestatus est in et contra perilrem rmum dnum Dominicum Kiełczewski STD, canonicum cathedralem Vladislaviensem, anno praeterito installatum archidiaconum Łoviciensem, praepositum Volboriensem, Causarum Curiae Archiepiscopalis Gnesnensis generalem auditorem et iudi$\mathrm{cem}^{57}$ idque super eo, quia ipse non ignorans, immo plene ex actis capitularibus extensisque in iisdem fundationibus ac erectionibus originalibus cuiusque praelaturae fundationis ac ditationis, tum praerogativarum uti praedecentiarum earundem ex antiquo solitarum, iuxta fundationes earundem. Signanter constito eidem de praerogativa custodiae in Insigni Collegiata Eoviciensi, tertio loco et stallo fundata, voce activa et passiva in eodem Capitulo possessa, quod uti clavi petitorii. Hoc eidem expressa authentica documenta desumpta testantur, et uti habentur et de-

55 Krzysztof Michat Dobinski h. Rola, m.in. kan. low. od r. 1725, prä. dziek. w l. $1738-1769$.

56 Tomasz Szczepański h. Dołęga, m.in. kan. low. w l. 1742-1757.

57 Por. przyp. 52. 
ducantur ex Archivo Rmi Capituli Metropolitani extracta et sigillata, et quidem: de anno Domini 1433 sub rmo patre et domino Jastrzębiec archieppo Gnesnensi, tum de anno 1440 sub rmo p. d. Vincentio similiter archiepiscopo, tum de anno 1521 sub rmo p. d. Ioanne de Łasko similiter archieppo Gnesnensi. Uti ex singulis documentis patet depromta, tum acta Capituli Łoviciensis ab aevo conservata et continuata edisserunt. [s. 476] Et quod cum pridem in eodem Capitulo deductum et demonstratum est, quod inquam praefata custodia ab origine et erectione sua exstat et continuo et adusque habita et reputata sit tertia dignitas et taliter vocata praelatura. Ac archidiaconatu longe prior ab annis centum quinquaginta ${ }^{58}$ in dicta Ecclesia Collegiata exsistens. Ac taliter tam loco, quåm voce custodes Łovicienses archidiaconos in ecclesia ac Capitulo dicto praecessissent et ubique archidiaconis in omni parte superio res fuissent, prout fundati et erecti sine ulla imaginabili clausula vel clausulis derogatoriis', prout tales clausulae minime reperibiles sunt ac unquam monstrari possunt. Nihilominus praepotenter nonnisi absque ullo fundamento praecedentiam talis dignitatis, iam enucleatae superius, super protestantem modernum qua custodem Łoviciensem rite ac legitime ex antiquo possessum, sibi arrogare, idque proprio nonnisi ausu, eundemque protestantem dicta praecedentia super archidiaconos ex antiquo et adhucusque habita et possessa, ac per actus et connotationes capitulares in regestris praesentiarum descripta, spoliare ausus est et praesumpsit. Dum cum idem custos feria sexta in vigilia Sancti Laurentii Gloriosi Martyris die 9-na mensis Augusti anno currenti 1743 Łovicium venerit, ac per rndum notarium capitularem de cadentia septimanae sequentis pro tali praelatura cadenti ordinarie informatus, eandem septimanam se suscepturum dicto notario Capituli declarasset. Eandem ipsam septimanam, attentate nonnisi et motu proprio, nullo habito super talibus consilio cum rmo praeposito ${ }^{59}$ ac manentibus protunc capitularibus personis, arrogando memoratam praecedentiam, se pro officiante dictae septimanae, idque independenter a quavis resolutione Capituli, sed dumtaxat auctorisando in proprio facto, se ipsum scribi ac imponi in solita tabella, in ecclesia consistenti, atque connotari iussit ac praefatam septimanam taliter, immo nulliter, usurpavit, nec statas devotiones ac divinorum absolvit celebrationes, cum statim sequenti die Lunae, relictis reliquis septimanae diebus, Eovicio Vladislaviam, acsi pro capitulo ibidem celebrando, discesserit. Quapropter isidem praenominatus custos, tertiae [s. 477] dignitatis in eadem Ecclesia Łoviciensi continuus possessor, ratione praescriptorum iterum atque iterum de illatis sibi iniuriis ac evidenti enormi spolio, tum de attentatis quibusvis sibi et successoribus suis, quomodo illatis vel inferendis protestans, seque iure de talibus actorum offerens, conservando clarum et integrum ius dictae custodiae, idque continuum et immediate tam per se a viginti quinque annis possessionis tentum, uti per praedecessores custodes a saeculis possessum et conservatum, contra praefatum perilrem modernum archidiaconum, repetitis toties protestationibus, easdem infert et innovat,

58 Wtaściwie tylko o 89 lat, najwyżej zaś o 95.

59 Aleksander Kolumna Walewski, m.in. kan. low. w l. 1728-1740, prat. prepoz. $1740-1743$. 
stando nec minime ab iisdem recedendo, salvoque omnique ac salvaque. Super quibus omnibus taliter, uti expressa sunt, praemissis manum suam propriam apponit ac sigillum. Gulielmus Robertson IUD, archidiaconus Posnaniensis cathedralis, Metropolitanus senior canonicus, custos Łoviciensis mp. Locus sigilli.

D. 8-14 Decembris, in capitulo generali Conceptionis:

[726] s. 486. Lectio statutorum, recapitulatio et approbatio capitulorum partialium. Perlectis statutis et decretis reformationis, factaque partialium capitulorum approbatione, connotatis nonnullis ex iisdem ad tractandum, Perillustres Domini ulterius processerunt.

[727] s. 488-489 (11 Dec.). Cappalia et iucundus ingressus. Quandoquidem aliqui perilres domini in solutione cappalium sunt resitentes, tum perficiendo iucundo ingressu, ideo praesens generale capitulum irrevocabiliter statuit, ut perillustres iam installati more solito satisfa[s. 489] ciant vigore puncti in statutis et decretorum. Ab hoc autem tempore installandi in futurum perilres domini praelati per tres ungaricales, canonici vero per duos tenebuntur statim ante peractam installationem ad manus $p$. procuratoris omnino enumerare decreti praesentis in perpetuum duraturi.

[728] s. 490 (13 Dec.). Revisio argenteriae ecclesiasticae. Ad revisionem argenteriae ecclesiasticae deputantur perilres dni Tarnowski ${ }^{\text {of }}$ et Szembek ${ }^{01}$, cum relatione capitulo praesenti.

\section{4}

D. 26 Maii - 13 Iunii, in capitulo generali Pentecostes:

[729] s. 498. Lectio statutorum, recapitulatio ac approbatio partialium capitulorum. Perlectis statutis et decretis reformationis, factaque tam generalis, quam partialium capitulorum recapitulatione et approbatione, connotatis ex illis nonnullis ad tractandum, Perillustres Domini ulterius processerunt.

[730] s. 498 (27 Maii). Cappalia. Quandoquidem anno praeterito in capitulo generali Conceptionis ratione cappalium stetit decretum, ut qui perillustres domini nondum persolverunt ad massam capitularem, in quo decreto est iniunctum omnino solvant, et adusque in hoc puncto non satisfecerunt: proinde et in praesenti consessu Perilres Domini Capitulares innovarunt et firmiter decreverunt, quatenus quilibet ex perillustrium de fundo suo hoc in negotio omnino satisfaciat decreti praesentis vigore.

[731] s. 500 (28 Maii). Revisio argenteriae ecclesiasticae. Ad revisionem argenteriae ecclesiasticae deputantur perilris Tarnowski [canonicus] et ilris notarius Capituli, cum relatione futuro generali capitulo Conceptionis.

[732] s. 502 (30 Maii). Petitum perilris dni Bajer. P. dno Bajer Tribunalis Regni vicepraesidenti ${ }^{62}$, uti confratri suo, Domini Capitulares

60 Stanisław Tarnowski $h$. Rola, kan. łow. i prepoz. tamt. Kol. Psałterzystów w l. $1731-1756$.

${ }_{61}$ Bonifacy Szembek h. wtas., m.in. kan. kow. w l. 1740-1753. biskup.

62 Andrzej Ignacy Bajer h. Leliwa, m.in. kan. low. $w$ l. 1742-1753, z czasem 
accommodanda esse duxerunt peristromata in floribus flavi quasi violacei coloris, idque tantum Petricoviam. Quae peristromata in eodem numero, specie, finita Petricoviae sua functione, restituere sine eorundem deterioratione tenebitur. Alias iuxta seorsivum scriptum circa extraditionem praedictorum peristromatum ${ }^{\text {h }}$ a rndo dno vicecustode huius ecclesiae perilris Bajer subscribendum et Venerabili Capitulo reddendum.

D. 8-12 Decembris, in capitulo generali Conceptionis:

[733] s. 514. Lectio statutorum, recapitulatio et approbatio capitulorum partialium. Perlectis statutis et decretis reformationis, factaque tam generalis, quam partialium capitulorum recapitulatione et approbatione, connotatis ex illis nonnullis ad tractandum, Perillustres Domini praesentes limitationem condictare censuerunt.

[734] s. 515 (9 Dec.). Argenteria ecclesiastica. Ad conscribendum de novo inventarium totius argenteriae ecclesiasticae deputantur perilres dni Tarnowski et Szczepański [canonici] atque ilris notarius. Qui perilres domini deputati tenentur pro futuro generali capitulo Pentecosten hoc negotium expedire.

[735] s. 515. Reparatio quattuor calicum. Reperiuntur in hac ecclesia destructi calices. Ideo praesens capitulum reparationem eorundem recommendatur et committitur perilribus dnis Tarnowski et Szczepański. Pro solutione vero a reparatione praefata, si opus fuerit, anulos aureos, qui sunt in Servatorio Capitulari, datur facultas accipiendi ex Servatorio et eisdem perilribus deputatis convertendi in satisfactionem aurimagistri.

\section{5}

D. 8-19 Iunii, in capitulo generali Pentecostes:

[736] s. 524-525. Lectio statutorum et decretorum reformationis atque recapitulatio. [ $s$. 525] Perlectis statutis et decretis reformationis factaque recapitulatione, nonnullis ex iisdem ad tractandum connotatis, Perillustres Domini praesens capitulum ob imminentiam Summi Sacri et concionis ad diem crastinam, scilicet 9-nam Iunii limitarunt.

[737] s. 525 (9 Iunii). Approbatio partialium capitulorum. Omnia partialium capitulorum decreta perlecta Perilres Domini praesentes approbant ac approbarunt.

[738] s. 526-527 (10 Iunii). Dispositio Sacristiarum. Innovantes anteriora decreta, ut in meliori ordinatione rndus vicecustos, praesertim Sacristiam Praelatorum [s. 527] habeat ornationem, per se vel per vicesacristianum invigilet et faciat praelatorum et canonicorum, ac non quemlibet ex sacerdotibus ad Sacristiam supratactam admittat.

[739] s. 527 (11 Iunii). Res ecclesiae non mutuandae. In praesenti capitulo decernitur, ne res ecclesiae mobiles tam argentae, quam etiam peristromata nullipiam mutuentur et concedantur. Et committitur perilri procuratori, nomine $\mathrm{Rmi}$ Capituli, rndum vicecustodem animadvertere, ut praesenti ordinationi exacte satisfaciat, nullasque res ecclesiae cuipiam concedere audeat sine scitu Rmi Capituli.

peristromatorum akta. 
[740] s. 544 (19 Iunii). Pocztmagister. Dno pocztmagistro praesens capitulum pro novellis ${ }^{63}$ assignat duos aureos, ut Venerabile Capitulum ab illo possit habere novellas ad perlegendum qualibet posta occurrente.

D. 8-20 Decembris, in capitulo generali Conceptionis:

[741] s. 564 (9 Dec.). Lectio statutorum et recapitulatio. Perlectis statutis factaque recapitulatione et approbatione capitulorum partialium, et ex iisdem nonnullis ad tractandum connotatis, Perilres Domini Capitulares ad ulterius processerunt.

[742] s. 566. Res ecclesiae non mutuandae. Renovantur anteriora decreta de non mutuandis rebus ecclesiae et in suo robore conservantur.

[743] s. 567 (11 Dec.). Ordo officiorum Divinorum. Rndo notario Capituli committitur, quatenus perscribat eundem ordinem et ad acta capitularia praesentia valeat ingrossare.

[744] s. 567. Duo aurei pro novellis. Assignantur ex massa capitulari quolibet anno pro novellis duo aurei nummi, incipiendo a mense Ianuario anni 1746-ti.

\section{6}

D. 31 Maii - 20 Iunii, in capitulo generali Pentecostes:

[745] s. 574 (1 Iunii). Lectio statutorum et recapitulatio. More antiquo et praxi, perlectis statutis factaque recapitulatione, atque approbatis partialibus capitulis connotatisque ad tractandum nonnullis ex iisdem negotiis, Perilres Domini Capitulares ulterius processerunt.

[746] s. 580 (17 Iunii). Calculus proventuum. Anteriora decreta, et praecipue anni 1740 innovantur, quaten us ante capitulum generale Pentecosten calculatio tam procuratoriae, quam oeconomiae [capitularis] quattuor septimanis inchoatur et perficiatur.

[747] s. 582 (18 Iunii). Regestra calculationum. Decernit praesens generale capitulum, quatenus omnes calculationes procuratoriae et oeconomiae, ac omnia regestra pos peractam et plene finitam calculationem perilres deputati quotannis in perpetuum et adpraesens in Archivo Capitulari reponant et conservent.

[748] s. 582. Revisio bonorum. Deputantur perilres dni archidiaconus " et Kosicki canonicus ad revisionem, visionem, ordinem faciendum in bonis mensae, tum familiam ordinandam, tam in Mysłaków ${ }^{65}$, quam in omnibus praediis, atque constituendum notarium proventualem.

[749] s. 583 (20 Iunii). Distinctio proventuum mensae. Ad faciendam separationem et distinctionem proventuum massae [capitularis] ab aliis proventibus et censibus fundationum tam pro anniversariis, quam aliis fundationibus, necnon ad specificationem expensarum, quae fieri debent ex massa, deputantur perilres dni Zajączkowski et Kosicki.

63 Abonament prasy przez kapitutę.

64 Józef Jaksa Marcinkowski h. Gryf, dr teol. lub prawa, 'm.in. prat. archid. low w l. 1743-1777.

${ }^{65}$ Mystaków wieś w par. Bednary. 


\section{KSIEGA JEDENASTA}

\section{OPIS}

Skrócony tytuł nadany (przeze mnie, tu) - Liber XI: Acta actorum Venerabilis Capituli Insignis Collegiatae Koviciensis 1746-1761.

Księga nie posiada tytułu, który pewnie miał być wypisany na $2 \mathrm{str}$. 1 karty ochr. A może nawet nie zamierzano go nadawać, albowiem od str. 1 tej księgi kontynuuje się wpisy z tegoż $1746 \mathrm{r}$.

W opracowanym na przeł. XVIII/XIX w. przez ks. SIladeckiego ${ }^{1}$ wykazie zawartości niniejszej jednostki aktowej posiada ona następujący nagłówek: Index decretorum capitularium Insignis Collegiatae Łoviciensis libri octavi, a die 8 Decembris anni 1746 (s. 133).

Sygnatury:

Not. Sladeckiego umieszczona na $1 \mathrm{k}$. ochr. wysoko: Liber Actorum

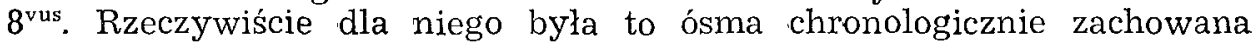
(realna) jednostka archiwalna. W lewym górnym rogu str. 1 dodał on jeszcze: $8^{\text {vus }}$.

Sygn. późniejsza, z przeł. XIX/XX w., znajdująca się na $1 \mathrm{k}$. ochr. w prawym górnym rogu, idealna: A. 1.10 [powinno być: 11].

Sygn. aktual. (moja, tutaj): AKŁ, ks. ideal. 11, real. 7.

Sygn. mikr. Ośrodka ABMK: 3523.

Księga in folio, stron 556, język (zasadniczo) łaciński. Oprawa współcz. w skórę. Stan zachowania dobry, chociaż pismo znacznie wyblakłe. Na marginesie wielu stron oznaczenia cyfrowe indeksującego akta kan. Janickiego.

\section{W'YPISY}

\section{Anni 1746 continuatio}

Dieb. 8-12 Decembris, in capitulo generali Conceptionis:

[750] str. 2 (9 Dec.). Lectio statutorum et recapitulatio. More antiquo et praxi, perlectis statutis factaque recapitulatione, atque approbatis capitulis partialibus, connotatis nonnullis ad tractandum ex iisdem negotiis, Perillustres Domini ulterius processerunt.

[751] s. 4 (12 Dec.). Mensura bonorum mensae. Ad verificandam mensuram, vulgo ć wi erć, pro consuetis consolationibus emensurata deputantur perilres dni Piaggia ${ }^{2}$ et Kosicki ${ }^{3}$.

\section{7}

Die 14 Ianuarii, in capitulo hebdomadali ordinario:

1 Piotr Sladecki, m.in. notariusz kapituly w latach 1796-1809.

2 Wojciech Piaggia, m.in. kanonik towicki $w$ l. 1729-1754, pratat kustosz $w$ l. $1754-1765$.

s pawet Kosicki ir ob. prawa, m.in kan. low. w l. 1736-1761, prat. dziekan $1762-1778$. 
[752] s. 5-6. Illatum ilmi Decani. Ilmus et rmus decanus ${ }^{4}$, providendo securitati iuris[s. 6]patronatus ecclesiae parochialis Piątkoviensis ${ }^{5}$, quod ipse super eadem privative competit, exposuit praesenti capitulo dictum ius suum per provisionem ordinariam derecenti subsecutam laesum fuisse. Rmum vero Capitulum censuit, ut omnia iura ad hunc effectum servientia pro informatione colligantur.

D. 23-29 Maii, in capitulo generali Pentecostes:

[753] s. 9 (24 Maii). Lectio statutorum et decretorum reformationis ac recapitulatio. Perlectis statutis, decretis reformationis, factaque recapitulatione tam generalis, quam partialium capitulorum, connotatisque nonnullis ex iisdem ad tractandum, Perillustres Capitulares ulterius processerunt.

[754] s. 10 (25 a Maii). Ordo Archivi. Committitur perilri procurato$\mathrm{ri}^{6}{ }^{6}$ et notario Capituli ${ }^{7}$, quatenus conficiant et disponent cistas ${ }^{\mathrm{b}}$ pro conficiendis documentis ceterisque Capituli chartis. Qui etiam omnia Capituli monumenta in ordinem redigent.

[755] s. 14 (29 Maii). Ilris Notarius resignat. Anno et die, quibus supra, comparens coram actis praesentibus ilris Stanislaus Drzewiecki ${ }^{8}$, motus gravitate annorum aliisque suis rationibus, Revendissimo Capitu.Io pro officio notariatus gratias egit, necnon sponte, libere ac voluntarie altaria duo in Ecclesia Collegiata, videlicet Sanctissimi Corporis unum et Sanctae Crucis ${ }^{3}$ alterum, per consuetudinem dicto notario ad pensionem ordinariam notariatus adiungi solita, omni meliori modo, stilo, forma, quibus melius potuit et debuit, in manus Capituli, liberamque eius dispositionem ${ }^{c}$ resignavit, seque in actis praesentibus manu propria subscripsit: S. Drzewiecki mp.

[756] s. 15. Electio Notarii capitularis. Capitulum praesens, post recessum a notariatu ilris Drzewiecki, ad electionem novi notarii processit ac liberis unanimibusque votis ac suffragiis adm. rndum Ignatium Zeleński psalteristam huius ecclesiae ${ }^{10}$ elegit et assumpsit, receptionem quoque eius et actorum traditionem capitulo partiali cum pleno vigore generalis capituli relinquit.

D. 17 Iunii $^{\text {d }}$, in capitulo hebdomadali:

[757] s. 16-17. Domus Notarii. Siquidem ilris Drzewiecki domum pro notarii habitatione commodam exstruxit sumptu non modico, pro qua aedificatione ducentos tantum florenos a $\mathrm{Rmo}$ Capitulo recepit. Ideoque circa gratiarum actionem pro notariatu liberum usum dictae domus ad

a 15 akta.

b listas akta.

c Wyraz dwukrotnie napisany.

d Iulii akta.

4 Krzysztof Michał Dobiński h. Rola, m.in. kan. low. od r. 1725, sufr. gnieźn. i praz. dziek. low. w l. $1738-1769$.

5 Parafia Piatel wcielona do uposażenia dzickanii tow. na mocy jej erekcji (1433).

6 Dotychcz. prokurator kan. Zajaczkowski, nowy kan. Kosicki.

7 Aktualny notariusz ks. Drzewiecki, nowy Ks. Żeleński (pisownia wlasna) względnie Żelinski (pisownia innych).

8 Ks. Stanisław Drzewiecki rezygnuje z notariatu kap.

- Ottarze Bożego Ciała i Sw. Krzyza objaśniane wyżej.

$10 \mathrm{Ks}$. Ignacy Żelenski h. Prawdzic, psatterzysta kolegiaty wybrany na nowego notariusza kap. 
vitae tempora sibi praecustodivit, ac pro conservatione sui circa dictam residentiam modo praemisso supplicavit. Proinde praesens capitulum, suspensa hoc in puncto sua resolutione, peril[s. 17]lustrem Szczepański ${ }^{11}$ ad componendum cum futuro notario omni meliori modo absque cuiuspiam iniuria deputavit.

[758] s. 17-18. Receptio Notarii. Attento recessu a notariatu ilris Drzewiecki praepositi Bednariensis, Rmum Capitulum adm. rndum Ignatium Żeleński psalteristam huius ecclesiae, in capitulo generali iam alias electum et assumptum, pro notario recipiendum esse censuit et recepit. Professionem fidei in praesenti capitulo, ad mentem Concilii Tridentini praestare necnon iuramentum in hanc formam:

Ego Ignatius Żeleński iuro, quod secreta et consilia Capituli nulli pandam neque revelabo, acta, decreta et resultata Capituli fideliter conscribam, praesentias et absentias Perillustrium Dominorum sincere et realiter connotabo absque omni respectu personarum, Archivum. custodiam, omniaque munia officii mei notariali incumbentia cum omni diligentia exercebo. Sic me Deus adiuvet et haec Sancta eius Evangelia.

Post cuius professionem fidei ac iuramenti super ea firmiter tenenda, praescriptisque observandis praestitionem Reverendissimum Capitulum eidem acta Capituli reddidit. Tum intuitu pensionis eidem centum florenos quolibet quartuali ex massa [capitulari] solvendos, tum medietatem omnium consolationum perillustribus dominis dari solitarum assignavit, ea tamen conditione adiecta, quatenus obligationes duarum missarum in septimana circa Altare SSmi Corporis Christi et S. Crucis ${ }^{12}$ semper absolvat sub onere conscientiae. Alliciendo quoque eundem adm. rndum notarium ad obsequia Capituli, eidem decimam post villas Plyćwia et Swięte ${ }^{13}$ in usum suum exdecimandas destinavit destinatque decreti praesentis vigore. Hoc vero praecavet Rmum Capitulum, quatenus libros ex Archivo, documenta aliosque libros in Loco Capitulari conservandos solito nulli, etiam personae capitulari, ni recepta de restituendo et promptim reponendo submissione circa acta conservanda, concedat, ut commode deperditioni librorum, documentorum ac instrumentorum Capituli obvietur. Pro intromittendo in possessionem notarialis domus perilrem Szczepański [s. 18] destinavit. In processionibus locum primum post clerum minorem huius ecclesiae eidem adm. rndo notario assignat. Siquidem ratione stalli, notario Capituli ab antiquo debiti, resolutionem suam ex certis motivis suspendit.

D. 8-16 Decembris, in capitulo generali Conceptionis:

[759] s. 23. Lectio statutorum. More et consuetudine antiqua Perillustres Domini ad lectionem statutorum processerunt. Quibus lectis, factaque recapitulatione omnium decretorum partialium capitulorum, connotatisque nonnullis ad tractanda, ad normas eorundem statutorum peragere declaraverunt.

[760] s. 28 (12 Dec.). Domus Notarii. Negotium ratione residentiae rndi notarii capitularis committitur partiali capitulo ad componendum cum anteacto notario.

11 Tomasz Szczepański h. Dologa, m.in. kan. łow. w l. 1742-1757.

12 Jak przyp. 9.

13 Por. przyp. $12 w$ kstędze X. 
[761] s. 29 (13 Dec.). Capitula partialia. Censuit Ven. Capitulum, quatenus ad mentem statutorum, capitula partialia qualibet septimana fiant.

[762] s. 29. Anniversaria superrestantia. Retulit rndus d. notarius Capituli ac in scripto Venerabile Capitulum informavit, qualiter tam multa anniversaria, et vel maxime antiquarum fundationum, circa declivium anni praesentis necdum sunt absoluta et restant absolvenda. Proinde Perillustres Domini, providendo tenuitati fundationum praefatorum anniversariorum, expostularunt perilrem Szczepański, quatenus, adhibito sibi rndo notario, fundationes omnium et singulorum aniversariorum colligat ac eorum, quae in exiguis proventibus sunt fundata et quorum fun-. dationes sunt deperditae, dignetur a S. Sede Apostolica reductionem postulare. Cui perilri domino omnes expensas pro expeditione postae in hoc negotio erogatas $\mathrm{p}$. procurator ex massa Capituli refundere debebit ac pro labore suscepto debita gratia et specialis consolatio spondetur. Nunc vero adinterim dies amicorum per quattuor septimanas eidem assignantur.

[763] s. 29. Sigillum Capituli. Innuatur perilri procuratori, quatenus sigillum cum insigniori stemmate reimprimere iubeat.

\section{8}

D. 16 Februarii, in capitulo partiali ordinario:

[764] s. 34-35. Ecclesia in Kurdwanów ${ }^{14}$. Pro decore Ecclesiae Kurdwanoviensis ac pro usu et supellec[s. 35]tili eius destinantur: casulae una miniati coloris cum columna alba, argenteis floribus adaptata; altera deterior coloris albi ex semiserico, floribus adaptata, materia cum columna rubra, musulbosowa dicta; cappa usu attrita rubea, antea aureis floribus fuit colorisata, materia semiserica viridi subducta. Quae ex inventario et supellectili Ecclesiae Collegiatae Eoviciensis a rndo vicecustode recepta, pro perpetuo usu et supellectili Ecclesiae Kurdwanoviensi per perilrem procuratorem applicabuntur.

D. 16 Martii, in capitulo partiali ordinario:

[765] s. 37. Rndus Notarius deputatur. Ad promovendum causas ratione censuum ex bonis Borysławice, Łąkoszyn, Piaski et Sobota ${ }^{15}$ in Iudiciis Officii Castrensis Lanciciensis pendentes deputatur rndus notarius. Cui datur facultas decreta quaevis attentandi, a gravaminosis appellandi, census praefatos ex iisdem bonis, quam etiam ex aliis quibusvis bonis Venerabile Capitulum respicientes percipiendi, de perceptis quietandi.

D. 4-12 Iunii, in capitulo generali Pentecostes:

[766] s. 43 (5 Iun.). Recapitulatio. Facta decretorum partialium capitulorum recapitulatione, illa Perillustres Domini in pleno robore haberi voluerunt.

D. 13 Septembris, in capitulo partiali ordinario:

[767] s. 55-56. P. m. celmi primatis Christophori Szembek fata et legatum. Clara quidem paterni affectus celmi p. m. primatis Christophori Antoni Szembek archieppi Gnesnensis ${ }^{10}$, pastoris amantissimi patet memoria, ut quemadmodum in vita sua singulari erga hanc ecclesiam anhe-

14 Kurdwanów par. w diec, pozn. (archidiak. warsz.) inkorp. kap. tow.

15 Borystawice, Eakoszyn, Piaski $i$ Sobota wsie w d. woj. leczyckim.

16 K. A. Szembek $h$. wtas. m.in. arcybp gnieźn. i prymas w $l$. 1739-1748. 
lebat amore, etiam mortalis sui corporis depositionem ultima sua dispositione in eadem ecclesia ordinavit. Posuit tandem vitae suae terminum sabbato die sexta mensis Iulii hora decima meridiana anni praesentis. Cuius corporis depositio in sepulcro Prażmoviano ${ }^{17}$ ante Altare S. Crucis ${ }^{18}$, praemissa sollemni devotione triduana sub die decima nona, vigesima et vigesima prima mensis Augusti, est peracta. Cessit pro memoria perpetua ac decore ecclesiae, ad mentem dispositionis ultimariae eiusdem Celmi Principis: crux argentea sollemnis, quae publice pro insigni primatialis dignitate deferebatur; casulae cum omni apparatu auro contextae - una coloris albi, altera coloris violacei; item coloris rubri ex materia Persica auro adaptatae duae; coloris nigri casula una et cappa una, floribus aureis partialiter colorisatae; gremiale coloris rubri cum insigni stemmatis Szembeciani; peristromatis, alias o b i cia a da m a szkow e go, rubri coloris par[s. 56] tes quadraginta eiusdem materiae et coloris; baldachinum auro concinctum; faldistoria ad insignia primatialia tria; genuflexorium unum; tumba quercea condecorata cincturis; infula auro consuta, rosa consignata; alba aurea circumdata corona; pannus Gallicus rubicundi coloris in quattuor cunctas stallarum partes. His itaque gratiosissime de manibus perilris rmi dni Dominici Kiełczewski canonici cathedralis Vladislaviensis, Volboriensis et loci praesentis praepositi $^{19}$ capitulique praesidentis, testamenti eiusdem p. m. Celmi Principis exsecustoris ${ }^{\text {e }}$ receptis, praemissa sollemni gratiarum actione, ea omnia et singula in perpetuum inventarium huius ecclesiae Rmum Capitulum ascribere mandavit.

D. 5 Octobris, in capitulo partiali ordinario:

[768] s. 57. Crux argentea. Ilmus rmus Christophorus Dobiński episcopus Serrensis, decanus ${ }^{20}$ et praesidens capituli praesentis crucem argenteam, pro insigni primatum deferri solitam, per p. m. celmum principem Christophorum Szembek archieppum Gnesnensem huic ecclesiae donatam, accommodandam esse, praemisso vadimonio et omnimoda cautione, flagitavit. Cui expostulationi Perilres Capitulares unanimiter assensum praebuerunt.

\section{9}

D. 11 Ianuarii, in capitulo partiali ordinario:

[769] s. 64. Anniversaria. Cum adpraesens commissio a S. Sede Apostolica in ordine ad reducenda anniversaria suis carentia censibus, uti sunt absoluta, ita et in libro anniversariorum anni immediati exstant connotata, censuit Rmum [Capitulum], ut collectionem annotatae pensionis in tabula anniversariorum rndus notarius non prius computet, donec aut per capitulum generale imminens, aut per supranominatam commissionem ab anniversariis, quae suum certum fundum habent, condistinguantur.

\footnotetext{
e Stowo dwa razy napisane.

17 Mikołaj Prażmowski h. Belina, m.in. arcybp gnieźn. i prymas w l. 1666-1673 .

18 Por. przyp. 9.

19 Dominik Kielczewski h. Pomian, dr teol., m.in. kan. low. w l. 1740-1742, prat, archid. 1742-1743, prat. prepozyt 1743-1776, od 1760 biskup.

${ }_{20}$ Biskup i prat. dziek. Dobinski - jak przyp. 4.
} 
D. 27-31 Maii, in capitulo generali Pentecostes:

[770] s. 73 (29 Maii). Inventarium ecclesiae. Perilres Archidiaconus ${ }^{21}$ et Bajer ${ }^{22}$ inventarium supellectilis ecclesiasticae verificabunt, quod vero noviter accessit, ad inventarium praemissum ascribent.

[771] s. 73. Archivum. Considerato, quod cum magno detrimento ac signabili iniuria iurium Capituli noscitur, quo casu libri actorum duo deperierunt, pro quorum deperditione longis ab annis in annis subsequentibus exstant querimonia, ac etiam non pridem elapso tempore liber erectionum ac alter inscriptionum originalium authenticarum non sine motu vix adinventi sunt. Obviando itaque similibus iniuriis ac damnis capitulum praesens statuit perpetuoque statuere vult, ne ex Archivo libri praemissi authentici sine consensu Capituli efferantur, sed documenta opportuna ex eisdem ad affectationem sub sigillo Capituli desumantur.

[772] s. 74. Sebum ex Arce Eoviciensi et scamma. Iuxta decretum partialis capituli pro cura et sollicitudine circa vindicationem aureorum quadraginta ex Arce Łoviciensi perceptorum, tum et alterius summae aureorum viginti pro reparatione ab exsecutoribus p. m. Celmi Principis enumeratae Rmum Capitulum perilri procuratori condignam ascribit gratitudinem.

[773] s. 77-78 (30 Maii). Pannum ad velanda altaria. Succurrendo. exigentiae et decori ecclesiarum $\mathrm{S}$. Leonardi [s. 78] ac parochialis Kurdwanoviensis, pannum vile, alias półkierze, ad velanda altaria, pro exsequiis Celmi immediati Principis comparatum, perilris procurator ${ }^{23}$ proportionaliter extradet et applicabit.

D. 30 Augusti, in capitulo partiali ordinario:

[774] s. 82-83. Oblatum perilris Wężyk. P. rmus Valentinus Wężyk Ecclesiae Metropolitanae custos, cathedralis Cracoviensis et Insignis Collegiatae praesentis canonicus ${ }^{24}$, revificando gratissimam clarissimorum et huius ecclesiae benefactorum memoriam, et signanter ilmi Ioannis Wężyk archieppi Gnesnensis ${ }^{25}$, cernendo candelabra argentea, olim per eundem ilmum ${ }^{f}$ [s. 83] suum proavum huic ecclesiae applicata, cum tractu temporis attrita et deteriorata, pro reficiendis iisdem candelabris seu deintegro conflandis obtulit praesenti capitulo mille trecentos viginti tinphones seu verius scriptum certum suprasignificatam summam in se complectens, per rmos exsecutores olim rmi Francisci Wysocki immediati. custodis Gnesnensis ${ }^{26}$, non adeo pridem vita functi recognitam et ad solvendum eidem Rmo Capitulo Łoviciensi assecuratam. Et Perilres Domini Capitulares, praevia eidem perilri dno Custodi moderno Gnesnensi

f Nastepuje po raz drugi wyraz eundem.

21 Józef Jaksa Marcinkowski h. Gryf, dr teol. lub prawa, m.in. prat. archid. tow. $w$ l. $1743-1777$.

${ }_{22}$ Andrzej Ignacy Bajer h. Leliwa, m.in. kan. low. w l. 1742-1753, od 1758 biskup.

2s Kan. Wojciech Piaggia.

24 Walenty Wężyk $h$. Waż, dr ob. prawa, m.in. kan. łow. w l. 1745-1752, od 1753 biskup.

${ }_{25}$ Jan Wężyk $h$. Waż, dr teol. $i$ prawa, m.in. arcybp gnieźn. $i$ prymas $w l$. $1627-1638$,

${ }_{26}$ Franciszek Kazimierz Wysocki h. Leliwa, m.in. prat. kust. gnieżn., zm. w $1749 r$. 
gratiarum actione, scriptum receperunt et obligationi, ut praefertur, postquam eadem summa exsoluta fuerit, omni meliori modo satisfacere decreverunt.

[775] s. 83. Pyxis ad Ecclesiam Kurdwanoviensem. Ut Deus ter Optimus Maximus ubique honorificetur, et praesertim qui sub mysticis Sanctissimae Eucharistiae speciebus praesens nobiscum esse non detractat, condignius in Ecclesia Parochiali Kurdwanoviensi, non adeo pridem impensis Rmi Capituli exstructa, tradetur et adoretur, pro pyxide conficienda Perillustres Domini tres marcas argenti ex minutioribus votis seu tabellis huius Ecclesiae Collegiatae, ad usum minus valentibus, destinaverunt et ad ponderandum idem argentum perficiendamque quantocitius pyxidem perilres dnos Procuratorem et Karśnicki ${ }^{27}$ deputaverunt.

D. 8-13 Decembris, in capitulo generali Conceptionis:

[776] s. 87 (9 Dec.). Sebum ex Arce Eoviciensi. Cum in virtute privilegiorum sebum seu quota ex Arce Łoviciensi solvi consueta, pro lampade ante Sanctissimum Sacramentum ardere solita, in anno elapso, alias vacante sede, non est persoluta, idcirco eius vindicationem $\mathrm{Rmum} \mathrm{Ca}$ pitulum perilri Procuratori praecommisit.

[777] s. 87. Pannus. De panno vili, alias półki e r z e, si a tegimentis altarium et graduum supererit, ecclesiis Kurdwanoviensi et Sancti Leonardi extra muros Łovicienses ad velanda altaria perilris Procurator proportionaliter exdividet et applicabit.

[778] s. 88. Candelabrorum per p. rmum Wężyk restauratio. Perilris rmus Valentinus Wężyk custos Gnesnensis innovavit per litteras ad p. Karśnicki directas intentionem suam in contextu decreti partialis capituli sabbato die trigesima mensis Augusti immediate lati exploratam. Quo attento Rmum Capitulum indilatam vindicationem summae per eundem perilrem rmum Wężyk legatae, curandamque reparationem candelabrorum argenteorum p. Procuratori insinuavit.

[779] s. 89. Sigillum Capituli. Animadversionem perilris Procuratoris resolvendo, non quidem titularem Ecclesiae Bmae Virginis Mariae, sed Conceptionis eiusdem Deiparae effigiem, ad norman antiqui et in noviter curando sigillo imprimere Rmum Capitulum iniunxit.

[780] s. 90. Notarius eligitur in canonicum supernumerarium. Dispositionem per capitulum generale Festorum Pentecosten anni 1747 protunc circa electionem adm. rndi Notarii praesentanei quoad stallum canonicatus supernumerarii per Rmum Capitulum eidem Notario conferri solitum, suspensam resolvendo ac considerando gressus obsequiorum eius, tam circa attendentiam officiorum in ecclesia ac vigilantia functionis suae, quam in vindicatione iurium Capituli peractorum, Rmum Capitulum eidem adm. rndo Żeleński electo et constituto notario stallum canonicatus supernumerarri cum plenitudine iuris contulit, ac ad assequendam possessionem eiusdem stalli installationemque favendam de-gremio Capituli perilres Zajączkowski ${ }^{28}$ et Tarnowski ${ }^{29}$ deputavit. In quorum

27 Stanisław Karśnickił h. Jastrz̨̧biec, m.in. kan. łow. w l. 1745-1759.

${ }_{28}$ Adam Zajaczkowski h. Zarz̧ba? m.in. kan. tow. w l. 1729-1770.

29 Stanistaw Tarnowski $h$. Rola, kan. łow. i prep. tamt. Kol. Psaltérzystów w l. $1731-1756$. 
perilrium deputatorum ac multorum astantium pro actu praemisso aggregatorum hominum praesentia installatus, intromissus ac in pacifica possessione manutentus est manuteneturque decreti praesentis vigore.

[781] s. 90. Consolatio eidem. Gratificando applicationem eiusdem adm. rndi Notarii, ut alacrior ad ulteriora obsequia reddatur, ex massa capitulari aurei sex eidem pro extraordinaria consolatione, pronunc tantum, dandos: signantur.

\section{0}

D. 21 Maii - 3 Iunii, in capitulo generali Pentecostes:

[782] s. 95 (22 Maii). Recapitulatio. Decretorum reformationum, tam immediati generalis capituli, quam et partialium capitulorum est effectuata recapitulatio, ac praemissorum partialium capitulorum decretorum in omnibus approbaturis declaratio praesenti publicatur decreto.

[783] s. 96 (23 Maii). Litterae ad perilrem rmum Custodem. Decretum anterioris capituli generalis reassumendo, ne in locum sui ex residentibus continuo perilribus praelatis vel canonicis ad conscriptionem noviter accessorum verificationemque rerum ecclesiae antehac conscriptarum substituat, ac residentiae curam habeat, litteras ad perilrem $\mathrm{Cu}$ stodem ${ }^{30}$ scribendas Rmum Capitulum decrevit.

[784] s. 96. Candelabrorum per p. rmum Węzyk restauratio. Licet perilris Procurator ${ }^{31}$ summam per p. rmum Wężyk Tribunalis Regni praesidentem pro reparatione candelabrorum argenteorum dispositam ab exsecutoribus p. m. perilris rmi Wysocki vindicare et decreto immediati capituli generalis quantocitius satisfacere interdie ei [non posset], tamen considerato quod eandem summam praefati exsecutores in spatio unius anni eodem scripto se exsoluturos obligarunt, quod tempus necdum exspiravit. Proinde omni studio piam intentionem perilris rmi Tribunalis Regni praesidentis ad effectum deducere cupiendo, in termino praeinserto $\mathrm{p}$. Procurator diligentiam omnem in vindicatione summae suprafatae adhibebit.

[785] s. 102 (3 Iunii). Res derelictae fatis p. Krajewski. Fatis olim perilris Krajewski ${ }^{32}$, improvise intercessis, res nonnullae supellectilis domesticae et oeconomicae, in fundi eius residentia relictae, devenerunt ad dispositionem p. rmi Kiełczewski praepositi loci praesentis ${ }^{33}$. Pro quibus divenditis et dispositis summam quadringentorum florenorum polon. capitulo praesenti obtulit. Quam summam, uti post fata intestati dispositioni Rmi Capituli subiectam, non aliter tamen quam in reparationem apparamentorum Sacristiae convertendam Rmum Capitulum esse voluit perilrique Procuratori erogare permisit.

[786] s. 103. Cappalia et consolationes. Conformando se aequitati tam vicinarum cathedralium, quam collegiatarum ecclesiarum iuribus et laudabili insistendo consuetudini, Perillustres Domini Praelati et Canonici statuerunt perpetuoque observari voluerunt, ut augendo cappalia in parva certe quota per duos aureos, nonnisi solvi solita accedentes ad Capi-

\footnotetext{
so Jan Wilhelm Robertson dr ob. prawa, min. prat. kust. tow. w l. 1719-1753.

31 Aktualny i przyszty kan. W. Piaggia.

32 Jan Krajewski h. Jasieńczyk, dr ob. prawa, m.in. kan. tow. w l. 1724-1742.

33 Dominik Kietczewski - jak przyp. 19.
} 
tulum perilres praelati et canonici solvant, quisque in persona sua, per aureos sex, illosque ad seorsivum thesaurum pro decore Sacristiae ac ecclesiae convertendos perilris Procurator reponat. Utque non sine robore, nec pro solis successoribus sit praeinsertum statutum, quisque ex perilribus dnis praelatis et canonicis in auctionem cappalium, per se iam exsolutorum, ad praemissum thesaurum de summa quattuor aureorum hungaricalium pro consolationibus ex capitulis binis generalibus, nempe Festorum Pentecosten 1748 et Immaculatae Conceptionis anni eiusdem quemque respicientibus, pro comparatione saepedictorum apparamentorum convertenda cesserunt ac perilri Procuratori erogandi ac convertendi plenariam facultatem dederunt.

[787] s. 104. Caecus et Sacristia. Regimen ac curam boni ordinis in hac ecclesia optatissimo animo ad meliora satagendo deducere in virtute statutorum ac decretorum reformationum praesens capitulum decrevit, ut Thesaurus ecclesiae a communi massa separetur summaeque iam ex collectis Sacristiae, quam et ex consolationibus quotidianis sub titulo Caecus, sub seorsivo titulo in libro rationum ac Thesauro ecclesiae reponatur, et nisi in solam reparationem et ornamentum ecclesiae expendatur.

D. 20 Iunii, in capitulo, partiali ordinario:

[788] s. 105-106. Perilris rmi Wężyk oblatum. Considerato, quod terminus solutionis summae mille trecentorum tinphonum, per p. rmum Wezżyk custodem Gnesnensem Rmo Capitulo pro reparatione candelabrorum argenteorum, ad percipiendum praecommissae ex scripto manuali a perilribus [s. 106] rmis p. m. rmi Francisci Wysocki immediati custodis Gnesnensis exsecutoribus favore Capituli praesentis dato, imminet. Cum vero summa a perilri dno Antonio Wysocki nominati testatoris exsecutore ${ }^{34}$ Gnesnae commemorante, ob distantiam itineris non sine sumptu vindicari queat, Rmum Capitulum ilmum Decanum ${ }^{35}$ abeuntem Gnesnam efflagitavit, ut pro sua erga hanc ecclesiam benevolentia praeinsertam vindicationem in se assumat ac scriptum praedictum, praemissa cautione, ex Archivo extradere ac ad levandam saepedictam summam, de levata quitandum ac omnia pro exigentia negotii nomine Rmi Capituli peragendum, facultatem dedit.

D. 8-12 Decembris, in capitulo generali Conceptionis:

[789] s. 113 (12 Dec.). Purgatio sepulcrorum. Praeparatoria ad purgationem sepulcrorum curandam ${ }^{36}$ provideri destinantur adm. rndi Vicecustos $^{87}$ et Caeremoniarius ${ }^{88}$, quibus, si contigerit, aliquando collectam facere pro impensis circa eandem purgationem faciendis facultas plenaria tribuitur.

[790] s. 114. Oblatum perilris Wężyk. Assecurationem reversalem a p. rmo [Antonio] Wysocki, pro summa per p. rmum Wężyk Rmo Capitulo pro candelabrorum reparatione cessa, ilmus Decanus loci praesentis transmisit, cum assecuratione solutionis summae diebus 1-ma Februarii

34 Antoni Wysocki h. Godziemba, dr ob. prawa, m.in. kan. $i$ prat. gniezn., $z m$. $w 1762 r$.

${ }_{35}$ Biskup i prał. dziek. Dobinski - jak przyp. 4.

${ }_{36}$ Porzqdkowanie grobów $w$ kolegiacie odbywato się $w$ ostatnim kwartale roku.

37 Ks. Pawel Tworkowski - jak przyp. 32 w księdze X.

38 Ks. Eliasz Sciborowicz wik. kolegiaty. 
anno proxime imminenti. Qua percepta perilris Procurator reparationem candelabrorum, iuxta nexum dispositionis anteactae, indilate curabit.

\section{1}

D. 21 Iulii, in capitulo generali Pentecostes:

[791] s. 117. Recapitulatio. Post subsecutam statutorum et decretorum visitationum atque immediati generalis capituli et insubsequens partialium recapitulationem, ex eis, tamquam legalibus et firmis, negotia ad tractandum desumpta Capitulum connotari fecit.

[792] s. 119. Candelabra. Non modica certe pars Thesauri huius ecclesiae in argenteis candelabris exsistit, quae ad ea noviter conficienda impensis perilris rmi Valentini Wężyk custodis Metropolitani Gnesnensis conflanda sunt. Proinde, ut proprimo argentum iuxta praesentem exigentiam ponderetur et conscribatur, perilrisque Procurator praemature provideat quemnam aurifabrum, qui secure possit, ad hoc opus perficiendum conduci. Summam vero mille sescentorum septuaginta septem florenorum, de manibus exsecutorum p. m. perilris rmi Francisci Wysocki anteacti custodis Gnesnensis perceptam, in Thesauro Rmum Capitulum reponendam esse voluit.

[793] s. 119. Tapes, pastorale et baldachinum. Circa conscriptionem inventarii ecclesiastici adm. rndus Vicecustos pastorale argenteum, per exsecutorem immediati Celmi Principis ${ }^{39}$ ecclesiae huic applicatum, nunc Celmo Principi ${ }^{40}$ commodatum curabit annotare. Iam enim tapetem magnum circa declarationem exstructionis ambonae novae plenarie eidem Celmo Principi cessisse. Baldachinum vero novum nunc adhuc ad beneplacitum Celmi Principis ad usus Squierniewiciis manere specificabit.

D. 8-11 Decembris, in capitulo generali Conceptionis:

[794] s. 123-124 (9 Dec.). Inventarium ecclesiae. Deperditae sunt antehac duae patenae argenteae deauratae ex inventario huius ecclesiae, et nunc non adeo praeterito tempore calix et pate[s. 124]na, furto ablata. Et fractae, in minimis fragmentis, a complicibus furti receptae sunt. Ex eo reliquo argento recepto, ac pro summa decem aureorum hungaricalium a praemissis complicibus circa vindicationem adinventum similem craterem, quantum sufficere poterit summa haec. Et patenas tres conficere adm. rndus Vicecustos curabit.

[795] s. $124-125$ (10 Dec.). Candelabra argentea. Perilres rmi supradeputati ${ }^{41}$ humiliter Celmi Principis benignum exposuerunt consensum, ut nonnulla vota argentea huius ecclesiae, non adeo ad usus necessaria, conflare illaque pro candelabris argen [s. 125] teis noviter in maiori forma, quam adpraesens exstant, perficiendis convertere Rmum Capitulum possit. Iam vero aurifabro pro manufactura, si summa de benignitate perilris rmi Valentini Wężyk data non suffecerit, p. Procurator de Summa censuali Wężykoviana ${ }^{42}$, pro pestiferis percepta et collata, titulo

s9 Arcybp K. A. Szembek - jak przyp. 16.

40 Adam Komorowski h. Korczak, dr. ob. prawa, m.in. arcybp gnieźn. i prymas 2o $l .1748-1759$.

${ }^{11}$ Kan. St. Karśnicki - jak przyp. 27. - Jan Michą Awedyk dr teol., ob. prawa, filoz. i maed., m.in. kan. łow. $w$ l. 1749-1760.

42 Fundacja arcybpa Jana Wężyka, już objasniana. 
commodati, quantum opus fuerit, coassumet. Eius vero restitutionis viam ex summa proventuali massae, adpraesens in subsidium subditis bonorum Capituli pro coemptione pecorum, clade pestis interfectorum, commodata et percipienda atque rehabenda, Rmum Capitulum demonstrat.

[796] s. 126-127 (11 Dec.). Mons Pietatis. Ilmus pariter Decanus looi praesentis supplicatur, uti Montis Pietatis praefectus, ut consultores nominet, qui attendant obligationibus, in erectione positis, in evenientique casu, quod circa aggressionem violentam nobilis Bleyza tinphones sexaginta cum marsupio rndo Notario eius[s. 127]dem Montis deperierunt, de modo restitutionis providendum; utque securius Thesaurus eiusdem Montis Pietatis in post conservetur, dignitarii eligendi cavebunt et observabunt.

\section{2}

D. 23 Maii - 14 Iunii, in capitulo generali Pentecostes:

[797] s. 130 (24 Maii). Recapitulatio et limitatio. Tam statutorum, quam et decretorum reformationum ac partialium capitulorum resolutionum facta recapitulatione ac in omnibus approbatione, annotatisque negotiis, quae in tractu capituli praesentis sunt decidenda, Perilres Rmi Domini Capitulares praesens ad feriam quintam, diem nempe vigesimam quintam Maii limitarunt.

[798] s. 131 (25 Maii). Peristromata. Notificata parendo dispositioni Celmi Princips - - in adornanda hac ecclesia, ad baldachinum in Skierniewice exsistens peristromata eiusdem coloris in frustis triginta sex ibidem transmittenda Rmum Capitulum determinavit.

[799] s. 132. Inventarium ecclesiae. Ex supellectili et argenteria ecclesiastica multae res post conscriptum inventarium per continuum usum vetustateque consumptae, aliquae vero sunt deperditae, in decreto anterioris capituli generalis specificatae. Multae tamen ex oblatis benefactorum accesserunt. Ut itaque easdem res supellectilis et argenteriae ecclesiasticae cum antiquis regestris rndus Notarius Capituli verificet ac noviter accessas conscribat, inventariumque novum conficiat, praesenti iniungitur decreto.

[800] s. 136 (14 Iunii). Candelabra argentea. Ut contractum ad conflanda candelabra argentea cum aurifabro Slaubicz cive Gedanensi ${ }^{4 \mathfrak{s}}$ perficiat perilris Procurator ${ }^{44}$ ad ultimarie praesentatam Perilribus Capitularibus normam et formam ab eodem aurifabro transmissam; et ut candelabra pariter argentea in Monte Pietatis oppignorata eximat, aut partem aliquam proportionatam argenti ecclesiastici in commutationem eiusdem pignoris det et haec ipsa candelabra minutiora ad argentum inante pro candelabris Gedanum transmissis apponere curet, ut si possibile sit, adhuc altera fiant praedicta candelabra - eidem p. Procuratori omnimoda datur facultas.

D. 8 Iulii, in capitulo partiali ordinario:

[801| s. 138. Posta. Efflagitatus ilmus Decanus ad tractandum cum nobili Lipski magistro postae ${ }^{44 a}$ retulit, qualiter ab falcastratione faeni

4s Slaubicz złotnik $w$ Gdańsku.

${ }^{44}$ Tegoroczny $i$ przyszloroczny kan. W. Piaggia.

44a Por. przyp. sia w księdze X. 
in emensurato ei prato in vim compensationis expensarum pro posta perilribus capitularibus oblata recedit, sibique solutionem parata pecunia affectat. Ut itaque idem ilmus Decanus etiam de quanto parati peculii conveniat cum nobili Magistro postae, praesenti expostulatur decreto.

D. 8-9 Decembris, in capitulo generali Conceptionis:

[802] s. 141. Recapitulatio. Facta tam statutorum et decretorum ac reformationum, quam et generalis capituli immediati et partialium recapitulatione, ad connotationem tractandorum sese Rmum Capitulum accinxit.

[803] s. 141. Candelabra argentea. Virtute decreti capituli generalis: immediati perilris Procurator candelabra argentea in Monte Pietatis perimente necessitate reparationis organorum in summa 1300 florenorum polon. oppignorata, pro summa simili ex massa capitulari se exemisse praesenti in capitulo clarificavit.

[804] s. 142 (9 Dec.). Inventarium ecclesiae. Ut commodius in vere et aestate verificatio inventarii ecclesiasticae supellectilis ac noviter accessorum conscriptu subsequatur, perilres iidem Archidiaconus ${ }^{45}$ et Karśnicki opportuno et bene viso tempore eiusdem inventarii descriptionem peragent.

\section{3}

D. 8 Februarii, in capitulo partiali extraordinario:

[805] s. 145-146. Installatio p. Żeleński ad canonicatum. Comparens: in praesenti capitulo personaliter perilris adm. rndus Ignatius Żeleński secretarius Capituli praesentis ${ }^{46}$, exhibitis litteris institutionis ad canonicatum seu praebendam huius Ecclesiae Insignis Collegiatae Łoviciensis fundi Mastki, post liberam resignationem rmi dni Andreae Bajer abbatis commendatarii Vagrovieciensis, canonici Metropolitani Gnesnensis et cathedralis Vladi[s. 146]slaviensis, Collegiatae Crusviciensis praepositi, illius ultimi et immediati possessoris vacantem, ad praesentationem ilris magci Feliciani Trzciński castellani Ravensis, capitanei Eoviciensis ${ }^{47}$, eiusdem canonicatus legitimi collatoris, Łovicii sub die ${ }^{48}$ mensis Decembris anno proxime elapso 1752, a celmo ilmo et rmo Adamo Ignatio de Liptów et Orawa Komorowski archiepiscopo Gnesnensi - - benigne impertitis. Vigore quarum litterarum petiit se ad praedictum canonicatum suscipi, vocem in capitulo sibi concedi et locum in stallo eidem canonicatus competentem assignari, atque in realem et actualem possessorem dicti canonicatus se intromitti. Et Perillustres Rmi Domini, suprascripti praelatus et canonici, receptis cum debita, qua par est, reverentia iisdem litteris institutionis, eundem perilrem Żeliński admittendum et installandum esse duxerunt, prout praevio, iuxta praescriptum statutorum capitularium, corporali iuramento cum fidei catholicae professione in manibus perilrium adm. rndorum Stanislai Tarnowski et eiusdem nominis Karśnicki deputatorum in facie totius Capituli praestito. Eundem per praefatos perilres deputatos in stalli competentis possesionem itromitti fecerunt,

45 Prat. J. Marcinkowski - jak przyp. 21.

46 Not. kap. Zelenski zostat kanonikiem gremialnym.

47 Felicjan Trzciński h. Rawicz, m.in. starosta arcybiskupi lowicki.

48 Dnia nie wpisano. 
vocemque in capitulo cum plenitudine iuris canonicalis ipsi concesserunt, qualiter intromissus, susceptus et installatus exsistens in facie totius Rmi Capituli et cleri necnon et populi, ad Divina audienda congregati, de pacifica possessione dicti canonicatus ter ultra vicibus sollemniter protestatus est. Circaque praemissam possessionem canonicatus per praesens Capitulum manutentus est manuteneturque decreti praesentis vigore.

D. 12-20 Iunii, in capitulo generali Pentecostes:

[806] s. 149. Lectio statutorum et decretorum. Facta decretorum statutorum, reformationum ac partialium capitulorum recapitulatione, factaque tractandorum computatione, propter imminentem devotionem Perillustres Domini praesens capitulum ad sequentem diem limitarunt.

[807] s. 150-151 (13 Iun.). Electio et iuramentum Notarii. Postquam de benigna gratia Celmi Principis perilris Zeleński, anteactus notarius et secretarius capitularis, ad canonicatum fundi Mastki institutus et installatus extiterit, praesens capitu[s. 151]lum ad electionem in locum eius Notarii condescendendo, ex unanimi votorum consensu ad praemissam functionem rndum Felicianum Wyszyński ${ }^{49}$ assumpsit. Qui taliter receptus professionem fidei iuramentumque in capitulo praesenti ad mentem Concilii Tridentini [praestitit] in eam rotam:

Ego Felicianus Wyszyński iuro, quod secreta Capituli nulli pandam neque revelabo, acta, decreta et resultata Capituli fideliter conscribam, praesentias et absentias perillustrium dominorum sincere et realiter connotabo absque omni respectu personarum, Archivum custodiam, omniaque munia officio meo notariali incumbentia cum omni diligentia exercebo. Sic me Deus adiuvet et haec Sancta Dei Evangelia.

Praestitis itaque in manibus perilris Żeliński tam professione fidei, quam et iuramento praeinserto, eidem novo electo et assumpto Notario acta Capituli tradidit, assignando eidem pro annua pensione, intuituque duarum missarum, unius ad Altare Corporis Christi, alterius ad Altare Sanctae Crucis ${ }^{50}$ qualibet hebdomada per eum seu eius substitutum sub onere conscientiae absolvendarum, quadringentos florenos. Atque, ut alacrius munus functionis suae obeat, ipsi decimas post villas Płyćwia et Swięte ${ }^{51}$ in usum suum exdecimandas superaddedit, omnem vigilantiam ac attendentiam in custodiendo Archivo Capitulari serio intimando. Pro intromittendoque in domum notarialem capiendamque eius possessionem perilrem Żeliński designavit praesentium vigore.

[808] s. 152 (14 Iun.). Candelabra argentea. Retulit perilris Piaggia se puncta cum aurifabro nobili Slaubicz cive Gedanensi in ordine ad conflanda noviterque conficienda candelabra argentea ad contractum per litteras missivas inivisse, clarificavitque se a qualibet marca per florenos bonae monetae sex appromisisse, ea tamen adiecta condicione, ut iuxta mentem anteacti capituli, propter firmius fundamentum et longiorem conservationem, eadem candelabra frustis ferreis intus sint subducta et corroborata, ita ut pondus argenti in eodem ferro subsistat et longius conservari queat. Cui quidem perilri referenti Rmum Capitulum gratiis de-

\footnotetext{
${ }^{49} \mathrm{Ks}$. Fielicjan Wyszyński następca Żeleńskiego na notariacie.

so Ottarze wyżej objaśniane.

51 Wsie objaśniane powyżej.
} 
bitis exhibitis, ulteriorem curam eorundem candelabrorum dereliquit et indesinens adminiculum expostulando dimisit.

D. 7 Iulii, in capitulo partiali ordinario:

[809] s. 160. Res mobiles fatis p. Szembek derelictae. Post intestatum obitum perilris olim p. m. rmi Bonifacii Szembek ${ }^{52}$, insistendo statutis res mobiles p. Procurator ${ }^{53}$, ad curiam eius seu ubi res eius proveniri poterint condescendendo conscribere, futuroque capitulo seorsivo regestro porrigere obligatur praesentibus.

D. 21 Augusti, in capitulo partiali ordinario:

[810] s. 162. Postulatum rndi Notarii. Obstrictus vinculo obsequii sui Capitulo praesenti rndus Notarius, ad amovendum et resignandum beneficium parochiale Czermnense ${ }^{54}$, supine desolatum remoteque a loco praesenti distans, petiit, a Capitulo praesenti Altare Barbarae Sanctae ${ }^{53}$, ad aedes Ecclesiae Collegiatae praesentis situm, sibi propter titulum tradi et ad idem se posse institui. Verum quoniam nondum plene constat rndum Traciewicz ${ }^{50}$ alium alicubi titulum assumpsisse et huic altariae renuntiasse, proinde ad pleniorem de eodemmet suprascripto rndo Traciewicz notitiam, expostulationem eiusdem rndi Notarii Rmum Capitulum distulit, in omni tamen facilitate assequendae eiusdem altariae, postquam praemissa innotuerint eundem determinavit.

D. 15 Septembris, in capitulo partiali ordinario:

[811] s. 163. Postulatum ilmi rmi Decani. Ilmus rmus Christophorus Dobiński episcopus Serrensis, suffraganeus Gnesnensis, decanus loci praesentis et Tribunalis Regni praesidens postulavit a Capitulo praesenti sibi pro functione memorata perisomata parieti affigenda commodari. Ad cuius postulationem Capitulum debitam praestando facilitatem eadem communicare (praevio scripto reversali a recipiente accipiendo, in quot frustis sibi applicari velit) permisit.

D. 15 Septembris, in capitulo partiali ordinario [secundo]:

[812] s. 164. Crux argentea. Ad stubam iudicialem pro functione sua praesidentiali, sin aliquam Petricoviae ilmus rmus Decanus et praesidens Tribunalis Regni commodandae crucis difficultatem habuerit, ipsi ex collegiata praesenti crux argentea extunc concedi declaratur.

D. 6 Octobris, in capitulo partiali ordinario:

[813] s. 165. Petitum rndi Notarii. Quandoquidem luculenter constat rndum Traciewicz, immediatus Altaris S. Barbarae, ad aedes Ecclesiae Collegiatae praesentis Łoviciensis siti, pridem officiose ${ }^{b}$ post assecutionem alterius beneficii idem altare resignasse, rndum quoque Notarium per decretum anteacti capituli sui in assecutione eiusdem altaris determinatum fuisse. Proinde Capitulum praesens, parendo in praemissis declarationi suae, idemmet altare praedicto rndo Notario cum onere absolvendarum iuxta mentem fundatoris missarum et pensione debita commisit, pro praesentationeque ac institutione, ad quem de iure [pertinet], remisit per praesentes.

g Nie uwzględnitem potożonych tu stów idem altare.

52 Kan. Bonifacy Szembek - jak przyp. $61 w$ księdze X.

53 Kan. I. Żeleński - jak przyp. 10 i 46.

54 Czermno par. $w$ d. archidiak. kurzelowskim.

55 Ottarz Ŝw. Barbary $w$ kolegiacie, objaśniany.

$56 \mathrm{Ks}$. Traciewicz kaptan $z$ kolegiaty. 
D. 1 Decembris, in capitulo partiali ordinario:

[814] s. 166. Obitus p. rmi Robertson custodis ${ }^{57}$. Subveniendo animae immediate pie defuncti Gnesnae olim perilris Custodis, moresque solitos intacte obeundo, tota hebdomada indiem vicibus trinis pulsabunt campanis ad impetranda suffragia animae eius; imminenti autem feria secunda exsequiae celebrabuntur.

[815] s. 166-167. Installatio rndi Notarii ad canonicatum honorarium. Coram perilribus rmis praelatis et canonicis Capituli praesentis comparens personaliter adm. rndus Felicianus Wyszyński actorum Capituli eiusdem notarius, exhibitis litteris institutionis suae ad canonicatum honorarium, sibi a Celmo Principe - - Archiepiscopo Gnesnensi - - Skier:niewiciis die vigesima sexta mensis Novembris anno praesenti datis et benigniter impertitis. Virtute et auctoritate earundem petiit se ad realem et actualem dicti canonicatus supernumerarii possessionem admitti et investiri, stallumque in choro et locum in processionibus, aliaque quaevis sibi competentia committi et assignari. Quibus Capitulum praesens visis lectisque litteris, postulatum [s. 167] eiusdem grato animo suscipiendo, in actualem possesionem dicti canonieatus supernumerarii seu installationem adm. rndi Notarii ratihabuit, ad installationemque pecilrem adm. rndum Ignatium Żeliński canonicum et procuratorem Capituli pracsentis deputavit. Qui perilris ad praemissa deputatus eidem adm. rndo $\mathrm{Fe}$ liciano Wyszyński notario Capituli praesentis ultimum a parte dextra stallum, in processionibus ante canonicos locum assignavit, cum plenitudineque iuris contulit. In quorum reali et actuali possessione manutentus est manuteneturque praesentium vigore.

D. 8-13 Decembris, in capitulo generali Conceptionis:

[816] s. 168 (10 Dec.). Lectio statutorum. More solito Perillustres Capitulares statuta ac decreta reformationis decretaque tam anteacti capituli generalis, quam et partialia sibi perlegere demandarunt.

[817] s. 170 (11 Dec.). Reductio fundationum. Nondum effectuata, ad mentem decreti anteacti capituli sui generalis Festorum Pentecosten, iurium et fundationum Collegiis ac Altaristis applicatarum revisio et reductio, nunc perilrium Karśnicki et Weżyk ${ }^{58}$, unius tamen eorum absentia non obstante, curae et sollicitudini captato tempore ad effectuandum commendatur.

[818] s. 170. Inventarium ecclesiae. Perilres Tarnowski et Meline ${ }^{59}$ revisionem rerum omnium eclesiasticarum, totius nempe supellectilis ad normam et tenorem regestrorum, cum distincta annotatione noviter accessorum in Ecclesia Collegiata praesenti peragent ac coaequentur.

[819] s. 171. Tabella anniversariorum. Propter lucidiorem incidentiae anniversariorum notitiam, tabella eorundem iuxta antiquiorem consuetudinem parieti in ecclesia affingatur.

[820] s. 172. Ecclesia Sancti Leonardi. Vacantem adpraesens Ecclesiam Praeposituralem Sancti Leonardi cum canonicatu honorario et poenitentiaria in Ecclesia Collegiata praesenti Łoviciensi, post mortem et obitum p. m. olim ilris rndi Valentini Majorowski ${ }^{60}$, illius ultimi et im-

57 Zmart prat. kust. Robertson - por. przyp. 30.

58 Wojciech Węży h. Waż, m.in. kan. Łow. w l. 1752-1789.

s9 Ludwik Meline poch. francuskiego, m.in. kan. łow. w l, 1753-1765.

co Sp. Walenty Majorowski prep. Kośc. Szpit. Sw. Leonarda $i$ kan. hon. low. 
mediati possessoris, ilri adm. rndo Paulo Tworkowski vicecustodi Ecclesiae Collegiatae eiusdem praesentis et vicario emerito, cum attinentibus ${ }^{\text {h }}$ fructibus et emolumentis, virtute iurium et privilegiorum, ad eandem ecclesiam spectantibus et pertinentibus Capitulum praesens contulit confertque praesentibus ac eundem denuo, postquam de iure competit ad praemissa praesentandum esse duxit. Qui postquam institutus et introductus ad eandem ecclesiam fuerit, extunc habito respectu tenuitatis proventuum adm. rndi Dąbrowski ${ }^{\circ 1}$ circa ecclesiam praesentem, eundem circa poenitentiariam, quoadusque utiliorem et sufficientiorem modum sibi subsistendi non adinvenerit, more et praxi dicti praedecessoris sui, conservare et ad certum tempus (salvo per omnia iure ad eandem poenitentiariam, uti perpetuo ad dictam Ecclesiam S. Leonardii annexam sibi praecustodito) dimittere se obstrinxit et obligavit.

[821] s. 173 (12 Dec.). Altare Maius. Altare Maius seu Fundatio Lesciniana ${ }^{62}$ in Ecclesia Collegiata praesenti, post obitum olim ilris Valentini Majorowski vacans, committitur daturque ius ad eandem ilri adm. rndo Paulo Tworkowski [vicecustodi], quem, cui de iure competit ad praemissa praesentare et instituere, dignabitur.

[822] s. 174 (13 Dec.). Candelabra. Perlecto capitulariter contractu respectu conflandorum candelabrorum cum nobili Slaubicz cive Gedanensi confecto, commendatam in anteactis capitulis perilri rmo Piaggia circa eandem operam, iterum Capitulum praesens cum enixa obligatione renovavit.

D. 29 Decembris, in capitulo partiali ordinario:

[823] s. 178. Installatio ilris Tworkowski ad canonicatum honorarium. Coram ilmis rmis ac perilribus Capituli praesentis praelatis et canonicis personaliter comparens ilris adm. rndus Paulus Tworkowski vicecustos et vicarius Ecclesiae Collegiatae praesentis, exhibitis litteris institutionis sui ad Ecclesiam Praeposituralem in Kierchów tituli Sancti Leonardi cum poenitentiaria ac canonicatu honorario in Ecclesia Collegiata praesenti, eidem praepositurae virtute iurium et privilegiorum perpetuo annexis, sibi a Celmo Primate - - benigniter Skierniewiciis die 22 mensis Decembris anno praesenti 1753 impertitis, virtute et auctoritate eorundem petiit se ad realem et actualem dicti canonicatus supernumerarii possessionem admitti et investiri, stallumque in choro et locum in processionibus, aliaque quaevis sibi competentia assignari. Quibus Capitulum visis, postulatum eius grato animo suscipiendo, in actualem possessionem dicti canonicatus supernumerarii dictum ilrem Tworkowski admisit installationemque eius ratihabuit, ad installandumque perilres Karśnicki et Meline canonicos suos deputavit. Qui perillustres ad praemissa deputati eidemmet installato ultimum a parte sinistra stallum, in processionibusque ante canonicos locum assignarunt et cum plenitudine iuris contulerunt. In quorum reali et actuali possessione manutentus est manuteneturque praesentibus.

[824] s. 178. Electio Notarii Montis Pietatis. Vacantem post obitum

n attinentiis akta.

61 Ks. Alojzy Dabrowski zast. penitencjarza w kolegiacie; por, nr 722.

82 Fundacja arcybpa W. Leszczyńskiego, objaśniona wyżej. 
olim ilris Valentini Majorowski Montis Pietatis notariatum Perillustres Capitulares ilri adm. rndo Paulo Tworkowski canonico honorario et praeposito Ecclesiae Sancti Leonardi [ac vicecustodi] cum plenitudine iuris contulerunt et disposuerunt. Cui Archivum Montis eiusdem iuraque ac privilegia, summas et pignora (postquam per perilres a capitulo generali deputatos revisio et reductio eorundem peracta fuerit) eidemmet perilres deputati, iuxta mentem decreti anteacti generalis capituli, tradent et porrigent. Quoniam demum ilmus rmus Christophorus Dobiński episcopus Serrensis, suffraganeus Gnesnensis, loci praesentis decanus et praesidens Tribunalis Regni Montisque praetacti Pietatis praefectus, publica sua functione praesidentiali impeditus, eidem revisioni et reductioni praesens adesse nequit, proinde se a praemissis, iusta et evidenti legalitate eximendo, perilrem rndum Adalbertum Piaggia canonicum et iudicem surrogatum loci praesentis capitulariter in locum sui obligavit, ut totus dictae revisioni et lustrationi Montis Pietatis una cum perilribus a capitulo generali deputatis attendere dignetur.

[825] s. 181. Consolationes pro candelabris dispositae. Succurrendo exigentiae ecclesiae, exquo et summa ab ilmo episcopo Chełmensi ${ }^{63}$ pro conflatione et nova exstructione candelabrorum argenteorum non sufficit, virtute vero contractus cum Aurifabro terminus exemptionis imminet. Ut proinde fervidior benefactorum reddatur pietas pro decore et Thesauro ecclesiae, perilris rmus Praepositus ${ }^{64}$ siliginem seu potius pro eo Gedani divendito summam apud p. Procuratorem ${ }^{65}$ haerentem, ultra alias parato peculio pro isdem candelabris enumeratas, cedendam declaravit. Quam itaque munificam perilris Praepositi erga hanc ecclesiam benevolentiam Perillustres Capitulares non solum debita gratitudine persolvendo, verum se alacriores ad praemissam collectam reddendo, consolationes ex capitulo Festi Immaculatae Conceptionis Bmae Virginis Mariae ${ }^{66}$ perilri Procuratori pro coemptione praemissorum candelabrorum convertendas esse iniunxerunt. Ilmus vero Decanus ${ }^{67}$, beneficando suam sub tempus praemissi capituli absentiam, de gratia sua aureos duos ininstanti in manus p. Procuratoris exsolvit.

\section{4}

D. 4-14 Iunii, in capitulo generali Pentecostes:

[826] s. 183. Lectio statutorum et decretorum. Recapitulatio. Perilres Domini Capitulares, lectis statutis, visitationibus reformationibus $[s]$ decretisque tam in anteacto capitulo generali, quam in partialibus subsecutis, eadem approbarunt et ratihabuerunt ratihabentque praesentibus.

[827] s. 188-189. Candelabra argentea. Retulit perilris Procurator Aurifabrum pro die 4ta Augusti exstructionem candelabrorum determinasse. Seque eidem iam in vim exstructionis eorundem candelabrorum summam duorum millium nongentorum triginta quinque flor. gross. trium polon. exsolvisse. Proinde obligatur perilris futurus Procurator ${ }^{68}$,

\footnotetext{
63 Bp Walenty Weżyk - jak przyp. 24.

64 Prep. Dominik Kielczewski - jak przyp. 19.

65 Prok. Ignacy Zeleński - jak przyp. 53.

66 Przypadato każdemu po 2 zl węg.

67 Bp i prat. dziek. Dobinski - jak przyp. 4.

$68 \mathrm{Kan}$. Adam Zajaczkowski - jak przyp. 28.
} 
ut postquam plene finitorum eorundem can [s. 189]delabrorum notitiam acceperit, eadem conducere residuumque ad mentem contractus eidem Aurifabro exsolvere dignetur.

D. 31 Augusti, in capitulo partiali ordinario:

[828] s. 199. Purgatio sepulcrorum. Quandoquidem cura et sollicitudine perilris Procuratoris sepulcra intra aedes Ecclesiae Collegiatae latentia purgata esse constant, et nonnulla ignota, nunc primum adinventa dicuntur. Idcirco obligatur rndus Jaramowski vicecustos ${ }^{69}$, ut eadem de integro graphice et distinctim describat, ad actaque capitularia porrigat.

D. 7 Septembris, in capitulo partiali ordinario:

[829] s. 201. Dies amicorum. Censuerunt per praesentes Perillustres Capitulares, ut praesentia octo septimanatis, in ordine ad lucrandos dies amicorum ${ }^{7}, \mathrm{ab}$ inchoatione capituli generalis Festorum Pentecosten numeretur, dies vero amicorum non aliter quam post continuatum capitulum generale, et expletam punctualiter octo septimanarum residentiam connotentur.

[830] s. 201. Tabella fundationum absolvendarum. Quandoquidem obligationes fundationum missarumque privatarum per collegia et altaristas plene et punctualiter cursu adimpleri non constant; ut propter sufficientiorem informationem, quae illarum aliquando intermissae fuerint, tabella ordine debito conscripta parieti in Sacristia affingatur.

D. 13 Septembris, in capitulo partiali extraordinario:

[831] s. 201-202. Installatio p. Piaggia ad praelaturam custodiae. Coram perilribus rmis suprascriptis praelatis et canonicis comparens personaliter perilris Adalbertus Piaggia canonicus loci praesentis, Curiae Suae Celsitudinis Primatialis iudex surrogatus, exhibitis litteris institutionis sui ad praelaturam custodiae Ecclesiae huius Collegiatae Eoviciensis (praecustodi[s. 202].ta tamen sibi de integro sui canonicatus huius ecclesiae ad tramites iuris possessione, ad futurum litis eventum ratione huius custodiae sibi in Urbe motae), ex praesentatione ilris et magci Feliciani Prandota Trzciński castellani Ravensis, capitanei Eoviciensis ${ }^{71}$, eiusdem praelaturae custodiae legitimi patroni et collatoris sub die 22-da mensis Decembris anno proxime elapso 1753 , a celmo ilmo et rmo dno dno Adamo Ignatio de Liptów et Orawa Komorowski - - archiepiscopo Gnesnensi - - Skierniewiciis benigniter impertitis, [petiit] se ad dictam praelaturam custodiae, morte et obitu olim perilris Gulielmi Robertson cathedralis Gnesnensis canonici, custodis Eoviciensis illiusque ultimi et immediati possessoris vacantem, recipi, vocem in capitulo et stallum in choro eidem praelaturae competens assignari et concedi, atque in realem et actualem possessionem eiusdem praelaturae induci. Et Perilris Domini Capitulares, visis et lectis suprascriptis tam praesentationis, quam et institutionis litteris, cum debita, qua par est, reverentia susceptis, eundem perilrem institutum unanimi voce et consensu in gremium sui recipiendum ac in possessionem praefatae praelaturae inducendum esse censue-

69 Nowy (po kan. hon. Tworkowskim) wicekustosz czyli zakrystian Jaramowski. Nie zapisano o tym następstwie. cych.

70 Dies amicorum, dawniej vindemiae - urlop od rezydowania dla rezyduja-

71 Jak przyp. 47. 
runt, atque pro eadem sui inductione et installatione facienda, recepta ab ipso, iuxta praescriptum Concilii Tridentini, et praesertim bullae Pii IV felicis recordationis papae ${ }^{72}$, fidei professione, tum etiam de observandis huiusce Capituli novis et antiquis statutis corporali iuramento, perilres Stanislaum Tarnowski et Ludovicum Meline canonicos deputarunt. Qui taliter deputati eundem perilrem institutum in facie totius cleri et populi, protunc ad Divina congregati, stallum in choro, iuxta usum et privilegia eidem praelaturae servientia, locum et vocem in capitulo assignarunt, in possessionem curiae, iurium, proventuum et redituum dictae custodiae cum solitis caeremoniis induxerunt et intromiserunt.

[832] s. 202. Cautio p. Archidiaconi. Circa installationem perilris Piaggia ad praelaturam custodiae perilris Archidiaconus ${ }^{73}$ respectu praecedentiae cautionem fecit.

[833] s. 203. Res mobiles fatis olim p. rmi B. Szembek. Ad recognoscendam in actis Consistorii praesentis quietationem per magcam Pstrokońska $^{74}$ de receptis rebus mobilibus fatis olim perilris rmi Bonifacii Szembek derelictis, et in deposito Capituli sui exstantibus, deputatur rndus Notarius, qui in quam sufficientissima et plena forma quietationem eandem recognoscendam curabit.

D. 20 Septembris, in capitulo partiali ordinario:

[834] s. 203. Postulatum p. Custodis. Ad postulationem perilris Custodis praesens capitulum permittit extraditionem documentorum statum suae praelaturae, videlicet custodiae Eoviciensis explanantium.

D. 4 Octobris, in capitulo partiali ordinario:

[835] s. 204-205. Connotatio sepulcrorum ${ }^{75}$.

D. 20 Novembris, in capitulo partiali ordinario:

[836] s. 206. Subditi bonorum capitularium. Introductum in praesenti capitulo negotium respectu dationum, contributionum et redituum dierumque laboratilium ex agris per subditos bonorum eorundem tentis pendendorum, ad futurum proxime imminens capitulum generale, in ordine conscribendi inventarii, constituendorumque praemissorum redituum et provenientiarum ab eisdem pendendorum, reicitur. Interim vero deputantur perilris Archidiaconus et rndus Notarius, ut revisionem bonorum eorundem faciant, futuroque capitulo porrigant.

D. 9-13 Decembris, in capitulo generali Conceptionis:

[837] s. 208 (10 Dec.). Lectio statutorum et recapitulatio. Lectis statutis, decretis reformationum, tum et decretis tam anteacti capituli generalis, quam et partialium capitulorum, eadem decreta Perillustres Capitulares ratihabuerunt.

[838] s. 209. Fistula aquatica, vulgo strzykawka. Commodo ac securitati saepe saepius in Civitate praesenti excurrentis incendii providendo, nobilis et spect. Barszcz proconsul Civitatis praesentis ${ }^{76}$ clarificavit se alterum instrumentum nuncupatum $\mathrm{sik} \mathrm{a} \mathrm{w} \mathrm{k} \mathrm{conducturum} \mathrm{velle.} \mathrm{Sic-}$ que ad Reverendissimum Capitulum praesens eo intuitu supplicari fecit,

72 Pap. Pius IV rzqdzit Kościolem w l. 1559-1565.

${ }^{73}$ Prat. J. Marcinkowski - jak przyp. 21.

74 Pstrokońska siostra zmartego kan. Bonifacego Szembeka.

$75 \mathrm{~W}$ podziemiach kolegiaty zidentyfikowano 13 grobów, przeważnie wspólnych.

7o Jerzy Barszcz (Barzcz) burmistrz m. towicza. 
ut etiam pro coemendo instrumento eodem contribuere dignetur. Rmum itaque Capitulum, perpensa re utili et necessaria, consolationes ex capitulo praesenti perilres rmos praelatos et canonicos concernentes ${ }^{77}$, tum ex Summa Wężykoviana (praevio consensu Celmi Primatis) aureos hungaricales decem, ita ut efficiat summa triginta aureorum hung. solvendos contribuendosque assignavit. Praecavendo tamen sibi, ut postquam idem instrumentum conductum fuerit, prope ad aedes Ecclesiae Collegiatae praesentis, nempe sub campanili, ad expostulationem Civitatis assignato, delitescat et asservetur, ad usumque communem et potissimum Ecclesiae Collegiatae praesentis (in casum alicuius inopinati, quem Deus avertat, casus) sit. Super quam clausulam sibi per Capitulum praesens reservantam et praecustoditam, documentum signanter scriptum a proconsulibus et consulibus Civitatis praesentis per perilrem Procuratorem exquiratur.

[839] s. 210. Inventarium ecclesiae. Ad conscribendum inventarium supellectilis Collegiatae praesentis deputantur perilres Tarnowski et Żeleński. In quod inventarium res derelictas post fata $\mathrm{rmi}^{\mathrm{i}}$ Szembek, in decreto receptionis eorum specificatas, inducent.

[840] s. 210-211. Res ecclesiasticae non mutuanda?. Iuxta mentem et dispositionem statutorum res ecclesiasticae sine consensu Rmi Capituli, sive maioris partis perillustrium $[s, 211]$ capitularium scriptoque reversali, nemini concedantur.

[841] s. 211 (11 Dec.). Disponuniur summae pro Sacristia. In Monte Pietatis, circa revisionem per perilres Deputatos factam, repertos ultra omnes summas aureos hungaricales decem - cuiusnam sint, non compertum. Tum ex superaccrescenti summa, pariter in eodem Monte Pietatis, 288 florenos gross. 26. Ac summam triginta aureorum hung. per ilrem Jaramowski, ecclesiae praesentis vicecustodem, in exstructionem mensarum seu scriniorum ad servandos apparatus aliasque res ecclesiasticas in Sacristia Vicariali oblatam, addederunt praesentibusque Perilres Capitulares disposuerunt.

[842] s. 214 (12 Dec.). Inventarium bonorum. Ad conficiendum inventarium generale bonorum Rmi Capituli deputantur perilres rmus $\mathrm{Cu}-$ stos et Karśnicki. Quibus datur facultas omnes dationes, labores constituere, et cunctas in genere ac singulas in specie querimoniarum inter subditos circumstantias sopire, immutationem horti in Strzelczew perficere eaque, quae utiliora fundo et rei oeconomicae videbuntur, peragere.

[843] s. 215 (13 Dec.). Candelabra argentea. Antiquam appromissam a benefactoribus pro candelabris collectam ad complementum integralis Aurifabro solutionis perilris Żeliński recipiet, si haec, quae iam est collecta, non sufficiet. Extunc Rmum Capitulum censuit, ut aliquam summam ex Provisionibus Wężykovianis a perilri Procuratore commodet.

\section{5}

D. 26 Ianuarii, in capitulo partiali ordinario:

[844] s. 218. Tabella anniversariorum. Vi deputationis suae ad disponenda per annum anniversaria perilris Meline sufficienter et ordine de-

' Celsmum akta.

77 Por. przy. 66. 
bito descripta et disposita in tabella praesentavit. Pro quo et debitam gratiarum actionem Rmum Capitulum praestitit.

D. 1 Martii, in capitulo partiali ordinario:

[845] s. 218-219. Crux argentea. Ilmo Dobiński suffraganeo Gnesnensi, loci praesentis decano, immediato Tribunalis Regni praesidenti, crucem argenteam pro functione accommodatam. Cum etiam ilmus Swinarski praesentaneus Tribunalis praesidens ${ }^{78}$ per litteras missivas, ad Capitulum directas, Lublinum sibi accommodari postulat, cum sponsione restitutionis, seu potius post finitam sui Lublini functionem, huc secum advectionis, Rmum Capitulum, parendo postulatis eius, eandem crucem com [s. 219] modare non dedignavit. Eoque intuitu litteras rescribendas nomine Capituli sententiavit.

D. 3 Maii, in capitulo partiali ordinario:

[846] s. 219. Litterae ab Aurifabro. Ex reproductis in praesenti capitulo litteris constat, quod nobilis Slaubicz civis et aurifaber Gedanensis intra spatium trium septimanarum exstructionem candelabrorum argenteorum determinavit, pro eisque hoc eodem tempore condescendi affectat. Verum quoniam nullum adpraesens modum aliquem condescendi et transmittendi Capitulum habet, proinde ad futuram defluctationem adorum conductionem eorundem candelabrorum distulit, eoque intuitu litteras ad eundem rescribendas determinavit.

D. 20-26 Maii, in capitulo generali Pentecostes:

[847] s. 221 (21 Maii). Recapitulatio. Solito more, relectis decretis tam anteacti capituli generalis, quam et partialium capitulorum, eadem Perillustres Capitulares ratihabuerunt.

[848] s. 221. Fundatio Lipsciana adiungenda. Praesens Rmum Capitulum perspectam bene habens tenuitatem proventuum in Collegiis Psalteristarum et Rorantistarum, proinde ut presbyteri in iisdem collegiis exsistentes maiorem sufficientiam habere possint, supplicandum censet Celmo Principi - Lociordinario, ut in futuro actu visitation is suae benigniter dignetur adiungere eisdem collegiis fundationem Lipscianam ${ }^{79}$, ita ut iidem psalteristae et rorantistae obeant insimul munera capellanorum Lipscianorum.

[849] s. 222. Revisio supellectilis ecclesiasticae. Ut revisio descriptioque universae supellectilis ecclesiasticae quantocius perficiatur et concludatur, Rmum Capitulum obligat perilres dnos anterius deputatos.

[850] s. 223 (22 Maii). Donatio pro candelabris. In praesenti capitulo perilris rmus dnus Piaggia custos Collegiatae, ex sua liberalitate, pro exemptione candelabrorum argenteorum Gedani factorum summam centum quinquaginta florenos polon., ex massa Rmi Capituli sibi ad solvendum assecuratam, decreto capituli generalis Festorum Pentecosten anni immediate praeteriti 1754 prolato, cessit et donavit. Pro quo Rmum Capitulum eidem summas peregit gratias.

[851] s. 223. Relatio p. Custodis circa aurum. In praesenti capitulo generali retulit perilris rmus dnus Piaggia custos, quomodo Celmus Prin-

${ }^{78}$ Wawrzyniec Swinarski h. Poraj, m.in. kan. i prat. gnieznieński, zm. w 1761 r.

$79 \mathrm{Kol}$. Psalterzystów (Tarnowskiego) erygowane $w$ r. 1609, Rorantystów (Rokickiego) w 1637, Kapelanów (Lipskiego) w 1648. 
ceps - - lociordinarius archiepiscopus Gnesnensis - - et benefactor singularis huius ecclesiae, ex sua speciali gratia et munificentia, contulit huic ecclesiae notabilem quantitatem auri, ponderis in summa trecentorum unius hungaricalium pro comparando calice. Quod aurum rmus dnus Michael Awedyk canonicus in capitulo reposuit. Ideo praesens capitulum generale pro tanto beneficio et munificentia singulari humillima gratiarum actione rependatur. Ad eum effectum faciendum nomine Rmi Capituli deputat perilres rmos Adalbertum Piaggia custodem et Paulum Kosicki canonicum. Qui quidem perilres rmi domini simul implorabunt humillime a Celmo Principe consilium, qui artifex adhibendus sit ad comparandum eundem calicem.

[852] s. 225 (23 Maii). Sacristia. Committitur partiali capitulo, ut dimensionem pro conducenda scintula lapidea faciat.

[853] s. 225. Oblatum p. Zajaczkowski. Perilris Zajączkowski canonicus loci praesentis siparium seu perisomata in frustis viginti quattuor et medio, per celmum olim Potocki archieppum Gnesnensem sibi donata, ad Capellam Lipscianam in Ecclesia Collegiata praesenti, pro maiori decore zelo pietatis suae applicavit et perpetuis temporibus donavit. Pro quo Rmum Capitulum eidem debitas gratias egit ac in tutiorem et longiorem conservationem pluteos ligneos, in quibus suspendi idem siparium possit, muro affingere mandavit.

[854] s. 227 (26 Maii). Candelabra. Quoniam Aurifaber per litteras Gedano directas notabilem argenti quantitatem ad candelabra addidisse se innotescit, modus vero extunc alius quam ex massa capitulari non est. Proinde futurus perilris Procurator, quantum necesse fuerit, p. Żeliński pro conductione eorundem candelabrorum deputato ex massa tribuet. Compensatio vero erogata ex massa in exemptionem eorundem candelabrorum summae ex collectis sive etiam ex Summa Wężykoviana, praevio Celmi Primatis consensu, repetetur.

[855] s. 228. [Procurator et oeconomus bonorum in annum sequentem canonicus Tarnowski electus est].

D. 7 Iunii, in capitulo partiali ordinario:

[856] s. 229. Lapideum postumentum ad Sacristiam. Quoniam Civitas praesens lapides albos ad formandum postumentum in Sacristia idoneos se habere testatur, ex eisdem divendere intendit. Proinde respectu eordundem perilris Procurator, cum quo intererit, componet. Perilris quoque canonicus Żeliński residuum Gedani coëmet. Quique viliores erunt, ad angulos applicentur, nitidiores vero et selectiores in medio collocentur.

D. 14 Iunii, in capitulo partiali ordinario:

[857] s. 230. Relatio deputationis ad Celsissimum. Celmus Princeps benigne gratioseque perilribus a Capitulo praesenti deputatis benevolentiam suam testatus est, et circa facultatem conflandi vota et vasa ex Thesauro ecclesiae pro constructione candelabrorum argenteorum. Itidem pro candelabris stanneis, cum non sit alius modus comparationis eorundem, facultatem dedit urnam ilmi Lipski ${ }^{80}$ convertendi. Pro quo capitulum praesens perilribus deputatis gratias egit ac pro ossibus ilmi Lipski,

so Jan Lipski h. Lada, m.in. arcybp gnieźn. i prymas $z m$. w $1641 r$. 
ut urnam parvam p. Procurator ex aere comparare mandet, obligavit. De modoque conflationis candelabrorum ex materia praemissa stannea, ut provideat, insinuavit.

D. 7 Octobris, in capitulo partiali extraomdinario:

[858] s. 240. Illatum ilris Vicecustodis. Illata per ilrem Vicecustodem loci praesentis, respectu diminutionis luminis in Altari Maiori propositio, ad futurum capitulum generale suspenditur.

D. 8-11 Decembris, in capitulo generali Conceptionis:

[859] s. 243 (9 Dec.). Recapitulatio. Lectis statutis, decretis visitationum ac decretis tam anteacti capituli generalis Festorum Pentecosten, quam et partialium capitulorum, Perilres Domini Capitulares decreta eadem in toto approbarunt, vimque et robur suum obtinere debere dictararunt.

[860] s. 244. Quietatur p. Żelinski. Quoniam perilris Żeliński ad exemenda ab Aurifabro candelabra, virtute decreti Capituli sui deputatus, regestra tam perceptarum ex collectis a benefactoribus et massa Capituli, quam erogatarum in rem Aurifabri et coëmptionem notabilis quantitatis seu residuitatis ad complementum ponderis deficientis argenti summarum liquide producit, et easdem perceptas summas manifeste erogasse demonstrat, proinde, praemissa eidem pro suscepto labore debita gratiarum actione, praesentibus de praemissis quietavit. Ac considerando in tot negotiis Capituli sollicitos eius labores, eundem ad actum praesentis eius adventus pro praesenti agnovit. Regestra eadem perceptarum et erogatarum summarum manu perilris praesidentis Capituli sui subscripta, actis suis inserere mandavit, in tenore sequenti legatur ex copia hic insuta ${ }^{81}$.

[861] s. 244-245. Breviarium a p. rmo Awedyk donatum. Perilris rmus Awedyk Metropolitanus Gnesnensis et loci praesentis canonicus, benigno suo erga ecclesiam praesentem affectu, Breviarium ${ }^{j}[s$. 245] ad chorum multum commodum et decorum perpetuo ecclesiae praesenti applicavit. Pro quo ei Rmum Capitulum debitas gratias egit.

[862] s. 245. Inventarium ecclesiae. Produxerunt perilres anteacto capitulo suo deputati inventarium rerum ecclesiasticarum, per conscriptum verificatum et collectum. Cum tamen res noviter accessae nondum in eodem inventario reperiuntur, proinde Rmum Capitulum per eosdem perilres deputatos adimplendum idem inventarium indilate sanxivit.

[863] s. 246 (10 Dec.). Candelabra stannea ex summa p. Zajaczkowski. Multum contribuit perilris Zajączkowski confectis ad altare in Capella Lipsciana candelabris stanneis, pro quo eidem Rmum Capitulum gratias debitas egit - -

[864] s. 248. Specula ad Sacristiam. Ad Sacristiam specula quattuor perilris Procurator, ut solvat ex massa, obligatur. Non tamen pluri pretio quam sex aureis hungaricalibus. Pro quibus perilris rmus Awedyk, ex sua munificentia erga ecclesiam praesentem, contribuit adpraesens aureos hung. duos, pro quo eidem Rmum Capitulum gratias egit.

\footnotetext{
j Opuścitem wadliwy kustosz pro.

81 Rachunków tych trzeba szukać w aktach gospodarczych.
} 


\section{6}

D. 15 Ianuarii, in capitulo partiali extraordinario:

[865] s. 252. Deputantur ad revisionem regestrorum. Post fata perilris Tarnowski canonici et procuratoris loci praesentis sine testamento decessi ${ }^{82}$, conscribendi inventarii rerum fatis eius derelictarum, pensandorumque regestrorum perceptarum et erogatarum summarum ex proventibus bonorum capitularium et aliis provenientiis pullulantium, tum quorumvis onerum tam per olim praedictum perilrem Tarnowski contractorum, quam eidem debitorum perilris rmus Custos onus in se suscepit. Ad revisionem vero bonorum et perficiendum in eisdem calculum perilris Zajączkowski adpraesens unanimi voto et assensu in locum dicti olim p. Tarnowski procurator electus et expostulatus, tum perilris rmus Karśnicki deputantur. Qui etiam massam Capituli revidebunt, denumerari facient, futuroque capitulo omnia referent. Demum obligatur praesens perilris modernus Procurator, ut anniversaria, consolationes et refectiones indilate exsolvere perilribus capitularibus dignetur.

[866] s. 252. Crux argentea. Crucem argenteam ex Ecclesia Collegiata praesenti perilris rmus Swinarski canonicus cathedralis Gnesnensis pro functione sua praesidentiali in Tribunali Regni commodavit. Quae itaque crux quandoquidem per manus perilris rmi Awedyk eiusdem Meiropolitanae Gnesn. et ecclesiae praesentis canonici, Curiae Suae Celsitudinae Primatialis generalis auditoris est adpraesens restituta. Proinde Rmum Capitulum pro restituta gratias egit.

D. 20 Martii, in capitulo partiali ordinario:

[867] s. 258. Alba ad Sacristiam. Perilris Moline canonicus loci praesentis ad coronas, ab alba post fata olim celmi Teodori Potocki primatis Regni ad Sacristiam praesentem destinata et tractu temporis deteriorata, carbasum suam propriam dedit et eandem restauravit, et eandem itidem Sacristiae praesenti applicavit. Pro quo Rmum Capitulum gratias egit.

[868] s. 258. Sepulcrum pro Feria 6-ta Magna. Ilris Jaramowski vicecustos Ecclesiae Collegiatae praesentis proposuit in capitulo praesenti diminuendam structuram Sepulcri in diem Parasceves comparandi, uti vetustate deteriorati. In quo negotio ad conferendum cum eodem ilri Jaramowski perilrem Procuratorem Rmum Capitulum obligavit.

D. 9-16 Iunii, in capitulo generali Pentecostes:

[869] s. 262 (10 Iun.). Lectio statutorum et recapitulatio. Lectis statutis, decretis reformationum et visitationum [s], decretorumque tam anteacti capituli generalis et partialium recapitulatione facta, Rmum Capitulum eadem decreta in to to ratihabuit.

[870] s. 268-269 (15 Iun.). Tabella fundationum. Reassumitur decretum anterioris capituli obliganturque perilres [s. 269] deputati, ut quantocitius eandem tabellam fundationum cum sufficienti descriptione conficere et parieti Sacristiae affingere dignentur.

[871] s. 269. Liber ordinationis summarum transformandus. Quoniam summae Capitulum suum concernentes multae statum suum primitivum et locationes inscriptionibus originalibus determinatas immutarunt, sicque in libro ordinationum non comperitur sufficiens status earundem moderni enucleatio. Proinde committitur rndo Notario, ut eundem trans-

${ }_{82}$ Kan. St. Tarnowski, prokurator zm. 11 I 1756. Por. przyp. 29. 
formet, pro quo eidem Rmum Capitulum florenos trecentos in compensationem laboris assignavit.

[872] s. 269. Thesaurus Ecclesiae constituitur. Considerando varias in calamitatibus caristiis aliisque de manu Dei casibus necessitates, provisam in obvenientibus, quae Deus avertat, periculis intendentes erigere massam, Perillustres Capitulares sanxiverunt, praesentibusque in perpetuum statuunt et ordinant, ut quotannis, post peractam perilris Procuratoris calculationem, ex residua ab expensis massae Capituli summa, per perilrem Procuratorem derelinquenda, duo millia florenorum polon. separentur et ad Thesaurum distinctum reponantur. Quae itaque summa in nullas communes necessitates convertatur, sed indiminute quotannis seiuncta conservetur. Et ad eum effectum Perilres Capitulares ex moderna collecta, ultra expensas derelinquenda, eandem summam duorum millium flor. polon. seiunctam conservare separatim ad ulteriorem collectam sanxiverunt.

[873] s. 270. Inventarium bonorum. Perilres rmi ad calculum et revidenda ${ }^{\mathrm{k}}$ bona deputati inventarium eorundem bonorum capitularium confecturos se obligarunt.

[874] s. 270-271. Mensura pro adoribus. Maxima circa calculationem difficultas ex usu diversarum in praediis pro adoribus mensurarum. Cui Rmum Capitulum subveniendo censuit praesentibusque decernit, et tetrantem mensurae civitatensis pro dimensuratione in allodiis adorum constituit. Iam vero pro $[s .271]$ ordinariis hominibus inserviendam et emensuratione hordei pisti, pro cerevisia et cremato antiquo usu mensuram minorem, $\mathrm{r}$ o $\mathrm{zch}$ od $\mathrm{n}$ i a nuncupatam, ordinavit ordinatque per praesentes.

[875] s. 272 (16 Iun.). Crux aurea et torquis. Ilmus Decanus et praesidens capituli praesentis exposuit intentionem sui in solvendis adaequato valore cruce et torque aureis, in tumulo celmi Wezżyk ${ }^{8,3}$ compertis. Cuius postulationi Rmum Capitulum annuendo, easdem crucem et torquem auream, iuxta taxationem perficiendam, eidem ilmo Decano ${ }^{1}$ promisit.

[876] s. 272. [Procurator Capituli: Zajaczkowski (post mortem Tarnowski) - Zajaczkowski].

D. 19 Iunii, in capitulo partiali extraordinario:

[877] s. 273. Aurei nummi. Retulit perilris Procurator, quod in massa Capituli plus quam trecenti aurei hungaricales inadaequati et defectuosi ponderis reperiuntur, per idemque pondus minutum ad nullam quam piam necessitatem converti possunt. Proinde Rmi Capitulares, aliter iisdem consulere non valentes, pro praesentiis seu refectionibus perilres praelatos et canonicos ex praesentaneo dimidio anni concernentes convertendos et dispertiendos sanxivit, ea adiecta conditione, ut ad quemlibet aureum nummum perilris Procurator medietatem deficientis ponderis annumeret et cuique persolvet.

D. 7 Augusti, in capitulo partiali ordinario:

[878] s. 278-279. Census a retentoribus et moneta. Incusat mdus

k reddenda akta.

1 Znajduje się tu drugi raz eidem.

68 Arcybp i prymas Jan Wężyk zmarl 27 V 1638. 
Notarius renitentiam dnorum censistarum, qui stato moderno tempore et multa, respectu praesertim aureorum nummorum defectum ponderis biaequati in se continentium, difficultate in exsolutionem retentorum censuum, nonnisi aurum exigui ponderis aut in moneta pro aureo uno tinphones tredecim sextarium unum. Nonnulli tinphones quattuordecim sine $[s .279]$ sextario offerunt. Quapropter Rmum Capitulum, habito respectu proxime imminentis quartualis ${ }^{34}$, decrevit, quatenus idem rndus Notarius ad minora collegia se in hoc negotio referat, et si in pensionibus eadem collegia concernentibus pro aureis nummis quattuordecim tinphones absque sextario susceptura se obtulerint, etiam a retentoribus in hac quantitate census retentos recipiant?

D. 8-15 Decembris, in capitulo generali Conceptionis:

[879] s. 285. Recupitulatio. Lectis statutis, decretis reformationum, tum anteacti capituli generalis atque partialium, eadem relecta decreta praesens Rmum Capitulum ratihabuit.

[880] s. 286. Pallae et bursae. Exigentiam in Sacristia rndus Vicecustos pallarum et bursarum in praesenti capitulo intulit. Proinde Rmum ${ }^{1}$ Capitulum perilri Procuratori commisit, ut pro comparandis praemissis, quot et quantum potuerit, ex massa capitulari tribuat.

[881] s. 287-288 (10 Dec.). Tabella fundationum absolvendarum. Perilris rmus Karśnicki cathedralis Plocensis et loci praesentis canonicus, virtute decreti in anteacto capitulo generali Festorum Pentecosten lati, fecit codicillum omnium obligationum et funda[s. 288]tionum in ecclesia praesenti absolvendarum. Idemque sufficienter conscriptum in praesenti capitulo produxit et praesentavit. Quo capitulariter relecto, eidem perilri rmo Karśnicki Perilres Capitulares pro suscepto circa praemissa labore gratias egerunt et in tabella ad idem parata parieti ad Sacristiam affingere mandarunt.

[882] s. 291 (15 Dec.) Inventarium bonorum. Reassumuntur decreta anteacti capituli sui exposcunturque perilres Deputati, ut inventarium bonorum capitularium conficiant.

\section{7}

D. 5 Februarii, in capitulo partiali ordinario:

[883] s. 294. Crux aurea et torquis. Compertam in tumulo ilmi Wężyk archieppi Gnesnensis crucem auream cum torque, cum ilmus Dobiński non acquisivit, ilmus quoque Wężyk episcopus Chełmensis, in memoriali proavi sui easdem desiderasse constat. Proinde Rmum Capitulum votis eius annuendo, easdem crucem et torquem ponderari et in manus perilris rmi Karśnicki cathedralis Plocensis et loci praesentis canonici tradendas, per eundem vero suprascripto ilmo episcopo Chełmensi transmittendas permisit permittiturque praesentibus.

D. 19 Februarii, in capitulo partiali ordinario:

[884] s. 295. Litterae innotescentiales de capitulo optionis. Post subsecutam per perilrem rmum Szczepański canonicatus Ecclesiae Collegiatae praeșentis favore p. rmi Sztoltman ${ }^{85}$ resignationem, Perillu-

I Skrót wykonany dwukrotnie.

84 W kolegiacie dokonywano wyplat kwartalnie.

85 Jakub Sztoltman dr ob. prawa, m.in. kan. low. w l. 1757-1766. 
stres Capitulares, insistendo legibus et consuetudinibus suis, in ordine ad optandam avenam strenalem diem 5 Martii, in sabbato post dominicam primam Quadragesimae in anno praesenti proxime venturo incidentem, assignarunt. De quo termino omnibus, quorum interest, innotesci voluerunt inotescuntque per praesentes litteras ad fores $\mathbf{C a -}$ pitulares affingendas.

D. $5^{\mathrm{m}}$ Martii, in capitulo partiali ordinario:

[885] s. 296. Reponit crucem p. rmus Karśnicki. Virtute anterioris decreti Capituli sui perilris rmus Karśnicki crucem auream in tumulo ilmi Wężyl archieppi Gnesnensis cum torque compertam, et circa requisitionem ilmi Wężyk episcopi Chełmensis eidem per manus p. rmi Karśnicki communicatam, et denuo huc Łovicium retrotransmissam, isidem p. rmus Karśnicki in praesenti capitulo comportavit et in actu reponit. De qua comportata et restituta eundem Rmum Capitulum quietavit quietatque praesentibus.

[886] s. 297. Illatum perilris Custodis. Reproduxit in praesenti capitulo perilris Piaggia custos loci praesentis litteras testimoniales ab ilribus magcis Senatoribus et Ministris Regni super distinctas in Regno ilris magci capitanei Łoviciensis ${ }^{86}$ praerogativas et auctoritates, eidem virtute iurium et privilegiorum servientium datas, curaque et sollicitudine perilris rmi Awedyk cathedralis Gnesnensis et loci praesentis canonici, Curiae Suae Celsitudinis Primatialis generalis auditoris et iudicis, ad causam ratione Custodiae Eoviciensis in Urbe Romana agitatam exportatas, quas, exhibita gratiarum actione, in Archivo conservandas Capitulum censuit ${ }^{87}$.

D. 31 Maii - 13 Iunii, in capitulo generali Pentecostes:

[887] s. 301. Lectio statutorum et recapitulatio. Lectis statutis, reformationibus decretisque tam in anteacto generali, quam et partialibus subsecutis et ad actum praesentis capituli latis, eadem decreta Perillustres Capitulares ratificarunt.

[888] s. 302 (1 Iun.). Liber ordinationis summarum. Reassumitur anterius decretum Capituli sui obligaturque perilris Custos, ut cum rndo Notario transforment librum ordinationis summarum, salva rndo Notario anteriori decreto praecauta compensatione.

[889] s. 308 (6 Iun.). [Procurator Capituli: Zajaczkowski - Zajączkowski].

[890] s. 309. Summa Thesauri. Manutenendo decretam in anteacto capitulo summae duorum millium florenorum polon. quotannis ex qualibet perilris Procuratoris pro Thesauro Capituli repositionem: quoniam in anno praeterito $p$. Procurator ex eadem summa iam in anteriori separata et reposita, summam pro coëmendis bobus ad bona Kurdwanów notabilem expendit, proinde Rmum Capitulum eundem p. Procuratorem obligavit, ut quamprimum modum habere potuerit eandem adimplere curet; ex praesenti quoque provenientia summa similis reponatur.

[891] s. 311 (13 Iun.). Rndo Notario 200 flor. - - assignantur. Ut alacrior ad quaevis onera rndus Notarius reddatur, commendatur per-

m 6 akta.

86 Także ten starosta lowicki (Wężk) byt senatorem (kasztelan rawski).

87 O nie tak ważny spór poruszano niebo $i$ ziemię. 
ilri Procuratori, ut eidem ex massa florenos ducentos pro laboribus in anno praesenti exsolvat.

D. $13^{\mathrm{n}}$ Augusti, in capitulo partiali ordinario:

[892] s. 314. Imminens visitatio Ecclesiae Collegiatae praesentis. Litteris innotescentialibus determinata a Celsissimo Principe visitatio Ecclesiae Collegiatae praesentis in spatio trium septimanarum ab actu intimationis. Proinde, ut Celmus Princeps circa condescensionem sui omnia parata praeveniat, deputantur ad inscribendum statum ecclesiae perilres Archidiaconus, Karśnicki et Sztoltman; ad connotanda iura p. Żeliński; ad conscribendum quoque inventarium ecclesiasticum; perilres Custos et Tarnowski ${ }^{88}$. Qui, conscriptis omnibus graphice distinctim et enucleatim, in termino visitationis ad informationem Celsissimo porrigent.

D. 10 Septembris, in capitulo partiali ordinario:

[893] s. 316. Sepulcra intra aedes ecclesiae. Intra aedes Ecclesiae Collegiatae praesentis sepulcra numerosa, nullis signis notata et ignote, ob uniforme pavimentum, latentia. Nonnulla vix circa purgationem comperta, licet iam conscripta. Ut tamen lucidius appareant, Rmum Capitulum per conductum adpraesens lapidarium signis aliquibus notabilibus consignanda statuit et decrevit; curamque praemissorum circa impensas ex massa Capituli ilri Vicecustodi commendavit.

D. 1 Octobris, in capitulo partiali ordinario:

[894] s. 317. Salutatio Celmi Principis circa visitationem. Determinatam Celmi Principis D. N. C[lementissimi] Collegiatae praesentis visitationem, debito cultu Perilres Capitulares suscipere intendentes, ad salutandum eundem rmum Custodem obligarunt.

D. 13 Octobris, in capitulo partiali extraordinario:

[895] s. 319. Celmus Princeps in Capitulari salutandus. Circa visitationem in Capitulari Celmi Principis D.N.C. perilris rmus Karśnicki munus salutandi eiusdem in se suscepit.

D. 21 Octobris, in capitulo visitationis:

[896] s. 320. Capitulum praelatorum et canonicorum Ecclesiae Collegiatae Łoviciensis sub tempus visitationis generalis celmi _- - Adami Ignatii de Liptów et Orawa Komorowski - - f. 6 post dominicam 20 posit Pentecosten, die scilicet 21 Octobris 1757, praesentibus perilribus Archidiacono praesidente, Custode, Zajączkowski, Karśnicki, Janicki, Wężyk, Żeliński, Tarnowski, Sztoltman canonicis agitatum.

D. 9-13 Decembris, in capitulo generali Conceptionis:

[897] s. 329-330 (13 Dec.). Tabella fundationum. Ad revidenda iura Collegiorum Minorum, tam scilicet Vicariorum, quam Psalteristarum et Rorantistarum deputatur perilris rmus Sztoltman. Qui facta ex reinductis sibi inscriptionibus, erectionibus et aliis quibusvis documentis revisione [s. 330] fundationes et obligationes eorundem collegiorum conscribet.

\section{8}

D. 1 Aprilis, in capitulo partiali ordinario:

[898] s. 339. Purgatio pyxidis. Respectu conservationis seu purga-

n 31 akta.

88 Jozef Tarnowski h. Rola, kan. łow. $i$ prep. tamt. Kol. Psałterzystów $w$ l. $1756-1788$. 
tionis pyxidis negotium ad capitulum generale differtur.

D. 14 Maii - 1 Iunii, in capitulo generali Pentecostes:

[899] s. 341 (15 Maii). Lectio statutorum et recapitulatio. Lectis statutis decretorumque tam reformationum, quam generalis anteacti et partialium capitulorum facta recapitulatione, eademmet decreta in partialibus capitulis lata per Illustres Capitulares ratihabuerunt.

[900] s. 349 (27 Maii). Liber ordinationis summarum. Reassumitur anterius decretum in puncto annotatae consolationis mdo Notario pro reducendo libro ordinationis summarum.

[901] s. 350-351. Perilres Procuratores duo constituuntur. Cum ob involutionem et prementiam negotiorum iuridicorum unum perilrem Procuratorem rei oeconomicae et obvenientibus continuo causis nullatenus sufficere posse Capitulum perpendit: proinde subveniendo tam utilitati bonorum, quam faciliori negotiorum quorumvis promotioni, defensioni et vindicationi, in Procuratorem seu Commissarium Bonorum p. Zajączkowski, p. quoque Żeliński in Procuratorem Causarum votis suis [Domini] elegerunt. Ut vero quisque eorum notum sibi habeat officii sui munus, sequentem Perilres Capitulares fecerunt distinctionem. Perilris Zajączkowski bona administrabit, massam tenebit, proventus perceptae et expensas faciet, fabricam ecclesiae curabit, inventarium bonorum conficiet. Habebit pro labore frumenta in grano ordinaria, prout hucusque usus obtinuit, et praesentiam tempore functionis ac medietatem consolationum in capitulo Conceptionis Bmae Virginis Mariae. Perilris quoque Żeliński iura et causas ac [s. 351] census vindicabit, eosdemque recipiet, de receptis quietabit, perceptos Procuratori massae reddet, librum quietationum tenebit et census in eundem inscribet. Praesentiam tempore functionis et negotiorum; et medietatem consolationum tempore Immac. Conceptionis Bmae Virginis Mariae capituli habebit; pro consolatione seu labore percipiet florenos quingentos, id est eam pensionem, quam hactenus percipiebat Procurator.

[902] s. 352 (29 Maii). Crux aurea Wężykoviana. Crucem parvam auream cum torque, in tumulo olim ilmi Wezżyk archieppi Gnesnensis compertam, iuxta pondus et valorem debitum, perilri Wężyk canonico ${ }^{89}$, pro memoriali proavi sui, sive alii cuipiam iustum pretium offerenti Perillustres Capitulares (salvo consensu Celmi Principis) divendendam promiserunt.

[903] s. 354 (1 Iun.). Consolatio rndo Secretario Capituli. Providendo citiori censuum, in notabili quantitate retentorum, vindicatione ac obvenientibus saepe in diversis locis uno tempore causis, quibus unus perilris Procurator sufficere nequit, ut rndus Notarius adaugeat curam necessarii in praemissis iuvaminis, ipsi ultra competens salarium summa ducentorum florenorum polon. pro praesenti anno solvenda ex massa capitulari assignatur.

[904] s. 354. Mensura pro adoribus. Perilribus ad calculum deputatis committitur et insinuatur per praesentes, ut mensuram in omnibus bonis capitularibus, tam pro menisuratione singulorum adorum ex allodiis, quam pro extradendis hominibus inserviendis ordinariis (facto moderamine) ac pro aliis expensis, obviando nimiis circa calculum ex

${ }^{89}$ Kan. Wojciech Wężyk - jak przyp. 58. 
diversitate mensurarum, earundem difficultatibus et perplexitatibus, constituant unam.

D. 8-14 Decembris, in capitulo generali Conceptionis:

[905] s. 365. Revisio libri fundationum. Perilris rmus Sztoltman cathedralis Chełmensis et loci praesentis canonicus deputatur ad revisionem libri fundationum absolvendarum. Qui p. deputatus, utrum debito et punctuali cursu fundationes praemissae absolutae et in libro iuxta mentem anteriorum decretorum sunt annotatae, revidebit Capituloque relationem faciat.

[906] s. 367-368 (11 Dec.). Relatio deputationis ad revidendum librum fundationum. Retulit perilris rmus Sztoltman, ad revisionem libri fundationum connotandarum deputatus, quod in eodem libro omnes et in[s. 368]tegrae sint connotatae fundationes, praeter missas binas Rorate et ad Altare Sanctae Victoriae per rndum Dąbrowski absolvendas. Proinde subveniendo integritati fundationum, Rmum Capitulum eidem praesenti iniungit, ut de absolutis iisdem punctualiter missis doceat. Quo demum spectat iura Collegii Rorantistarum, iam toties per eundern rndum Dąbrowski comportari iniuncta, adusque non comportata. Obligavit Rmum Capitulum perilrem Procuratorem, ut eidem retineat adusque ex quartuali praesenti respicientem provenientiam, quoadusque eadem non comportabit -

[907] s. 368. Altare S. Rochi. Post recessum rndi Michalski vicarii ecclesiae praesentis et altaristae Sancti Rochi, vacat adusque idem altare. Ad quod documenta rndus Michalski retinet. Cum vero adpraesens Łovicii reperitur, deputatur ad eundem rndus Notarius, ut documenta praemissa recipiat.

[908] s. 368-369. Inventarium ecclesiae. Cum statuta et decreta reformationum indigitant quotannis faciendam rerum ecclesiasticarum revisionem et consoribendum earundem inventarium, proinde deputatur per praesentes perilris Meline. Ut easdem [s. 369] cum inventario recenter pro visitatione conscripto verificet, noviter accessas conscribat.

[909] s. 372 (13 Dec.). Erectio Altaris S. Ioannis Nepomuceni. Sat sufficienti demonstratione omnium et singularum summarum doti Altaris Sancti Ioannis Nepomuceni competentium et provenientiarum quarumvis ac obligationum, sculptam non sine labore per perilres ad id deputatos erectionem, cum sibi Rmum Capitulum adpraesens perlectam habuerit, eisdem p. rmis deputatis debitas gratiarum actiones pro suscepto onere et effectu exhibuit. Praesentique perilri rmo Auditori ${ }^{90}$ approbationem eiusdem erectionis (praeviis litteris cridae quantocius curandis) commendavit. Et postquam eadem erectio approbata fuerit ${ }^{31}$, denuo eandem in acta sua capitularia ingrossandam determinavit.

[910] s. 372. Altare S. Rochi. Licet rndus Notarius Capituli sui recepta fuisse a rndo Michalski documenta ad Altare Sancti Rochi Capitulo refert, verumtamen cum nonnullae necessitates ad constituendum altaristam instant - -

90 Kan. J. M. Awedyk - jak przyp. 41.

91 Odnowienie erekcji Ottarza i Bractwa Sw. Jana Nepomucena przez arcybpa Komorowskiego nastapito 20 XII 1758. Pierwsza erekcja, przez prym. Potockiego, miała miejsce 25 IV 1737. 
[911] s. 379 (14 Dec.). Revisio et conscriptio librorum. Ad revisionem et conscriptionem librorum Bibliothecae, in Archivo Capitulari exsistentis, obligatur praesenti perilris Meline [canonicus].

\section{9}

D. 2 Martii, in capitulo partiali extraordinario:

[912] s. 382. Fata celmi olim principis Komorowski $A$. G. In die hodierna, nempe 2-da Martii, Skierniewiciis celmus princeps Adamus Ignatius de Liptów et Orawa Komorowski Dei et Apostolicae Sedis gratia archiepiscopus Gnesnensis, legatus natus, Regni Poloniae et M. Ducatus Lithvaniae primas primusque princeps ultimam vitae suae posuit periodum. Quod cum primum ad Capitulum devenerit, non sine ingenti dolore et lacimis invidi fati pastoris sui amantissimi lugubrem suscepit notitiam. Cuius munifica beneficia Capitulo et Ecclesiae praesenti in vita praestita, cum nos cogunt merita fore aeternae gratitudinis memores, movent etiam singularius ad exhibenda quaevis demortui obsequia. Et hinc est, quod Capitulum praesens ex debito et praecipuo erga indolebilem saeculis pastorem suum amoris motivo ad assistentiam corpori perilres Adalbertum Piaggia custodem et Iacobum Sztoltman canonicum deputavit. Ac quidquid ${ }^{\circ}$ ex Sacristia praesenti postulatum fuerit, praevio scripto reversali seu annotatione in seorsivo regestro rerum extraditarum, commodari censuit per praesentes.

D. $16^{\text {p }}$ Martii, in capitulo partiali extraordinario:

[913] s. 383. Cum Collegio Vicariorum conferendum. Rndi Vicarii Ecclesiae Collegiatae praesentis ius aliquod spolii post defunctos sibi vindicare et competere testantur, de quo idem Capitulum non est informatum. Ut vero sub tempus modernae sepulturae Celmi Primatis D. Clem. aliquod inconveniens non oriatur, perilris dnus Praepositus onus cum iisdem tractandi in se suscepit.

[914] s. 383. Aurum pro calice. Negotium respectu auri trecentos circiter aureos hungaricales in pondere suo adaequantis, per celmum olim Primatem pro calice ad Ecclesiam Collegiatam praesentem destinati, suspenditur ad adventum perilris Procuratoris.

D. 24 Martii, in capitulo partiali ordinario:

[915] s. 386. Aurum pro calice. In suspenso ad adventum perilris Procuratoris negotio respectu auri pro calice, per celmum olim Primatem destinati, cum p. Procurator per p. rmum Awedyk, praevio scripto reversali ad Artifices receptum fuisse demonstrat, proinde Rmum Capitulum idem negotium ad adventum rmi Awedyk suspendit.

[916] s. 386. Tympana. Respectu tympanorum ex Ecclesia Collegiata praesenti Squiernievicium celmo olim Primati commodatorum perilres ad alia negotia tractanda cum exsecutoribus deputati etiam eadem tympana expostulabunt.

[917] s. 386. Ordinatio devotionis funebrialis. Ut in futuro actu funeris Celmi olim Primatis, die 28 mensis praesentis in Ecclesia Collegiata praesenti subsequendo, ordo bonus servari queat, pulsum pro

- quod quod akta.

b 15 akta. 
devotione hora 3-tia, ut officium matutinum per Vicarios anticipate absolvatur, Perillustres Capitulares determinarunt. Demum inchoatis vigiliis, per extraneos sacerdotes missas inchoandas statuerunt. Et praesertim conventibus regularibus seorsivum altare assignandum. Pro Perilribus vero Capitularibus in Sacristia locum ad absolvendas missas assignarunt. Demum subveniendo securitati ecclesiae, homines tam ab infra, quam ab extra cum aqua locandos, ne quid ex numeroso eruat lumine, decreverunt. Ceteramque curam et vigilantiam omnium rndo Vicecustodi Ecclesiae Collegiatae praesentis commendarunt.

D. 28 Martii, in capitulo partiali extraordinario:

[918] s. 387. Res mobiles ecclesiasticae circa funus. Perilres Capitulares praesentes statuerunt, ut ilris Vicecustos loci praesentis nullas res cuipiam circa funus adpraesens reperibiles sine Capituli sui consensu extradat.

D. $31^{\mathrm{A}}$ Martii, in eapitulo partiali ordinario:

[919] s. 388. Deputatio ad celmum eppum Cracoviensem. Celmus princeps episcopus Cracoviensis ${ }^{92}$, amore ecclesiae et Altaris Sancti Ioannis Nepomuceni, ad aedes Ecclesiae Collegiatae praesentis siti, reliquiare argenteum cum reliquiis eiusdem S. Ioannis ecclesiae praesenti applicavit. Quas quoniam in praesenti capitulo comportatas Rmum Capitulum cernit, ut beneficio et indesinenti amori debitae exhibeantur gratiae, perilris rmus Dominicus Kiełczewski cathedralis Cracoviensis canonicus, loci praesentis praepositus, cum toto Capituli gremio, eidem celmo principi eppo Cracoviensi, 'pronunc Łovicii praesenti, sese gratias acturum obtulit.

[920] s. 388. Res ex funere celmi olim Primatis derelictae. Res ex funere celmi olim Primatis derelictas perilris Custos, cum ilri Vicecustode Ecclesiae Collegiatae praesentis, regestrare dignabitur.

[921] s. 388. Perisoma, pastorale et crux. Perisoma magnum, tum pastorale et crux argentea, celmo olim Primati communicata, quoniam adpraesens sunt Capitulo restituta, proinde pro reliquis rebus restituendis perilres anteriori decreto deputati agere dignabuntur.

[922] s. 388. Tympana. Perilres exsecutores tympana, celmo olim Primati communicata, Varsaviae adpraesens exstasse fatentur. Quae quamprimum exinde huc asportari valuerint, restituenda determinant.

[923] s. 388-389. Res ex Sacristia celmi olim Primatis. Considerando notabilem rerum sub tempts funeris in ecclesia praesenti deteriorationem, Perillustres Capitulares ad perilres rmos [s. 389] Kosicki et Awedyk exsecutores celmi olim Primatis supplicarunt, ut in compensationem praemissorum res aliquas ex Sacristia derelictas ecclesiae praesenti applicare velint. Quorum ratione iidem perilres rmi exsecutores cum aliis coexsecutoribus sese collaturos obligarunt. Demum desolationem circa funus idem tam in muro, quam et postumento ecclesiae apparentem eisdem perilribus rmis exsecutoribus commendarunt. Iisdemque pronunc praesentibus, ut amore Capituli iustitiam tam in legatis testamento, quam in aliis iustis et legalibus praetensionibus atque rebus commodatis, nondum restitutis, accelerare dignentur, insinuarunt.

g 30 akta.

92 Kajetan Ignacy Soltyk $h$. wias., dr ob. prawa, biskup krakowski w l, 1759-1788 , byt kiedyś dwukrotnie kan. low. 
D. 3 Aprilis, in capitulo partiali extraordinario:

[924] s. 389-390. Pastorale commodatur. Pastorale argenteum ilmus Bajer eppus modernus Culmensis ${ }^{93}$ commodari sibi ad breve tempus postulat. Cuius postulationi [s. 390] Rmum Capitulum annuendo, praevio scripto reversali, commodandum decrevit.

[925] s. 390. Desideria ad ilmos Exsecutores p. m. celmi olim Primatis. Quoniam tam ex testamento, quam ex codicillis p. m. celmi olim Primatis D. Clem. patet summas et quidem: 1-mam viginti millium florenorum polon. pro anniversariis; 2-dam viginti millium [flor. pol.] pro Capella Smae Crucis; 3-tiam 10000 flor. pol. pro Sacristia Capitulari; 4-tam 18000 flor. pol. pro Emeritis circa Ecclesiam Collegiatam praesentem Łoviciensem; 5-tam triginta aureorum hungar. pro Sacristia; 6-tam ex anno gratiae a mense Ianuario anni currentis ex omnibus fructibus et reditibus Dueatus Łoviciensis provenientibus; tum segetes anni praeteriti 1758 pro mausoleis in Ecclesia Collegiata praesenti, secundum obloquentiam testamenti exstruendis, Capitulo et Ecclesiae Collegiatae praesenti legatas fuisse. Proinde exposcuntur praesentes perilres a Capitulo sui Deputati, ut praemissorum omnium ratione cum ilmis Exsecutoribus indilate tractent et exsolutionem summarum earundem exposcant. Qui quidem perilres deputati etiam ratione periscmatum sericorum in frustis quadraginta commodatorum, tum baldachini, iam alias restituti, verumtamen notabiliter deteriorati, atque tympanorum, similiter communicatorum, nondum restitutorum, tractabunt. Tum quoque deteriorationem sub tempus funeris apparatuúm, postumenti in ecclesia, scamnorumque, destructionem albedinis in parietibus muratis ecclesiae ex luminibus ardentibus, confuscationem exponent et compensationem praemissorum desiderabunt. Demum de dispositione summarum in subalterno codicillo specificatorum. Et in speciali ratione fundationis Cancellariatus mentem exsecutorum exquirent et pariter pro solutione summarum instabunt. Ac fine cultus Divini et boni Ecclesiae omnia efficaciter terminari postulabunt.

D. 5 Aprilis, in capitulo partiali extraordinario:

[926] s. 391. Apparatus ex Sacristia celmi olim Primatis et cappa. Quioniam ex relatione fidedignorum testium et nonnullis connotatis constat celmum olim Primatem D.N.C. apparatum cum cappa et alba ad ecclesiam praesentem disposuisse: proinde obligatur praesentibus perilris canonicus Zeliński, ut memoriale praemissorum ratione ad exsecutores conficiat idemque indilate porrigatur.

[927] s. 391. Deputantur ad levandas summas legatas. Perilres Custos, Zajączkowski procurator et Żeliński ad numerandas summas, per celmum olim Primatem ad ecclesiam praesentem legatas, postquam tempus exsolvendi summis iisdem per ilmos exsecutores determinatum fuerit, per praesentes deputantur. Quibus plenaria facultas respectu summarum earundem quovis meliori modo componendi easdem, levandi, recipiendi et ad aerarium massae capitularis comportandi datur et committitur. Dispositio vero earundem levandarum summarum ad futurum imminens generale capitulum reservabur.

os Biskup chetmiński Bajer (1758-1785) również byt przedtem kan. low. Por. przyp. 22 , 
D. 16 Aprilis, in capitulo partiali extraordinario:

[928] s. 391. Crux argentea. Cum celmus nominatus Princeps archiepiscopus Gnesnensis ${ }^{94}$ commodari sibi crucem argenteam ex Ecclesia Collegiata praesenti postulat, proinde Perilres Capitulares favendo eius postulationi commodari determinarunt.

D. 19 Aprilis, in capitulo partiali ordinario:

[929] s. 393. Deputati ad tractandum respectu summae 160000 flor. pol. Respectu dispositionis summae 160000 florenorum polon. pro fundatione Cancellariatus Łoviciensis cum canonicatu Gnesnensi ${ }^{95}$, atque pro capellanis [Capellae] Smae Crucis in Ecclesia Collegiata Eoviciensi, testamento et codicillis celmi olim Primatis D.N.C. legatae, perilres Archidiacionus et Custos cum quo intererit tractabunt.

D. 5 Maii, in capitulo partiali ordinario:

[930] s. 393. Salutatio Celmi Principis. Cum celmus princeps feliciter modernus ilmus rmus dnus Vladislaus Pomian a Łubna Łubieński archiepiscopus Gnesnensis, primas Regni in die crastino adventurus speratur, proinde, ut congrue suscipiatur, perilris Archidiaconus munus salutationis eiusdem in se suscepit.

[931] s. 393-394. Crux, genuflexorium et alia commodantur. Determinatam inante commodationem crucis argenteae ex Ecclesia Collegiata praesenti celmo Principi manutenendo, extunc referendam Celsissimo, Perilres Capitulares, cum supervenerit, censuerunt. Quae quandoquidem per Aurifabrum ${ }^{95}$ est ponderata et manu ilris Vicecustodis in pondere suo circumscripta, proinde eadem ponderis descriptio actis inseritur in tenore sequenti: Anno Domini 1759, die trigesima Aprilis w Kowiczu. Waga i opisanie krzyża srebrnego Szembekowskiego ${ }^{97}$, na pożyczenie J. O. Xciu Jmci Władysławowi Łubieńskiemu arcybiskupowi gnieźnieńskiemu, prymasowi Korony Polskiej. 1-mo. Krzyż z gałkami, na którym pasyja i sztuki inne złociste nr 6 , dico sześć i na gał[s. 394]ce aniołków nr trzy i róźów trzy; w środku śruba żelazna. To wszystko waży grzywien czternaście, dico grzywien $n r$ 14, i z żelazem w środku. 2-do. Do laski sztuk cztery, ważących grzywien $\mathrm{nr} 12$, dico dwanaście. In summa grzywien nr 26. Do tego laska drewniana, okowana na końcu, z śrubą żelazną, i puzdro do tego krzyża. Franciszek Gruszewicz mp. Quandoquidem vero et genuflexorium sericum, aurea corona circumductum, commodandum similiter ab eodem Celmo Principe desideratur, idem etiam extradendum Perilres Capitulares sanxiverunt.

[932] s. 394. Crux altera, Wężykoviana et campanula, ac alia. Crucem alteram, Wezżykovianam et campanulam parvam, tum perisomata parietalia coloris rubri, materiae a da $\mathrm{m}$ a s z ek nuncupatae, carbaso rubri coloris subducta, in frustis triginta tribus, atque baldachinum ad requisitionem celmi Primatis feliciter moderni D.N.C. extunc commodari Perilres Capitulares permiserunt; suntque praemissa actu commodata.

D. 5-23 Iunii, in capitulo generali Pentecostes:

[933] s. 396 (6 Iun.). Lectio statutorum et recapitulatio. Lectis de

94 Wladystaw Aleksander Łubieński $h$. Pomian, m.in. arcybp gnieźn. i prymas w) l. $1759-1767$.

${ }_{85}$ Do fundacji pratatury kanclerskiej w Eowiczu nie doszto.

o6 Franciszek Gruszewicz złotnik w Łowiczu.

${ }^{97}$ Krzyż z daru arcybpa Krzysztofa Antoniego Szembeka. 
more statutis ac decretis reformationum, tum et capituli praeteriti generalis atque partialium, eadem Perillustres Capitulares ratihabuerunt.

[934] s. 397 (7 Iun.). Revisio libri fundationum. Ad revidendum librum connotandarum fundartionum deputatur per praesentes perilris Janicki ${ }^{98}$.

[935] s. 397-398. Res ex funere celmi olim Principis derelictae. Res ex funere celmi olim Principis derelictae non omnes commodo et usui ecclesiae necessariae esse videntur. Proinde deputantur per praesentes perilres rmi Custos ${ }^{99}$ et Awedyk, ut easdem pensare et dignoscere dignentur, et quae iis minus necessariae videbuntur, easdem taxare et divendere man[s. 398]dent, salva relatione Capitulo facienda.

[936] s. 398. Inventarium ecclesiae. Ad conscribendum et verificandum inventarium ecclesiasticum deputantur perilres Meline et Tarnowski.

[937] s. 400 (8 Iun.). Liber ordinationis summarum. Reassumitur decretum anterius intimaturque rndo Notario, ut eundem tempore captato conficiat.

[938] s. 402 (9 Iun.). Sanctuarii duo novi constituuntur. Considerando indispensabilem auctionis numeri sacristarum necessitatem, perilris Zajączkowski canonicus loci praesentis [et procurator] ex proventibus a summis suis, pro ecclesia praesenti dispositis, summam centum florenorum polon. quotannis pro conservatione eiusdem sacristae convertendam et exisolvendam in perpetuum designavit. Quorum itaque sanctuariorum praesens capitulum sequentem fecit dispositionem, ut praeter sacellanum et calcantistam duo in perpetuum ex proventibus bonorum Strzelczew ${ }^{100}$ omnino subsistant, tertius ex proventibus, ut supra, per perilrem Zajączkowski assignatis. Quartum vero capitulum praesens ex proventibus a summa undecim millium flor. polon. in et super bonis Zglinna ${ }^{101}$ haerenti, per cels. olim principem pie defunctum Adamum Komorowski - - Capitulo demissa, pro fabrica ecclesiae et conservatione sacristae unius dispositis, conservandum similiter in perpetuum Capitulum statuit. Qui omnes quattuor, ut supra, constituti sanctuarii florenos centum quotannis percipere et propter debita obsequia in ecclesia ad pulsandas campanas spectare debebunt et tenebuntur.

[939] s. 404-405 (11 Iun.). Crux aurea Wężykoviana. Compertam in tumulo celmi olim principis Wężyk archieppi Gnesnensis crucem auream cum tórque, ponderis ${ }^{102}$ [s. 405] aureorum hungar., ad ulteriorem dispositionem in Thesauro Capituli conservandam Capitulum censet.

[940] s. 407 (13 Iun.). Summa 72 flor. pol. pro sebo ex Arce. Ut perilris rmus Kosicki metrop. Gnesnensis et loci praesentis canonicus, generalis bonorum Archiepiscopatus commissarius, propter maiorem posteriori saeculo notitiam in inventariis summam septuaginta duorum florenorum polon. ex Ance pro sebo quotannis ad Ecclesiam Collegiatam praesentem provenientium annotari mandet, praesentibus eundem Rmum Capitulum supplicavit.

98 Adam Janicki h. Rola, dr ob. prawa, m.in. kan. low. w l. 1748-1771.

${ }^{99}$ Prat. kust. W. Piaggia - jak przyp. 2, - Por. nr 831.

100 Strzelczew wieś w par. kolegiackiej.

101 Zglinna wieś $w$ b. pow. rawskim.

102 Cįżaru nie podano. 
[941] s. 408. Cancellariatus, praebendarii et annus gratiae. Negotium respectu fundationis Cancellariatus Łoviciensis cum canonicatu Gnesnensi per cels. olim pie defunctum Primatem dispositae in futuro capitulo Immac. Conceptionis BVM finaliter dicedendum capitulum praesens relinquendo, tractanda tam [cum] ilmis exsecutorjbus, quam successoribus, pro exigentia temporis et negotii (etiam decisive cum auctoritate Celmi Principis) vigorem partialibus capitulis reliquit.

[942] s. 409 (16 Iun.). Aurum pro calice a celmo Komorowski. Sollemniori gratia favore celmi ilmi et rmi Adami Komorowski, immediate pie defuncti archieppi Gnesnensis, destinatum pro calice aurum ponderis trecentorum unius aureorum hungar., inante comportatum et extraditum, adpraesens vero per perilrem rmum Awedyk metrop. Gnesn. et loci praesentis canonicum ad conflandum receptum, cum adpraesens Rmum Capitulum praesens per manus eiusdem rmi Awedyk denuo recepit, eidem debitas rependit gratias. Ut autem minoris ponderis quantitas auri in igne consumpti pateat, circa conflationem absumptos a pondere aureos octo capitulum praesens demonstrat. Et sic conflati nonnisi pondus ducentorum nonaginta trium aureorum hungar. in se continere propter notitiam posteritati praesentibus elucidat.

[943] s. 410. [Procuratores in annum sequentem electi: bonorum A. Piaggia, causarum I. Zeliński].

[944] s. 411 (18 Iun.). Status ecclesiae ad visitationem porrectus restituitur. Cum perilris rmus Awedyk ex sua speciali gratia statum ecclesiae praesentis tam in erectionibus, fundis, fundationibus, obligationibus, dotationibus totoque situ Capituli et Ecclesiae, ac Collegiorum circa ecclesiam praesentem exsistentium pro inchoata, fatis demum interrupta, celmi olim Primatis visitatione porrectum, in praesenti capitulo reponit, eidem Rmum Capitulum praestita gratiarum actione, in actis propter informationem retinendum mandavit.

[945] s. 412 (19 Iun.). Capella Komoroviana et Capitulare ac Sacristia. Licet quidem complanatio cum ilmis successoribus ac exsecutoribus olim principis Komorowski confecta et conscripta (quam Capitulum per praesentes ratihabet) et summam 20000 florenorum polon. pro exstructione Capellae Sanctissimae Crucis receptam fuisse demonstrat. Cum tamen idem punctum magis ad contextum testamentariae dispositionis dicti olim celmi Principis regulari videtur, et numquam possibilem sumptu eodem praemissae capellae exstructionem Capitulo infert. Maxime, quod 'Sacristia et Capitulare aliam ante omnia exaedificationem exigit. Proinde Rmum Capitulum de transportatione Sacristiae et Loci Capitularis ac sumptibus sufficientioribus pro exstructione capellae memoratae vigorem tractandi cum ilmis exsecutoribus et successoribus etiam partiali capitulo relinquit.

[946] s. 413 (20 Iun.). Posta. Post abscessum perilris rmi Praepositi ${ }^{102}$ complebunt negotium ratione componendae postae perilres Meline et Sztoltman.

[947] s. 414. (21 Iun.). Relatio ratione postae. Quoniam Perillustres a Capitulo deputati cum nobili Lipski ${ }^{104}$ pro posta in annum centum octo

103 Prat. D. Kietczewski - jak przyp. 19.

104 Jak przyp. 44a. 
florenos solvenda composuerunt, pro annis vero retroactis flor. trecentos quinquaginta solvendos compactarunt: eoque intuitu contractum conscripserunt. Proinde Capitulum eundem ratione praemissorum conscriptum contractum praesenti ratihabet.

D. 7 Iulii, in capitulo partiali ordinario:

[948] s. 422. Usus mantoletorum et rochetarum. Ut conformiter ve-

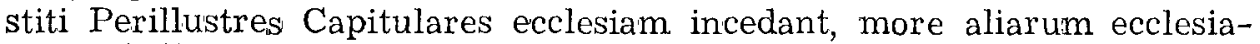
rum tabellam valvis capitularibus (cum denotatione in quibus festis mantoletis et rochetis uti debeant) affingendam Capitulum statuit.

D. 9-15. Decembris, in capitulo generali Conceptionis:

[949] s. 433 (10 Dec.). Recapitulatio. Lectis statutis reformationibus atque decretis tam generalis anteacti, quam et partialium capitulorum, eadem decreta Perillustres Capitulares ratihabuerunt.

[950] s. 435. Inventarium ecclesiae. Ad conscribendum inventarium ecclesiae deputantur parilres Sztoltman et Kaszowski ${ }^{105}$, quod commodo tempore conscriptum futuro capitulo generali porrigent.

[951] s. $441\left(13^{\mathrm{r}}\right.$ Dec.). Capella Komoroviana et Sacristia. Siquidem nondum secutus est effectus tractandi cum successoribus olim celmi Primatis tam intuitu capellae construendae, quam et Sacristiae, atque fundationis Cancellariatus et capellanorum Smae Crucis. Proinde quodsi possibilitas permiserit (reassumpto decreto anterioris capituli generalis) vigorem tractandi etiam decisive partiali capitulo praesens Rnum Capitulum relinquit.

[952] s. $444\left(14^{\mathrm{s}}\right.$ Dec.). Tabella frumentorum. Comportatam per perilrem Custodem et Procuratorem bonorum ${ }^{106}$ tabellam frumentorum, per p. Praesidentem ${ }^{107}$ subscriptam, ad futurum calculum circa acta conservandam Perillustres Capitulares censuerunt.

\section{0}

D. 26 Aprilis, in capitulo partiali ordinario:

[953] s. 450-451. Deputantur ad formandam erectionem Praebendariorum Smae Crucis. Cum praesenti capitulo, virtute litterarum cridae ad formandam erectionem Praebendariorum Smae Crucis fundationis Komorovianae, pro die 2-da Maii anno praesenti Skiernieviciis tempus determinatum fuisse constat: proinde pro eodem termino perilres $\mathrm{Cu}$ stos ${ }^{108}$ et Janicki, cum praesentia ad reditum, deputantur. Quibus itaque perilribus deputatis datur facultas pro eodem [s. 451] termino comparando fundationem et erectionem praemissam acceptandi.

Dieb. 27 Maii - 9 Iunii, in capitulo generali Pentecostes:

[954] s. 452 (28 Maii). Lectio statutorum et recapitulatio. Lectis statutis, decretis tam reformationum, quam generalis immediati capi-

r 12 akta.

s IBrak w aktach.

105 Stanistaw Kaszowski h. Janina, dr ob. prawa. m.in. kan. kaznodzieja towicki od r. 1759, prat. archid. w l. 1774-i785.

100 Praz. Piaggia - jak przyp. 99.

107 Prat. archid. Marcinkowski - jak przyp. 21.

108 Prat. Piaggia - jak przyp. 99. 
tuli atque partialium, eademmet decreta Perillustres Capitulares ratihabuerunt.

[955] s. 453. Revisio libri fundationum et inventarium ecclesiae. Ut certo constet Capitulo de punctuali cursu fundationum per Collegia absolvendarum, ad librum earundem fundationum connotandarum deputantur per praesentes perilres Zajączkowski et Meline. Qui quidem perilres deputati etiam inventarium rerum ecclesiasticarum revidebunt antiquum, res accessas noviter conscribent et Capitulo porrigent.

[956] s. 453. Liber ordinationis summarum. Reasumptis anterioribus decretis, subveniendo bono ordini et lucidiori demonstrationi summarum, post peractam inante conscriptionem libri ordinationis mutatarum et de bonis ad alia bona translatarum, decernit Capitulum, quatenus rdus Notarius cum adiutorio Custodis et Żeliński, ad id capitulariter expostulatorum, librum eundem conficiat, salva pensione trecentorum florenorum polon, eidem pro praemissis anterioribus decretis determinata. Qui quidem rdus Notarius, ut etiam acta pro futuro capitulo conscribat, obstringitur.

[957] s. 455-456 (31 Maii). Capella Smae Crucis et Sacristia. Beneficia plurima cum munifica liberalitate per olim [s. 456] celmum et rmum dnum Adamum Ignatium Komorowski archieppum Gnesn. immediatum - - tam in vita sua huic Ecclesiae et Capitulo praestita, quam etiam in ultimis testamenti tabellis consignata, ut debita gratitudine grataque memoria perpetuo recolantur, ac omnis pientissima ipsius dispositionis testamentaria et codicilla res efficientur. Capitulum praesens generale, maturo tractatu et deliberatione praehabita, eo attento siquidem mediante auctoritate ordinarià et decreto celmi principis ilmi et rmi Lociordinarii moderni archiepp Gnesn. - - iam feliciter cessit erectio fundationis officii quotidiani cum missa de Passione Domini ad Altare Sae Crucis per praebendarios neofundatos decantantes. Benigniter annuit, consentit et disponit, ut Sacristia Dominorum Praelatorum et Canonicorum huius ecclesiae transformetur in capellam eidem Smae Crucis Altari, una cum mausoleo in se collocando ossa. Ita tamen, ut Locum seu Conclave Consiliorum Capitulare retro idem altare ingressus commodus cum gradibus reservetur, et per artifices paretur. Intuitu vero cessionis eiusdem Sacristiae cum asservatorio sursum eminenti, ab alia parte ecclesiae meridionali Capella Sanctae Victoriae contigua de nova a fundamentis in ea l.cngitudine, altitudine et latitudine, prout res exigit et proportionata dispositio architecti conducendi postulabit, ex muro solido erigatur et perficiatur. Omnimodam in hoc opere faciendi perilri rmo dno Paulo Kosicki canonico metrop. Gnesn. et Eoviciensi, coexsecutori testamenti dicti. olim Celmi Fundatoris tribuit facultatem. Et ad effectum eiusdem fabricae summam viginti millium flor. polon., per pientissimum Fundatorem dispositam et per Capitulum huius ecclesiae acceptam, in suoque aerario depositam, extradi levavique decernit, cum debita gratiarum actione pro cura et solicitudine, quas adhibet in expediendis huiusmodi negotiis.

[958] s. 458-459 (3 Iun.). Inventarium bonorum. Providendo bonorum ordini bono obligantur futurus [ $s .459]$ procurator et perilris Janicki canonicus, ad actum calculi immediati deputatus, ut inventaria et statum bonorum graphice et ordinate (assumpto sibi ad calamum aliquo, ex mas- 
sa Capituli pro labore salariando) conscribant et Capitulo porrigant. Ut denique custos Curiae ${ }^{109}$ unus ex villanis constituatur, futuro perilri Procuratori Capitulum commendavit.

[959] s. 461-462 (5 Iun.). Revisio libri fundationum. Facta relatione per perilres Zajączkowski et Meline de revisione libri fundationum, siquidem patet aliquas irrepsisse negligentias in connotatione [s. 462] absolutarum missarum. Proinde praesens capitulum statuit et ordinat, ut abhinc in posterum idem liber fundationum revideatur per unumquemque Dominum septimanam tenentem in determinatione suae septimanae, id est quolibet die sabbati subscribendus. Novusque liber per futurum procuratorem ad eum effectum comparetur.

[960] s. 462-463. Residentia Sanctuariis alias Swiatnikom. Providendo commoditati ministrorum ecclesiae praesens capitulum decernit, ut futurus perilris pro[s. 463]curator tempestive conducat magistrum ad domum molendinalem in aggere sitam et contractum faciat ex pretio condicto, ut iidem ministri ecclesiae seu S wiątnicy habeant, ubi caput reclinent.

[961] s. 472 (7 Iun.). Thesaurus. Insistendo anterioribus decretis decernit Rmum Capitulum, ut quolibet anno summa 2000 florenorum polon. pro Thesauro Capituli ex proventibus massae reponatur, in quolibet capitulo Festorum Pentecosten liquidanda.

[962] s. 472-473. Archivum. Subveniendo bono ordini decernit praesens capitulum, quatenus documenta omnia Archivi Praesentis ordinatim componantur, summariumque unum circa librum actorum, alterum circa documenta reperiatur. Pro [s. 473] quorum ita compositorum documentorum conservatione Archivum Novum, sumptibus maøsae, perilris Procurator comparare mandabit.

[963] s. 475 (9 Iun.). [Procuratores in annum sequentem electi: bonorum A. Zajączkowski, causarum I. Żeliński].

[964] s. 475. Consolatio rdo Capituli Secretario. Considerando difficilem per ${ }^{t}$ solummet perilrem Causarum Procuratorem negotiis omnibus Capituli attentionem, ut rdus Capituli Notarius etiam eundem in obvenientibus necessitatibus suppeditet, eidem pro consolatione intuitu praemissorum florenos 200 pro anno praesenti exsolvendos assignat.

D. 30 Augusti, in capitulo partiali ordinario:

[965] s. 490. Iura cancellariae Officio Consistoriali ${ }^{110}$. Adhaerendo anteriori decreto proxime lato [per] Rmum Capitulum, iura cancellariae a decreto erectionis Praebendariorum Smae Crucis solvantur.

D. 8-20 Decembris, in capitulo generali Conceptionis:

[966] s. 499-500 (11 " Dec.). Inventarium ecclesiae. Ad conscribendum et verificandum inventarium rerum ecclesiasticarum deputantur perilres Wężyk et Me[s. 500] line, cum relatione Capitulo facienda.

[967] s. 501-502 (12 Dec.). Effigies olim celmi principis Komorowski. Quoniam perilres olim rmi Michaëlis Awedyk metrop. Gnesn. et loci praesentis canonici exsecutores effigiem olim celmi principis Komorowski

t Opuścilem dublowany skrót prlem.

u 7 btęd. akta.

${ }_{109} \mathrm{~W}$ tym kontekście kuria oznacza dworek w danym majatku kapitulnym.

110 Mowa o Konsystorzu Łowickim. 
archieppi Gnesn. depictam, fatis eiusdem rmi Awedyk derelictam, pro maiore ornamento et memoriali ad Capitulare offerunt, proinde actis iisdem perilribus gratiis, affingendam parieti in Capitulari [s. 502] praesens Rmum Capitulum decernit.

[968] s. 502. Deputantur ad revidenda iura Collegiorum Minorum.

[969] s. 503. (13 Dec.). Calices. Quoniam ad usum ecclesiae, ob plures confractos et deterioratos calices, pauci boni et commodi reperiuntur, proinde committitur perilri Custodi ${ }^{111}$ et Vicecustodi ${ }^{112}$, ut (praevio consensu a Celmo Principe) eosdem fractos calices, adhibito aurifabro, se informari faciant, facto prius pondere eorundem fractorum calicum. Quodsi aurum a celmo olim principe Komorowski, pro calice destinatun et per rmum Awedyk datum, aptum fuerit pro deauratione eorundem calicum, ex eodem pars aliqua desumatur.

[970] s. 503. Residentia pro Sanctuariis. Inter desideria ad Celmum Principem etiam punctum de fundo prope ecclesiam pro Sanctuariis, ubi veteris molendini aedificia iacent, supplicando apponatur.

[971] s. 503. Fistula aquatica. Commendatur perilri Procuratori, ut locum ad aedes ecclesiae commodum pro conservanda fistula aquatica provideat.

[972] s. 504. Fores ad chorum et sub tectum. Providendo securitati ecclesiae decrevit Rmum Capitulum, ut fores ferreas tam ab extra in aditu ad chorum, quam sub tectum perilris Procurator comparare mandet.

[973] s. 508-509 (15 Dec.). Martyrologium novae editionis. Perilres exsecutores testamenti olim perilris rmi Awedyk metrop. Gnesn. et loci praesentis canonici Martyrologium novae editionis, fatis eius derelictum [s. 509] pro usu ecclesiae praesentis destinarunt, pro quo eis Rmum Capitulum gratias egit ac animae dicti p. r. Awedyk gratam reliquit memoriam.

[974] s. 510-511. In Sacristia Capitulari crates. Ad Sacristiam futuro, Deo dante, vere inchoandam crates ex veteri Sacristia applicandos Rmum Capitu[s. 511] lum decerevit, in eandem Sacristiam exstruendam inducendos.

[975] s. 512 (16 Dec.). Liber ordinationis summarum. Ut citius deducatur ad effectum liber ordinationis summarum originalium, de bonis ad bona translatarum, quam et noviter locatarum conficiendus, perilrem Janicki capitulum praesens obligavit, ut addat iuvamen et operam rdo Notario, inante capitularibus decretis ad conficiendum eundem librum destinato, methodo anterioris libri per olim perilrem Proszewski canonicum ${ }^{113}$ formati.

[976] s. 516 (17 Dec.). Acta Capituli. Continuanda ${ }^{114}$ acta pro futuro capitulo generali Capitulum censuit.

\section{1}

Die 31 Ianuarii, in capitulo partiali ordinario:

[977] s. 528-531. Igne combustum altare maius. Sive prospera sunt

111 Prak. W. Piaggia - jak przyp. 99.

112 Ks. Jaramowski - jak przyp. 69.

11 Aleksander Proszewski, m.in. kan, kow. w l. 1693-1727.

114 Chodziło o dalsze pisanie w kończącej siọ księdze. 
sive adversa, quae ita disponent Divino beneplacito, suas alternant vices. Expedit ea omnia ad posteriorem notitiam transmittere, quatenus de is edocti, quidquid deinde felici aut infelici fato sibi evenerit, si bona laeti susceperint de manu Dei, mala etiam iusto animo cum iusto Dei Iob gaudentes suscipiant et in omnibus gratias agentes semper glorificent $\mathrm{Pa}-$ trem, qui in caelis est. Tandem alieno periculo cauti, quae sunt cavenda et ipsi caveant ceterosque, quos opus fuerit, praecaveant. Notum sit igitur universis et singulis in posterum, praesentem annotationem de mandato Reverendissimi Capituli hic inscriptam lecturis, quod anno a salutifera Nativitate Domini Nostri Iesu Christi nunc currenti 1761, indictione Romana nona, pontificatus autem Smi Dni Nostri Clementis Divina providentia papae XIII anno tertio, felicis vero regiminis celmi ilmi et rmi dni Vladislai Alexandri de Łubna Łubieński archieppi Gnesnensis - anno secundo, die vero Lunae 26 mensis praesentis Ianuarii, finitis omnibus Divinis officiis totaque devotione antemeridiana in hac Insigni Ecclesia Collegiata Eoviciensi, circa benedictionem matrimonii inter parochianos de villa praepositurali Popów ante maius altare factam, post horam meridianam duodecimam, dum per incuriam aedituorum huius ecclesiae ex minus caute extincta candela in cornu Epistolae, ut ex potiori hac in parte igne conicere fas erat. Sita scintilla ad imum mensae altaris, non advertentibus quidquam iisdem ministris, delapsa fuisset. Factum est, ut post abitum aedituorum de templo, per eos ex omni parte clauso, in hoc eodem altari maiori excitatum fuerit incendium, nemine in ecclesia exsistente solumque in cubiculo a latere Capellae Lipscianae Sacrmi Corporis Christi sito, uno ex ministris saecularibus cantore, Divinum psalterium, cuius cantus assiduus die no[s. 529]ctuque, cessante devotione institutus est, decantante. Qui licet ab initio quemdam fragorem subaudivit, minime tamen ratio huiusmodi strepitus causam fuisse flammam, minus quoque rem apprehendit. Verum ex erumpente et per ecclesiam se protendente eo densiore fumo, quo diuturniore incendio devenit quod ageretur: atque illico inde exiens, ad maius ostium templi, ex opposito altaris ab occidente, patens. Dum per rimam animadverterit, immensam flammam sorpere, extunc quid acciderit voce vehementi conclamavit, et ad subveniendum ecclesiae quantocius universos suo clamore concitavit, idque non ampliori temporis intervallo quam uno medio quadrante ab obserato templo. Hinc perculsi clamore et tumultu hominum ab ictu maioris campanae universi Perilres Rmi Praelati et Canonici tunc residentes populusque Civitatis accurrentes, in reseratum templum ingressi, altare maius iam integrum ab immo sursum versus flamma obvolutum ardere conspicati. Obviando ulteriori periculo, longe maiori, fabrilium de lignis operum totiusque fabricae, illud altare ignitum sine mora uncis in nihilum distrahi et in terram prosterni lapsumque aqua circumfundi mandarunt. Quo incontinenti secuto et nihil quidquam attrito in cornu Evengelii: mausoleo et statua olim ilmi Henrici Firlej archieppi Gnesnensis ${ }^{115}$, quamvis in eam potior moles procidit. Incendium et omne quodvis periculum cessavit, nec ultra damni praeter hoc altare cum suis ornamentis universis, ut infra annotabitur, atque nigredinem sui, praecipue in superficie ac proximiore altari imagine olim ilmi Andreae Lesz-

115 Henryk Firlej h. Lewart, m.in. arcybp gnieźn. i prymas w l. 1624-1626. 
czyński archieppi Gnesn. ${ }^{116}$ domus Dei passa est. Etenim maioris securitatis, ergo statim ab introitu in templum, aliquot viri super laquear summum ad observandum, ne sursum flamma evomeret sub tectum furaminibus ocius amandati sunt, idque provide, nam funiculus, in quo appensa ante hocidem altare lampas argentea sustentabatur, contracto igne usque super [s. 530] laquear exarsit. Ut autem memoria sit prafati altaris: qualis structura cuiusque benefactoris opus et monumentum fuerit sciant posteri, illud ex lignis totum affabre factum totumque deauratum fuisse; munifica liberalitate olim ilmi dni Leszczyński archiepiscopi Gnesnensis ${ }^{117}$ non modico sumptu comparatum, densum ampla imagine Bmae Virginis Mariae in Caelum Assumptae una, et superius altera minore Smae Trinitatis, in tela eleganter depictis, conspicuum. In quarum una inferiore vestis argentea deaurata, circumdata varietate, tum aliae similes minores SS. Angelorum a lateribus hincinde, suam reginam in caelum attollentium, partim conflatae, partim convolutae sunt. Corona vero capitis integra de puro auro, in minuta confracta; posthac in ruderibus partim inventa. Tabella vero votiva similiter de puro auro elaborata, impensis olim ilmi dni Stanislai Szembelk archieppi Gnesn. ${ }^{118}$, appensa in praefata veste argentea, eidem agglutinata extitit. Supra mensam altaris sex consistentia candelabra de stanno Anglico, opere et magnitudine in latum et longum eminentia. Aliaque duo minora flamma conflavit. Crux de simili metallo, longe amplior et eminentior, in una parte pedestalis iacturam tulit, sola effigie Crucifixi Dni Nri Iesu Christi, mirum est quomodo avulsa a cruce, integra manente. Mausoleum binorum ilmorum archiepporum Leszczynianorum a cornu Epistolae in uno tantummodo capitali columnae, altari propioris, modico detrimento tactum, siquidem minusculis particulis de alabastro destitutum est cum una, ut supra, deformata imagine. Itaque postridie sollemnem missam votivam in gratiarum actionem Deo Omnipotenti, quod maius periculum et damnum avertere dignatus est, celebrari Domini unanimiter decreverunt. Quae in frequentia cleri populique Civitatis totius et parochiarum v villanarum absoluta est cum precibus et supplicationibus, qua [s. 531] tenus abhinc habitationem suam custodiat et ab ea totaque parochia et Civitate universisque praesentibus et posteris mala omnia repellat. Tu, qui legis, luge damnum et cave, ne quid simile aut deterius (quod Deus utrumque avertat) contingat. Deumque continuo precari non desine et bene vale.

[978] s. 531. Poena in Sanctuarios ecclesiae. Quoniam de causata fatalitate combustionis altaris maioris in ecclesia praesenti Sanctuarii ob inanimadvertentiam sui redarguntur, proinde Rmum Capitulum, ne id eis impune abeat sintque in ulterius cautiores, eisdem, ut tribus continuis festivis diebus sub tempus concionis in modum crucis iaceant, demandavit.

D. 20 Martii, in capitulo partiali ordinario:

[979] s. 534. Contractus cum aurifabro ratione calicum. Quoniam ilris Vicecustos loci praesentis ${ }^{119}$ in praesenti tempore Varsaviam conscen-

$\checkmark$ parohialium akta.

116 Andrzej Leszczyński h. Wieniawa, m.in. arcybp gniezn. $i$ prymas $w$ l. 1653$-1658$

117 Wactawa Leszczyńskiego arcybpa i prymasa w l. 1659-1666.

118 Stanistaw Szembek h. wlas., m.in. arcybp gnie界. i prymas w l. 1706-1721. 
disse aurifabroque ex antiquioribus calicibus et conflata veste argentea in altari maiori frusta bina, in qualitate argenti et quantitate ponderis eiusdem descripta reliquisse, contractum cum eodem conscripsisse, et eosdem calices pro Festo Smae Trinitatis comparandos determinavit, proinde Capitulum manutenendum eundem contractum decrevit.

Dieb. 12 Maii - 12 Iunii, in capitulo generali Pentecostes:

[980] s. 538 (12 Maii). Recapitulatio. Relectis statutis, decretis tam reformationum, quam immediati capituli generalis et partialium capitulorum decretis, eadem Perillustres Capitulares ratihabuerunt.

[98,1] s. 538 (13 Maii). Crux et candelabra. Quoniam plene constat materialia, nempe stannum, pro comparandis candelabris et cruce, igne absumptis exstasse, proinde commendatur futuro perilri procuratori, ut eadem methodo anteriori et forma comparari mandet.

[982] s. 539 (14 Maii). Relatio perilris ad revidendum librum fundationis Deputati. Retulit perilris Kaszowski, ad revidendum librum connotandarum fundationum deputatus, ordine debito easdem praeter unum maius Sacrum intermissum annotata fuisse. Pro qua relatione eidem Rmum Capitulum gratias egit. Quoniam demum isidem perilris Kaszowski, propter legalitates suas expositas praesenti capitulo in ulterum interesse nequit, proinde permittitur eidem facultas abscedendi cum participationibus in fine capituli determinandis per eum etiam participari.

[983] s. 540. Inventarium ecclesiae. Post patratum in Capitulari furtum, perillustres ad verificandum inventarium ecclesiasticum Deputati retulerunt res omnes inintegro verificasse et easdem integras, praeter notum Capitulo damnum, deprehendisse. Pro quo suscepto labore Rmum Capitulum iisdem perilribus Deputatis gratias egit.

[984] s. 540. Fores ad chorum et sub tectum ecclesiae. Perilris Żelinski retulit se in ferricudinis intuitu trinarum forium: ad chorum ex.turri et sub tectum, tum quoque ex minori ad maiorem chorum cum magistro composuisse. Rmum itaque Capitulum ulteriorem ei curam praemissorum commendavit.

[985] s. 542. Deputantur ad revidenda iura Collegiorum.

[986] s. 544 (17 Maii). Custodia ecclesiae. Providendo securitati ecclesiae praesentis, commendatur ilri Vicecustodi Ecclesiae Collegiatae praesentis, ut eligat aliquem hominem securum, qui in nocte invigilet ecclesiae ibidemque dormiat, cum quo compensationem pro praemissis concertabit.

[987] s. 544-545. Relatio ilris Vicecustodis circa calices. Ilris Vicecustos, anteriori decreto ad componendum cum aurifabro inituitu reformandorum ex veteribus in novos calicum deputatus, contractum cum eodem aurifabro conscriptum in praesenti capitulo produxit. Qu.o relecto eidem ulteriorem curam praemissorum Capitulum commendavit. Quo spectat particulas auri et argenti circa conflagrationem altaris maioris conflati et in frustis exstantis, in praesentique capitulo praesentati, easdem adulterius conservandas [s. 545] Rmum Capitulum censuit.

[988] s. 545 (18 Maii). Fistula aquatica necnon fores ex minori choro ad maiorem. Perilris rmus Kosicki tractandi cum magistro intuitu exstruendae ex muro sub campanili structurae pro conservando instrumen-

${ }_{119}$ Ks. Jaramowski - jak przup. 69. 
to $\mathrm{strzykawk}$ a nuncupato in se munus suscepit. Facta deinde relatione, committitur futuro procuratori aedificium hoc exstruendum atque aperiendae fores ex minori choro ad maiorem.

\section{KSIĘGA DWUNASTA}

\section{OPIS}

Skrócony tytuł nadany (przeze mnie, tu) - Liber XII: Acta actorum Venerabilis Capituli Insignis Collegiatae Koviciensis 1761-1778.

Księga nie posiada tytułu, którego przypuszczalnie nie zamierzano jej nadać, jako że od jej początku kontynuowano wpisy uchwał kapituły gen. Pentecostes $1761 \mathrm{r}$.

Jedynie na 1 str. pierwszej karty ochr. widnieje następująca zapiska dotycząca założenia samej księgi: Laudetur Iesus Christus. 1765. Hic liber sumptu massae Venerabilis Capituli Łoviciensis emptus pro conscribendis et inserendis decretis, per me Adamum Zajączkowski canonicum et procuratorem massae ${ }^{1} \mathrm{mpp}$.

W opracowanym na przel. XVIII/XIX w. przez ks. Śladeckiego ${ }^{2}$ wykazie ważniejszej zawartości niniejszej jednostki aktowej posiada ona następujący nagłówek: Index decretorum capitularium Insignis Collegiatae Eoviciensis libri noni, a die 27 Maii anni 1761 (s. 159).

Sygnatury:

Not. Sladeckiego, umieszczona nad zapiską Zajączkowskiego: Liber Actorum $9^{\text {nus }}$. Dla niego była to rzeczywiście dziewiąta z kolei zachowana (realna) księga akt kapitulnych. On też dodal w lewym górnym rogu str. 1: Lib. $9^{\text {nus }}$.

Sygn. późniejsza, z przeł. XIX/XX w., znajdująca się na tejże str. k. ochr. w prawym górnym rogu, idealna i pierwszy raz prawidłowa: A. 1. 12.

Sygn. aktual. (moja, tutaj): AKt, ks. ideal. 12, real. 8.

Sygn. mikr. Ośrodka ABMK: 3524.

Księga in folio, stron 752, język laciński i częściowo polski. Oprawa współcz. w skórę. Stan zachowania dobry. Pod koniec rękopisu atrament zalewał i tekst prześwituje na drugą stronę kart.

\section{W.YPISY}

\section{Anni $\mathbf{1 7 6 1}$ continuatio}

Diebus 27 Maii - 12 Iunii, cont. capituli gen. Pentecostes:

[989] s. 3 (28 Maii). Translatio Bibliothecae Capitularis. Quoniam imminet fabrica Capellae Komorovianae in hoc loco, iam alias ad id destinato, ubi Bibliotheca Capitularis consistit, ideo eandem transferendam et interim locandam perilri Procuratori in loco bene viso praesenti ${ }^{a}[\mathrm{Ca}-$ pitulum] commisit.

a Opuścitem powtarzane perilri Procuratori.

1 Adam Zajączkowski h. Zaręba? m.in. kanonik łow. w latach 1729-1770.

2 Piotr Sladecki, m.in. notariusz kapituly w 1. 1796-1809. 
[990] s. 6,7 (31 Mai, 10 Iun.). [Procuratores in annum sequentem electi: bonorum seu massae A. Zajaczkowski, causarum I. Zeliński ${ }^{3}$.

[991] s. 6 (10 Iun.). Relatio adm, rdi Vicecustodis. Adm. rdus Jaramowski vicecustos huius Ecclesiae Collegiatae, vigore decreti capituli gen. Festi Conceptionis BVM et consensus Celmi Lociordinarii ${ }^{4}$, conflari fecit veteres calices. Quos hic monstravit comparatos quinque albos et duos deauratos deintegro cum patenis. Et residuum argenti marcas tres in Aerario Capituli reposuit. Ex his albi calices quinque destinantur ad Sacristiam Minoris Cleri, duo inaurati ad Sacristiam Praelatorum et Canonicorum.

[992] s. 7. Archivum iurium et actorum. Reassumitur decretum capituli gen. Conceptionis BVM et iidem perilres Deputati ad id deputantur.

[993] s. 7. Donativum rdo Capituli Notario ${ }^{5}$. Habito respectu rdi Notarii, eidem 200 flor. [polon.] exsolvendi assignantur.

Die 27 Iunii, in capitulo partiali ordinario:

[994] s. 12. Altare maius [aedificare inchoandum].

D. 12 Iulii, in capitulo partiali ordinario:

[995] s. 13. Inventae in ruderibus particulae auri et argenti ${ }^{\circ}-$ Inventas in ruderibus particulas, nempe statuam parvam S. Dominici, tum coronulam et frustam parvulam fractam ex tabella, argenteas, necnon auream torquem et duas filulas margaritarum, utraque sedecim aureis hungar. taxata, Rmum Capitulum intra argenterias ecclesiasticas conservandas censuit - -

D. 28 Novembris, in capitulo partiali ordinario:

[996] s. 26. Deputantur ad dinumerandam massam. Perilres Janicki ${ }^{7}$ et Wężyk ${ }^{8}$ Capitulum ad dinumerandam massam Capituli segregandamque qualitatem isxta reductionem et cursum praesentem monetae deputavit. Cuius massae descriptionem iidem perilres Deputati futuro capitulo generali porrigent.

Dieb. 8-22 Decembris, in capitulo generali Conceptionis:

[997] s. 26-27 (9 Dec.). Recapitulatio. Relectis statutis et decretis tam reformationum, quam anteacti [ $s .27]$ capituli generalis et partialium capitulorum, eadem Perillustres Capitulares ratihabuerunt.

[998] s. 28. Revisio agrorum et inventarium in Boczki ${ }^{9}$ et aliis. Ad revisionem agrorum in Boczlki et Mysłaków ${ }^{10}$ conficiendumque inventarium ad normam dispositionis in Ducatu ${ }^{11}$ practicatae, omnium et singulorum tributorum, laborum et dationum, semel pro semper constituendorum, deputantur perilres Zajączkowski procurator et Janicki canonici.

[999] s. 28. Inventarium ecclesiae. Quoniam res nonnullae noviter accesserunt et nonnullae particulae minutiores argenti in sepulcris sunt

s Ignacy Żeleński (Żeliński) h. Prawdzic, m.in. kan. tow. w l. 1753-1787.

4 Władysław Aleksander Łubieński h. Pomian, m.in. arcybp gnieźn. i prymas w $l$. $1759-1767$.

5 Felicjan Wyszyński kan. hon. łow.

- Znalezione po pożarze $w$. ottarza.

7 Adam Janicki h. Rola, dr ob. prawa, m.in. kan. łow. w l. 1748-1771.

8 Wojciech Wężyk $h$. Wąz, m.in. kan. tow. w l. 1752-1789.

9 Boczki wieś kapituły w par. kolegiackiej.

10 Mysłaków wieś kapitulna w par. Bednary.

11 Księstwo Eowickie arcybiskupów gniezn. 
inventae, proinde ad verificationem inventarii, cum relatione futuro capitulo facienda, deputatur perilris Tarnowski ${ }^{12}$. Qui perilris Deputatus etiam argenti circa conflagrationem altaris conflati separationi attendet.

[1000] s. 28. Deputatur ad revidendum librum fundationum. Deputatur perilris Kaszowski ${ }^{13}$ ad revisionem libri connotandarum fundationum, cum relatione Capitulo facienda.

[1001] s. 29-30 (10 Dec.). Relatio perilrium ad dinumerandam massam Deputatorum. Perilres Janicki et Wężyk, anteriori decreto Capituli sui ad dinumerandam et separandam massam deputati, produxerunt [s. 30] in praesenti capitulo descriptionem monetae eiusdem massae in seorsiva scheda, quam manibus eorundem $\mathrm{p}$. Deputatorum et perilris Praesidentis ${ }^{14}$ subscriptam, conservandam Perillustres Capitulares censuerunt.

[1002] s. 30 (11 Dec.). Relatio perilris ad revidendum librum fundationum Deputati. Retulit p. Kaszowski, ad revidendum librum fundationum connotandarum deputatus, qualiter fundationes omnes, publice in cantu expediri solitae, plene et sufficienter sunt annotatae, praeter nonnullas obligationes altaristarum; tum quod non omnes septimanae, iuxta determinationem decreti immediati anterioris capituli generalis, sunt per perilres officiantes subscriptae. Proinde Rmum Capitulum diligentiorem praemissorum (habita ratione punctualis absolutionis fundationum) memoriam commendavit.

[1003] s. 31. Imago Bmae ad altare maius. Quoniam Varsaviae nob. Czechowicz pictor in arte sua perfectus et probatus reperitur, proinde capitulum praesens contrahendi cum eodem respectu depingendae imaginis Bmae Virginis Mariae ad altare maius vigorem partiali capitulo relinquit.

[1004] s. 31. Aurum Komorovianum.

[1005] s. 44 (14 Dec.). Liber ordinationis summarum. Ad distribuenda iura fundationum elucidandasque summas earundem: in quibus bonis inscripta originaliter et in quae bona successive translatae fuerint, et ubi adpraesens haerent, expetuntur perilres Janicki et Pstrokoński ${ }^{15}$.

[1006] s. 47 (22 Dec.). Sigillum argenteum. Committitur perilri Żeliński, ut ab aurifabro Gruszewicz ${ }^{10}$ aut sigillum argenteum in natura, aut pondus adaequatum argenti reparetur.

[1007] s. 47. Baculus pastoralis apud ilmum episcopum Culmensem ${ }^{17}$. Committitur partiali capitulo, circa Festa Paschalia celebrando, requisitio baculi pastoralis apud ilmum episcopum Culmensem haerentis, ita ut recipiatur ante visitationem generalem ${ }^{18}$ Celsissimi.

[1008] s. 47. Praesentiae legendae. Reassumitur anterius decretum

12 Jozef Tarnowslit h. Rola, kan. low. i prepoz. tamt. Kol. Psalterzystów wl. $1756-1788$.

${ }_{13}$ Stanistaw Kaszowski h. Janina, dr teol., m.in. kan. kazn. tow. od r. 1759, prat. archid. w l. 1774-1785.

${ }_{14}$ Józef Jaksa Marcinkowski h. Gryf, dr teol. lub prawa, m.in. prał. archid. tow. w l. 1743-1777.

15 Baltazar (Balcer) Pstrokoński h. Poraj, m.in. kan. tow. w l. 1761-1766.

10 Złotnik $w$ Łowiczu.

17 Andrzej Ignacy Bajer h. Leliwa, biskup chetminski w l. 1758-1785, dawn. kan. tow.

${ }_{18}$ Planowana przez arcybpa Łubieńskiego wizytacja kolegiaty. 
respectu legendarum in quovis capitulo praesentiarum. Quodsi non fuerit, in proximo pariter relegendae et per perilrem praesidentem capituli subscribendae.

\section{2}

Die 2 Ianuarii, in capitulo partiali ordinario:

[1009] s. 48. Quartuale praesens rdo Notario. Licet quidem anteriori dispositione in capitulo generali subscripta rdo Notario tamquam altaristae Sanctae Crucis et Smi Corporis [Christi] per medium quinquaginta, videlicet floreni, videntur fore assignati, considerando tamen Capitulum, quod eadem pensio etiam pro munere et laboribus notariatus eidem provenit, eidem tamquam in deservita mercede totum, nempe flor. centum solvendos Capitulum determinavit.

D. 9 Ianuarii, in capitulo partiali ordinario:

[1010] s. 49. Deputantur ad pensandum decessum monetae massae. Quoniam perilris Pstrokoński, ad pensandum decessum monetae massae in praesenti tempore abest, proinde ad effectuanda praemissa cum $p$. Janicki anterius deputato delegatur ex praesenti capitulo perilris Wężyk.

[1011] s. 49. Imago SS. Rochi et Sebastiani Martyris. Pro depingenda imagine SS. Rochi et Sebastiani nob. Petro Zayze pictori ${ }^{19}$ Rmum Capitulum aureos hungar. viginti, moneta iuxta reductionem seu (si possibilitas massae permiserit) in auro, quemlibet aureum hungar. florenorum octodecim computando, solvendos determinavit.

D. 13 Februarii, in capitulo partiali ordinario:

[1012] s. 61. Aurum pro laminis aëneis in tectum conducendurn.

D. 6 Martii, in capitulo partiali ordinario:

[1013] s. 63-64. Aurum Komorovianum.

D. $24^{\mathrm{b}}$ Aprilis, in capitulo partiali ordinario:

[1014] s. 70. Libri restituti fatis olim gnosi Stominski ${ }^{20}$. Libros Bibliothecae praesentis per olim gnosum Slomiński commodatos, nempe Abbatis Palermitani tomos duos, Cardinalis Tusculani tomos quattuor, Stanislai Szczygielski librum unum, Petri Folbri librum unum, per nob. Rylski eiusdem dicti olim gnosi Słomiński privignum restitutos, in Archivo reponendos Capitulum censuit.

Diebus 1-23 Iunii, in capitulo generali Pentecostes:

[1015] s. 73 (2 Iun.). Recapitulatio. Relectis statutis, decretis reformationum atque decretis tam anteacti generalis, quam et partialium capitulorum, eadem decreta Rmum Capitulum in toto ratihabuit.

[1016] s. 74. Revisio libri funáationum. Ad revidendum librum fundationum per Collegia absolvendarum deputatur perilris Archidiaconus ${ }^{21}$, cum relatione facienda.

[1017] s. 78 (9 Iun.). Procuratori Causarum pro tempore exsistenti. Capitulum praesens, perpendendo labores perilris Causarum Procuratoris moderni circa negotia sua, reassumendo decretum anni 1758 in ca-

\footnotetext{
b 27 bięd. akta.

19 Nie wiadomo skad ten malarz.

20 Kazimierz Stomiñski, dtugoletni notariusz Kurii Arcybiskupiej.

21 Prat. Marcinkowski $-j a k$ przyp. 14.
} 
pitulo generali Festorum Pentecostes de procuratoribus latum, constituit eidem pro annua pensione florenos quingentos, avenae modios duodecim mensurae proventualis et faeni currus octo assignavit; et pro conscribendis expensis litium librum distinctum novum comparandum voluit.

[1018] s. 80. Relatio perilris ad revisionem libri fundationum Deputati. Perilris Archidiaconus, ad revisionem libri connotandarum fundationum deputatus, retulit novas fundationes tabellae nondum ingrossatas, adeo$q{ }^{~}$ connotatas in libro praedicto fundationes perpendere de integro non valuisse. Capitulum itaque annotandas easdem novas fundationes ad tabellam censuit. Cum vero Collegia Minora et Altaristae nullum ius ad fundationes suas producere curant, monendos eosdem iterum Capitulum decrevit.

[1019] s. 82 (14 dun.). Aurum Komorovianum.

[1020] s. 82. Torquis Wężykoviana aurea ế alia. Supplicandum Celmo Principi capitulum praesens censuit, ut tam torquem auream in tumulo celmi olim principis Wężyk repertam, quam alias particulas aureas et argenteas, anterioribus decretis partialium capitulorum enuntiatas, divendere pro necessitatibus reparationis ecclesiae permittat.

[1021] s. 82. Liber ordinationis summarum. Documenta requisita ad extendum librum ordinationis summarum in actis inquirantur. Obliganturque perilres anteacto decreto Deputati, ut opus idem nimis necessarium perficere dignentur.

[1022] s. 83 (15 ${ }^{\mathrm{e}}$ Iun.). Imago Bmae ad altare maius. Cum Celmus Princeps ex sua speciali gratia testatur imaginem Beatissimae ad altare maius depingi Romae demandare, proinde Capitulum inter puncta desideriorum ${ }^{22}$ pro exhibenda gratiarum actione per perilres deputandos punctum inserere demandarunt.

[1023] s. 84 (16 Iun.). Pastorale. Offert se Capitulum scribendum litteras opportuno tempore ad ilmum episcopum Culmensem pro restitutione pastoralis ecclesiae nostrae, eidem Ilmo accommodati.

[1024] s. 85 (17 Iun.). Cera retenta in Civitate. Propter renitentiam Magistratus cera retenta pro cereo Paschali debita et per erectionem huius ecclesiae assignata, quoniam ab annis duobus per Capitulum requisita non restituetur, proinde negotium hoc inter desideria ad Celsissimum porrigendum Capitulum censuit.

[1025] s. 86 (18 Iun.). [Procuratores electi in annum sequentem: bonorum A. Zajaczkowski, iurium I. Zelinski].

[1026] s. 87. Recommendatio rdi Notarii. Respiciendo merita circa bonum Ecclesiae et Capituli rdi Notarii, eundem recommendandum Capitulum duxit Suae Celsitudini Primatiali.

[1027] s. 87, Donum gratuitum rdo Notario. Offert Capitulum rdo Notario pro applicationibus eiusdem doni gratuiti florenos ducentos per perilrem Procuratorem bonorum ipsi exsolvendos.

[1028] s. 88 (19 Iun.). Crux cum torque aurea in tumulo ilmi Wężyk reperta. Quoniam modus divendendae crucis aureae cum torque, in

c Występuje przy sobie 2 razy.

d 9 bled. akta.

e 10 akta.

22 Dezyderaty kierowane przez kapitute do arcybiskupa przed jej posiedzeniami gen. 
tumulo olim ilmi Wężyk archiepiscopi Gnesn. compertae, aureis decem hungaricalibus et florenis triginta sex in moneta suppetit, proinde recepto a Celsissimo consensu, perilris Procurator eandem divendendi facultatem habebit virtute praesenti.

[1029] s. 89 (21 Iun.). Relatio perilris ad verificandum inventarium ecclesiasticum Deputati. Quoniam perilris Tarnowski inventarium rerum ecclesiasticarum tam antiquioribus regestris comprehensarum, quam et noviter accessarum manu sua subscriptum produxit, proinde actis eidem pro suscepto labore gratiis, inducendum in librum [Capitulum] censuit.

[1030] s. 89. Sigillum argenteum. Sigillum argenteum quandoquidem spectabilis Gruszewicz aurifaber restitutum pollicetur, proinde commendatur id perilri Procuratori vindicandum.

D. $3^{ \pm}$Iulii, in capitulo partiali ordinario:

[1031] s. 93. Consolatio rdo Notario. Ad navandam operam in componendis et conscribendis transactionibus imminentibus respectu bonorum et summarum Kardwanoviensium ${ }^{23}$ delegatur rdus Notarius. Cui pro consolatione determinat Capitulum tinfones centum per perilrem Procuratorem eidem exsolvendos.

D. $31^{\mathrm{B}}$ Iulii, in capitulo partiali ordinario:

[1032] s. 95. Diploma pro Vicenotario Montis Pietatis et electio eiusdem. In praesenti capitulo reproducturn [est] et relictum diploma pro Vicenotario Montis Pietatis a Celmo Principe die 30 Iulii anno adpraesens currenti, tum et pro diminutione censuum a Summa Potociana ${ }^{24}$ impertitum, in librum erectionis eiusdem Montis Pietatis insuendum Capitulum censuit. Et ad electionem dicti Vicenotarii Montis Pietatis denuo accessit, sicque bene commendatum rdum Rochum Deriakubowicz, ad titulum psalteriatus in ecclesia praesenti noviter institutum, ad idem officium elegit. Eique curam et attendentiam commissorum sibi virtute privilegii memorati munerum, cum proventu designato commisit.

D. 2 Octobris, in capitulo partiali ordinario:

[1033] s. 98. Vestis pro apparatu coëmenda. Quoniam indispensabilis urget necessitas dalmaticarum sollemniorum, ob rationem veterum notabiliter deterioratarum, vestisque in praesentibus nundinis accoëmendum obvenit, proinde obligatur praesenti [decreto] perilris Procurator, ut de pretio eius cum Iudeo concertare et eandem coëmere dignetur.

Dieb. 8-17 Decembris, in capitulo generali Conceptionis:

[1034] s. 100 (9 Dec.). Recapitulatio. Relectis statutis et decretis reformationum, tum decretis tam anteacti capituli generalis Pentecosten, quam et subsequentium capitulorum partialium, eademmet decreta praesens capitulum ratihabuit.

[1035] s. 100. Revisio libri fundationum. Ad colligenda iura Altaristarum ex libris capitularibus et aliis documentis, ut videlicet pateat: quot et quantum, quo tempore et die, ad quodvis altare missae absolvi debeant obligatur perilris Kontowski ${ }^{25}$ ad porrigendum futuro capitulo

4 bled. akta.

g 29 akta.

${ }_{23}$ Kurdwanów parafialna wieś kapituly pod Sochaczewem.

${ }_{24}$ Teodor Potocki h. Pilawa, m.in. arcybp gnieźn. i prymas w l. 1723-1738.

25 Jan Kontowski m.in. kan. Łow. w l. 1759-1780. 
generali. Qui itaque perilris ad praemissa Deputatus etiam librum earundem fundationum connotandarum revidebit.

[1036] s. 101. Revisio rerum ecclesiasticarum et inventarium. Quoniam recenter per perilrem Tarnowski res omnes ecclesiasticae sunt conscriptae, proinde obligatur praesenti perilris Janicki, ut quidquid decesserit connotet.

[1037] s. 101. Cappa et dalmaticae. Ex coëmpta virtute decreti partialis capituli veste, quodsi possibilitas permiserit, cappa et dalmaticae comparentur.

[1038] s. 101. Praebenda Smae Crucis. Postquam resignaverit Praebendam Smae Crucis ilris Jaramowski vicecustos, ad eandem ven. Iaca bus Jaramowski filiaster eius praesentabit.

[1039] s. 103. Sigillum argenteum. Quoniam modus compensandi sigilli argentei a spect. Gruszewicz adinvenitur, proinde postquam ad plenam sanitatem ilris Jaramowski vicecustos pervenerit, effectuandam eandem compensationem Capitulum censuit.

[1040] s. 105 (11 Dec.). Aurum Komorovianum.

[1041] s. 105 (13 Dec.). Relatio perilris ad revidendum librum fundationum Deputati. Perilris Kontowski ad revidendum librum fundationum absolvendarum et connotandarum deputatus retulit eundem librum vidisse, in quo ob disordinem annotandarum fundationum tam cantatarum, quam lectarum nullo modo absque ordinatione earum sese informare posse, retulit.

\section{3}

Die 23 Aprilis, in capitulo partiali extraordinario:

[1042] s. 115. Innotescentiales pro futura visitatione generali. Transmissas pro futura visitatione generali litteras innotescentiales a Celsissimo Principe in capitulo praesenti relectas, die crastina publicandas et valvis Ecclesiae Collegiatae praesentis affingendas Capitulum decernit, perillustresque absentes notificandos de eodem termino visitationis imminentis censet.

D. 7 Maii, in capitulo partiali [ordinario]:

[1043] s. 115. Deputatio ad consecribendum statum ecclesiae. Ad describendum, seu reformandum statum pro anteriori visitatione celmi olim principis Komorowski conscriptum, pro futura visitatione Celmi Principis feliciter moderni obligatur perilris Janicki canonicus loci praesentis.

D. 21 Maii, in capitulo partiali ordinario:

[1044] s. 116. Visitatio imminens. Ad salutandum Celmum Principem in Capitulari circa imminentem visitationem obligatur perilris Custos ${ }^{20}$.

[1045] s. 116. Status ecclesiae pro visitatione conscriptus. In praesenti capitulo perilris Janicki canonicus loci praesentis statum ecclesiae praesentis conscriptum sufficientissime relegit, pro quo labore eidem Rmum Capitulum gratias egit.

Diebus 23 Maii - 30 Iunii, in capitulo generali Pentecostes:

[1046] s. 117 (24 Maii). Lectio statutorum et recapitulatio. Relectis

20 Prat. Piaggia - jak przyp. 2 w księdze XI. 
statutis et decretis reformationum, ad recapitulationem decretorum tam anteacti capituli generalis, quam subsequentium capitulorum partialium Perillustres Capitulares processerunt, quae pariter relecta ratihabuerunt.

[1047] s. 117-118 (27 Maii). Revisio libri connotandarum fundationum. Ad revidendum librum connotandarum fundationum depu[s. 118]tatur per praesentes, relatione Capitulo facienda, perilris rmus Wężyk.

[1048] 5. 118. Sigillum argenteum. Quoniam spect. Gruszewicz sigillum argenteum per olim nob. Słomiński pro lampade ante Altare S. Ioannis Nepomuceni traditum solvit, et pecuniam pro pretio eiusdem ad manus ilris Vicecustodis tradidit, proinde nullam hinc respectu sigilli praemissi praetensionem ad eundem habere se praesentibus Capitulum declarat.

[1049] s. 120 (1 Iun.). Actus visitationis Ecclesiae Collegiatae praesentis. Post habitam sollemniter in die hodierna in Ecclesia Collegiata prae-

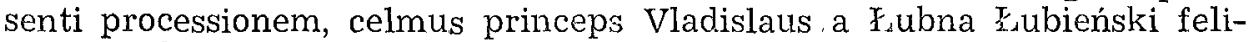
citer modernus archiepiscopus Gnesnensis visitationem in die dominica circa publicam exhortationem, praenissis debitis caeremoniis, inchoatam prosecutus est.

[1050] s. 121 (5 Iun.). Reformatio statutorum capitularium. A.d formandum proiectum reformationis statutorum capitularium obligantur praesentibus perilres Custos et Janicki canonicus.

[1051] s. 127 (11 Iun.). Pastorale commodatum. De pastorali ilmo episcopo Culmensi commodato capitulum praesens, referendo se ad anteriora decreta, mentionem facit.

[1052] s. 127. Supplex libellus Servitorum ecclesiae. Respiciendo maiores circa fabricam ecclesiae praesentis servitorum labores, dono gratuito Sacellano cum Lotrice siliginis coretum unum, reliquis vero quinque servitoribus per semicoretum tribuendum Perillustres Capitulares censuerunt.

[1053] s. 128 (16 ${ }^{\mathrm{h}}$ Iun.). Reliquiae S. Marci. Perilris rmus Meline canonicus loci praesentis, nomine nob. Petri Zayze capitanei exercituum Regni, reliquias Sancti Marci cum authentico ad ecclesiam praesentem offerentis, easdem in praesenti capitulo reposuit. Quas Rmum Capitulum grato animo suscepit et easdem aliis ecclesiae huius reliquiis adiungendas censuit. Et ut idem perilris canonicus Meline per litteras nomine Capituli eidem gratias referat, obligavit.

[1054] s. 129 (17 Iun.). [Procuratores electi in annum sequentem: bonorum A. Zajaczkowski, causarum I. Żelinski].

[1055] s. 129. Donativum rdo Notario. Pro suffragio in negotiis Capituli rdo Notario ducenti floreni [polon.] pro anno praesenti numerandi assignantur.

[1056] s. $129-130$ (18 Iun.). Descriptio arearum. Ad descriptionem arearum cum dimensione earum, post conflagrationem $\lceil s$. 130| Civitatis ${ }^{27}$ immutarum, deputantur perilris Żeliński et rdus Capituli sui Notarius. Quam descriptionem etiam capitulo partiali porrigent.

[1057] s. 134 (30 Iun.). Vigor reservatus. Tam recapitulationi, quam aliis negotiis partiali capitulo vigor reservatur.

h 17 blęd. akta.

27 Byto to wo r. 1726. 
Dieb. 8-15 Decembris, in capitulo generali Conceptionis:

[1058] s. 142 (9 Dec.). Revisio libri connotandarum fundationum. Ad revidendum librum fundationum connotandarum deputantur perilres Janicki et Pstrokoński.

[1059] s. 142. Status ecclesiae et iura beneficiatorum. Ad requirendum statum ecclesiae pro visitatione porrectum, tum et iurium beneficiatorum ad ecclesiam praesentem obligatur perilris Pstrokoński.

[1060] s. 146 (12 Dec.). Litterae ad ilmum eppum Culmens. Reassumetur decretum anterius partialis capituli decernentis ${ }^{28}$. Litterae ad ilmum episcopum Culmensem ordinandae cum gratiarum actione pro summa 200 florenorum [polon.] pro decore Sacristiae Novae oblata et recepta.

[1061] s. 146. Status ecclesiae circa acta conservandus. Statum ecclesiae pro visitatione porrectum, et ab ilri Notario Consistorii receptum, conservandum circa acta Capitulum censuit.

[1062] s. 147 (13 Dec.). Custodia nocturna ecclesiae. Providendo securitati ecclesiae censuit Capitulum, ut servitor ecclesiae unus, cum assignata inante pensione, ad festa futura Paschatis dormiat.

\section{4}

Die 3 Martii, in capitulo partiali ordinario:

[1063] s. 154. Privilegium incorporationis Ecclesiae Makoviensis ${ }^{29}$ ad Decanatum [Eoviciensem].

Diebus 10-28 Iunii, in capitulo generali Pentecostes:

[1064] s. 156. Lectio statutorum et recapitulatio. Relectis statutis decretisque tam reformationum, quam anteacti capituli generalis et partialium capitulorum, eadem decreta Perillustres Capitulares ratihabuerunt.

[1065] s. 156 (14 Iun.). Revisio libri fundationum. Ad revisionen libri fundationum absolvendarum deputatur perilris Kontowski.

[1066] s. 158 (15 Iun.). Relatio perilris ad revidendum librum fundationum Deputati. Reassumitur anterius decretum capituli generalis obstringunturque perilres Septimanantes, ut qualibet hebdomada librum fundationum revideant et eundem subscribant. Ex quo modernus perilris Deputatus ad revisionem libri eiusdem paucas subscriptiones ac perinde difficilem investigationem absolutarum fundationum se habuisse retulit.

[1067] s. 158-159 (16 Iun. $\left.{ }^{i}\right)$. Pastorale. Ad affectationem ilmi Bajer eppi Culmensis permittitur ulterio usus [s. 159] commodati eidem a Capitulo pastoralis, salva restitutione.

[1068] s. 160 (19 Iun.). Aurum Komorovianum.

[1069] s. 164, 165 (25, 26 Iun.). [Procuratores in annum sequentem electi: bonorum A. Zajaczkowski, causarum I. Zelinskił.

[1070] s. 165 (26 Iun.). Donum gratuitum rdo Notario. Dono gratuito rdo Capituli sui Notario ducentos florenos polon. exsolvendos Rmum Capitulum assignat.

[1071] s. 166 (27 Iun.). Liber ordinationis summarum. Cum perilris

i Iulii akta.

28 W aktach zdanie nie dolconczone.

29 Maków wieś $k$. Skierniewic, gdzie odnaleziono dolkument $z 1491 \mathrm{r}$. 
canonicus Żeliński pro visitatione Celmi Principis feliciter moderni summas generaliter omnes, cum ordinationibus earundem, noviter collegit, pro eodemque labore seu collectione et descriptione summarum earundarum rdo Notario floreni trecenti anterioribus decretis consignati fuerunt. Proinde solvendam summam eandem dicto perilri canonico Żeliński Capitulum censet, eo tamen adiecto, ut librum ordinatim noviter conscriptum pro futuro capitulo generali porrigat.

D. 11 Augusti, in capitulo partiali ordinario:

[1072] s. 167. Crux transferenda ad Capellam Komorovianam. Cum iam continuatur fabrica Capellae Komorovianae, proinde Rmum Capitulum transferendam crucem de Capella Wężykoviana ad eandem suam propriam capellam censuit. In locum autem crucis imaginem S. Ioannis Nepomuceni transportandam decrevit.

D. 21 Augusti, in capitulo partiali extraordinario:

[1073] s. 168. Anulus a perilri rmo Kosicki Smae Cruci oblatus. Perilris rmus Paulus Kosicki cath. Gnesn. canonicus, coad. decanus loci praesentis anulum aureum, suum proprium, duodecim lapidibus adamantinis circumductum, in medio lapidem ${ }^{j}$ vocitatum habentem, cordis figurae Crucifixi Christi Domini vulneri in Capella Komoroviana infixit et perpetuis temporibus applicavit. Cuius piam oblationem capitulum praesens actis suis annotare mandavit annotaturque per praesentes.

[1074] s. 168. Imago SS. Rochi et Sebastiani. Cum iam crux ex Capella Wężykoviana ad Capellam Komorovianam et imago in locum eius S. Ioannis Nepomuceni ad Capellam Wezżkovianam sunt translatae, proinde in loco imaginis S. Ioannis Nepomuceni imaginem SS. Rochi et Sebastiani locandam Capitulum censuit.

D. 1 Septembris, in capitulo partiali ordinario:

[1075] s. 169. Vota Altaris Smae Crucis. Vota argentea in servatorio exstantia, antiquitus Smae Cruci obla[ta], in tabulatura Altaris Smae Crucis Komoroviani appendantur.

D. 15 Octobris, in capitulo partiali ordinario:

[1076] s. 170. Candelabra argentea Potocciana. Quoniam in anteactis actis de candelabris sex argenteis ab celmo olim principe Potocki archieppo Gnesn., ad Altare Smae Crucis oblatis, nihil constat, proinde Rmum praesens. Capitulum gratam praemissorum per praesentes mentionem facit, statuendaque procontinuo in eodem altari decernit.

D. 13 Octobris, in capitulo partiali ordinario:

[1077] s. 171. Antependium ad Altare Maius. Ad antependium Maioris Altaris, in parte delaceratum, coëmendam materiam Capitulum censuit.

Dieb. 8-16 Decembris, in capitulo generali Conceptionis:

[1078] s. 173 (10 Dec.). Lectio statutorum et recapitulatio. Relectis statutis, tum decretis tam reformationum, quam anteacti generalis et partialium capitulorum, eadem decreta praesens capitulum ratihabuit.

[1079] s. 173. Revisio libri fundationum. Ad revidendum librum connotandarum fundationum deputatur ex praesenti capitulo perilris $\mathrm{Ka}$ szowski.

[1080] s. 174 (11 Dec.). Pastorale. Negotium pastoralis ilmo Bajer episcopo Culmensi commodati prorogatur ad ulterius.

Nazwy tego kamienia nie podano. 
[1081] s. 174 (12 Dec.). Expensarum fabricae Sacristiae et Capellae Komorovianae calculus. Perilris rmus dnus Paulus Kosicki cath. Gnesn. canonicus, infulatus praepositus Camenensis, loci praesentis coad. decanus, celmi olim principis Adami Komorowski archieppi Gnesn. exsecutor [testamenti] produxit in praesenti capitulo regestrum expensarum tam de summa viginti millium florenorum polon., mediante decreto capituli sui generalis die 31 Maii anno 1760 pro exstruenda Capella Smae Crucis fundationis Komorovianae sibi extradita, quam de aliis summis, utpote pro comparatione mausolei in capella Ecclesiae Collegiatae praesentis, ac demum de alia summa pro exstruenda Sacristia cum asservatorio sursum eminenti erogatis. Quae quidem summae tres, sicut praefertur, in exaedificationem praemissarum fabricarum expensae et erogatae efficiunt summam in unum computatam quinquaginta trium millium sedecim flor. polon. grossorum quattuor solidorum duorum. Quo itaque relecto calculo, actisque pro suscepto labore et favore erga ecclesiam praesentem eidem perilri rmo coad. Decano gratiis, eundem calculum, restituto denuo originali, conservandum in copiis circa acta Capitulum decrevit.

[1082] s. 174-175. Aurum Komorovianum.

[1083] s. 176 (13 Dec.). Relatio perilris ad revidendum librum fundationum Deputati. Quoniam difficilem agnitionem absolutarum fundationum in libro perilris Deputatus refert, proinde capitulum praesens decernit, quatenus quilibet altarista sub seorsivo capite missas suas absolutas in libro connotet. Qui p. Deputatus signabit capita distincta pro quolibet altarista in eodem libro.

[1084] s. 176. Liber ordinationis summarum et actorum. Adimplendo condicionem in anteriori decreto appositam, perilris Żeliński ordinationem summarum perscriptam in praesenti capitulo produxit. Quam Capitulum compactam determinavit, ac etiam librum pro continuandis actis comparandum sumptibus massae iniunxit.

[1085] s. 177. Supplex libellus Servitorum ecclesiae. Considerando carentiam $^{\mathrm{k}}$ temporum modernorum Servitoribus ecclesiae, nempe Sacellano coretum siliginis, reliquis per semicoretum dandos Capitulum permisit.

\section{5}

Diebus 28 Maii - 15 Iunii, in capitulo generali Pentecostes:

[1086] s. 188 (29 Maii). Recapitulatio. Relectis statutis decretisque tam reformationum, anteacti capituli generalis, quam et subsequentium capitulorum partialium, eadem decreta praesens capitulum ratihabuit.

[1087] s. 189. Deputatio ad revidendum librum fundationum. Ad revidendum librum connotandarum fundationum deputantur, cum relatione Capitulo facienda, perilres Żeliński et Kaszowski.

[1088] s. 189 (30 Maii). Inventarium ecclesiae. Revisionis Sacristiae et conscribendarum in ea rerum ecclesiasticarum tam antiquarum, quam noviter accessarum perilris Archidiaconus ${ }^{30}$ in se munus suscepit. Cui ad connotandum regestrum additur rdus Deriakubowicz psalterista.

[1089] s. 189. Liber ordinationis summarum. Perilris Żeliński canoni-

k caristiam akta.

30 Prat, Marcinkowski - jak przyp. 14. 
cus et causarum procurator reposuit librum ordinationis summarum omnium et singularum, noviter per se confectum. Pro quo ei Rmum Capitulum gratias egit ac determinatos pro labore florenos [polon.] trecentos exsolvendos determinavit.

[1090] s. 190 (31 ${ }^{\mathrm{I}}$ Maii). Pastorale apud ilmum eppum Culmen. Innovatur praesenti gratia ulterioris memoriae pastorale ilmo episcopo Culmensi praevio scripto reversali concessum.

[1091] s. 191. Argentum conflatum Altaris Maioris. Conflatum post combustionem Altaris Maioris argentum, circa revisionem et inventarium rerum ecclesiasticarum per perilres deputatos faciendum, ponderandum et circumscribendum, ad ulteriorem dispositionem sic manere Perillustres Capitulares censuerunt.

[1092] s. 191. Aurum Komorovianum. Iuxta nexum et disposiotionem anteriorem decretorum aurum Komorovianum ad divendendum in Thesauro Ecclesiae manebit.

[1093] s. 197 (8 Iun.). [Procuratores electi in annum sequentem: bonorum A. Zajaczkowski, causarum I. Zelinski].

[1094] s. $198-200$ (13 Iun.). Ingrossatio privilegii ${ }^{1}$ ad praelaturam Decanatus sese referentium.

[Modyfikacja przez arcybpa Łubieńskiego w $1765 \mathrm{r}$. dok. inkorporacyjnego par. Maków dla dziekanatu łowickiego z 1491].

[1095] s. 201. Donativum rdo Capituli Notario. Ex singulari gratia Rmum Capitulum rdo Capituli sui Notario florenos [polon.] ducentos solvendos pro anno praesenti assignat.

Die 17 Augusti, in capitulo partiali ordinario:

[1096] s. 206. Postulat commodationem imaginis praep. S. Spiritus. Postulatum ilris Praepositi Ecclesiae Sancti Spiritus ${ }^{31}$, intuitu commodationis imaginis Beatissimae ex Ecclesia Collegiata praesenti pro introductione Confraternitatis eiusdem Bmae Consolationis, committitur ilri Collegiatae praesentis Vicecustodi.

D. 4 Decembris, in capitulo partiali extraordinario:

[1097] s. 209. Obitus p. rmi Piaggia custodis. Indolebile ultimae vitae perilris rmi Adalberti Piaggia custodis loci praesentis, iudicis surrogati Curiae Suae Celsit. Primatialis fatum, in die hodierna hora duodecima circa mediam noctem, consummatum actis suis Capitulum connotare mandavit.

[1098] s. 209. Approbatio testamenti eiusdem.

Dieb. 8-11 Decembris, in capitulo generali Conceptionis:

[1099] s. 210 (9 Dec.). Recupitulatio. Relectis statutis et decretis tam reformationum, quam generalis anteacti ut et partialium capitulorum, eadem Parillustres Capitulares ratihabuerunt.

[1100] s. 211. Effigies olim celmi principis Szembek. Post fata et obitum perilris Piaggia custodis, effigiem olim celmi Christophori Szembek archieppi Gnesn. ${ }^{32}$ derelictam perilres eius exsecutores ad eccle-

121 blęd. akta.

1 privilegiorum akta.

${ }_{11}$ Ks. Jan Dziewierski, także zatożyciel Niższego Seminarium Duch. (tzw. Bartoszków) w Eowiczu.

32 Krzysztof Antoni Szembek h. wtas, m.in. arcybp gniezn. i prymas $w$ l. 1739-1748 , 
siam praesentem obtulerunt, eandemque proxime ad tumulum, ubi corpus eius iacet, in memoriam sepulturae eius parieti affigendam postularunt. Pro quo eis Rmum Capitulum gratias egit et effigiem eandem instantanee statuerdam ad tumulum eiusdem celmi Principis demandarunt.

[1101] s. 211. Imago Bmae ad Altare Maius. Quoniam imago Beatissimae ad Altare Maius nullibi corrigi seu reformari valet, proinde eandem, ut est depicta Romae, in altari eodem statuendam Capitulum censuit per praesentes.

[1102] s. 215-216 (10 Dec.). Mensura pro avena strenali coretorum antiquorum.

[1103] s. 217. Inventarium ecclesiasticum. Functus officio deputationis suae perilris Archidiaconus produxit in praesenti capitulo inventarium rerum ecclesiasticarum tam antiquarum, quam noviter accessarum et decessarum per se conscriptum. Quo relecto Rmum Capitulum eidem pro suscepto labore gratias egit.

[1104] s. 217. Revisio libri fundationum. Ad revisionem libri connotandarum fundationum deputatur ex praesenti capitulo perilris Wężylk.

[1105] s. 217. Pastorale apud ilmum eppum Culm. Pro memoria in ulterius servanda innovatur commodatum pastorale ilmo episcopo Culmensi.

[1106] s. 225 (11 Dec.). Recapitulatio. Relectis decretis capituli praesentis, eadem Perillustres Capitulares ratihabuerunt.

[1107] s. 225. Limitatio capituli. Ob rationem visitationis Celmi Principis seu porrectionis decreti reformationis limitatur capitulum.

D. 20 Decembris, in capitulo partiali ordinario:

[1108] s. 225-226. Installatio p. rmi Szaniawski ad praelaturam Custodiae. Coram pilbus rmis suprascriptis Praelatis et Canonicis capitulariter congregatis comparens personaliter pilris rmus Thomas Szaniawski metrop. Gnesn. canonicus, Collegiatae Volboriensis et Parochialis Komarniewicensis praepositus ${ }^{33}$ exhibut litteras institutionis sui ad praelaturam Custodiae Insignis Ecclesiae Collegiatae Eoviciensis fundi Ecclesiae Parochialis in Bąków eidem praelaturae Custodiae incorporatae, morte et obitu olim p. rmi Adalberti Piaggia illius ultimi et immediati possessoris vacantem, ex praesentatione ilris magci Rochi Zbiewski ca.stellani Calissiensis, capitanei [s. 226] Łoviciensis uti dictae praelaturae Custodiae legitimi patroni et collatoris, sub die 18 mensis Decembris anno praesenti 1765 sibi a celmo principe Vladislao Alexandro Pomian a Eubna Łubieński Dei et Apostolicae Sedis gratia archieppo Gnesn. etc. benigniter impertitas, manu eius subscriptas et sigillo maiori communitas. Vigore quarum petiit se ad dictam praelaturam Custodiae recipi, vocem in capitulo concedi et stallum competens assignari. Et Rmum Capitulum, receptis cum debita, qua par est, reverentia praefatis institutionis litteris, isdemque capitulariter relectis, eundem pilrem rmum Institutum unanimi voto et consensu in gremium sui recipiendum ac in possessionem dictae praelaturae Custodiae inducendum esse censuit, atque pro eadem sui inductione et installatione facienda (recepta ab eo iuxta praescriptum Concilii Tridentini, et praesertim bullae felicis recordationis $\mathrm{Pii}$ IV papae, fidei professione, tum quoque de observandis

${ }^{33}$ Tomasz Szaniawski h. Junosaa, m.in. prat. kustosz tow. w l. 1765-1780. 
huius Capituli novis et antiquis statutis corporali iuramento) pilrem Iosephum Marcinkowski archidiaconum ét Adalbertum Wężyk canonicum Capituli sui deputavit. Qui taliter Deputati eundem pilrem Institutum in facie totius cleri et populi, protunc ad Divina congregati, stallum in choro eidem praelaturae competens locumque in capitulo assignarunt, in possessionemque curiae, iurium, proventuum et redituum dictae Custodiae cum solitis caeremoniis induxerunt et intromiserunt. De quorum pacifica possessione idem pilris rmus Installatus iterum atque iterum protestatus est.

\section{6}

Die 25 Ianuarii, in capitulo partiali ordinario:

[1109] s. 228. Transactiones igne absumptae in Archivo Ravensi. Transactiones ad Capitulum sese referentes igne cum Archivo Raven$\mathrm{si}^{34}$ in anno praesenti absumptas per oblatam porrigendas, capitulum praesens censuit.

Diebus 20 Maii - 6 Iunii, in capitulo generali Pentecostes:

[1110] s. 233 (21 Maii). Lectio statutorum et recapitulatio. Relectis statutis et decretis tam reformationum, quam anteacti capituli generalis et partialium capitulorum, eadem decreta Perillustres Capitulares ratihabuerunt.

[1111] s. 234 (23 Maii). Cultus Divinus et revisio libri fundationum. Ad revisionem libri fundationum absolvendarum per Collegia Minora et Altaristas connotandarum deputatur ex praesenti capitulo pilris canonicus Kaszowski.

[1112] s. 236 (26 Maii). Inentdrium ecclesiae. Ad verificandum inventarium ecclesiasticum conscriptionemque noviter accessorum et decessorum deputantur pilres Tarnowski et Kaszowski, cum relatione futuro capitulo facienda.

[1113] s. 243 (30 Maii). Pastorale. Pastoralis apud ilmum episcopum Culmensem haerentis capitulum praesens mentionem fecit.

[1114] s. 247, 249 (5, 7 Iun.). [Procuratores in annum sequentem electi: bonorum A. Zajqczkowski, causarum A. Wężyk].

[1115] s. 248 (6 Iun.). Caeremoniarius constituitur. In locum rdi Szymankiewicz constitutitur in praesenti capitulo rdus [Iosephus] Sladecki vicarius. Apud quem rolum Szymankiewicz anteactum caeremoniarium partiale capitulum vim investigandi de libris caeremonialibus habebit.

D. [13] Septembris, in capitulo partiali ordinario:

[1116] s. 258. Communicandi tapetes pilri rmo Pstrokoński vicepraesidenti Tribunalis Regni. Quodsi postulaverit pilris rmus Pstrokoński cath. Gnesn. et loci praesentis canonicus, vicepraesidens Tribunalis Regni commodationem pro sua functione tapetum parieti affigendorum, extunc commodandos eosdem Potoccianos Capitulum determinavit. Tandem non accepit.

Dieb. 8-13 Decembris, in capitulo generali Conceptionis:

[1117] s. 262 (9 Dec.). Lectio statutorum et recapitulatio. Relectis

s4 Archiwum Grodu Rawskiego. 
statutis, tum decretis reformationum atque decretis anterioris capituli generalis et partialium capitulorum, eadem Perillustres Capitulares ratihabuerunt.

[1118] s. 263 (10 Dec.). Pastorale. Commodati pastoralis ilmo episcopo Culmensi praesens capitulum mentionem facit.

[1119] s. 272 (13 Dec.). Recapitulatio. Relectis decretis capituli praesentis eadem ratihabuerunt.

\section{7}

Die 17 Ianuarii, in capitulo partiali ordinario:

[1120] s. 273. Pro actu consecrationis Ilmi Procancellarii res concedendae. Praevio regestro, per commodationem dando et subscribendo pro consecratione Ilmi Regni Procancellarii ${ }^{35}$, quae exigentur, concedendas Capitulum permisit.

D. 23 Maii, in capitulo partiali ordinario:

[1121] s. 275-276. Postulatum Rdorum Patrum Reformatorum Miedniewiciensium. Licet quidem Rdi Patres Reformati Conventus Miedniewiciensis ${ }^{36}$ tapetes pro imminenti sollemnitate coronationis Bmae Virginis Mariae a Capitulo commodandos requirunt, cum tamen imminentibus Festivitatibus ${ }^{37}$ etiam ecclesia propria decus suum requirit, proinde obstantibus praemissis, quantum exempli valet commodandos ex Capella saltem Sanctae Victoriae, eosdem tapetes capitulum praesens, praevio scripto [s. 276] reversali permittit praesentium vigore.

Diebus 9-25 Iunii, in capitulo generali Pentecostes:

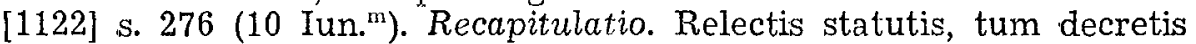
reformationum necnon capituli immediati generalis et partialium, capitulorum, eadem decreta Perillustres Capitulares ratihabuerunt.

[1123] s. 277. Imago celmi olim princ. Komorowski. Effigiem celmi olim principis Komorowski in Sacristia Capitulari parieti affigendam Capitulum censuit, compartimentum pilris futurus Procurator construere mandabit.

[1124] s. 278 (12 Iun.). Reparatio ciborii. Reparatio seu exstructio novi ciborii, obstantibus modernis circumstantiis temporis, felicioribus temporibus praesens capitulum reliquit.

[1125] s. 280 (13 Iun.). Transactiones ad Acta Ravensia conflagratas per oblatam porrigendas. Transactiones post conflagrationem Actorum Castrensium Ravensium, ad negotia Capituli sese referentes, captato tempore per oblatam porrigendas Capitulum censuit.

[1126] s. 230. Pastorale et apparatus apud ilmum eppum Culmensem. Pastoralis et apparatus commodatorum ilmo episcopo Culmensi capitulum praesens mentionem fecit.

[1127] s. 285 (25 Iun.). Exsequiae pro anima Celmi Principis. Cum celmum principem Vladislaum Eubieński archiepiscopum Gnesnensem

m Maij akta.

85 Andrzej Stanistaw Mlodziejowski $h$. Korab, dr ob. prawa, biskup przemyski $w r .1766$, kanclerz kor. 1767 , bp poznański $w 1768$.

30 Klasztor Reformatów w Miedniewicach k. Sochaczewa.

87 Zbliżaty się Zielone Swiatki i kapituka gen. 
die 20 praesentis Varsaviae morte obiisse constat, proinde exsequiis pro anima eius decantandis capitulum praesens diem crastinam, videlicet 26 praesentis assignat.

[1128] s. 28\%. [Procuraiores elecli in annum sequentem: bonorum A. Zajaczkowsti, causarum S. Szeliski].

[1129] s. 288. Donativum rdo capitulari Notario. Rdo Capituli Notario, pro iuvamine in negotiis Capituli, ducentos florenos pro anno praesenti Capitulum assignavit.

[1130] s. 288. Recapitulatio. Facta recapitulatione decretorum praesentis capituli, eadem decreta praesens capitulum ratihabuit.

D. 11 Iulii, in capitulo partiali ordinario:

[1131] s. 289. Devotio transferenda ad Ecclesiam S. Leonardii. Ob imminentem maiorem structuram mausolei in ecclesia praesenti celmi olim principis Eubieński immediate vita functi, transferendam devotionern ad Ecclesiam Sancti Leonardi. Ad tempus terminandi funeris Capitulum censuit anniversaria capitularia et missas lectas in loco absolvi posse.

D. [18] Iulii, in capitulo partiali ordinario:

[1132] s. 289-290. Inventarium advocatiae in Zabostów. Pilris canonicus Janicki produxit in praesenti capitulo inventarium advocatiae in Zabostów ${ }^{38}$, per se una cum pi]ri [s. 290] Kontowski conscriptum. Quo relecto eisdem plbus Deputatis Rmum Capitulum gratias egit. Et quoniam maius longe inventarium inibidem per ilmurn anteactum Tenutarium ${ }^{39}$ est relictum, proinde dirigendas ad eundem cum gratiarum actione litteras Capitulum censuit.

D. 12 Septembris, in capitulo partiali ordinario:

[1133] s. 295. Argenteria fatis celmi olim Principis ad ecclesiam praesentem in recompensam peristromatum disposita. In recompensam deterioratorum tapetum parietalium, tam baldachini ac aliarum rerum, celmo olim Principi commodatarum, ilmi Exsecutores obtulerunt res infranominatas, regestro specificatas, cuius tenor eiusmodi - Regestr rzeczy odebranych do Zakryistyi po śp. J. Xciu Jmci Łubieńskim arcybiskupie gnieźnieńskim: pacyfikał srebrny pozłocisty 1; miednica cała wyzłacana 1 ; nalewka takaż herbowna 1 ; tacka $\mathrm{z}$ wierzchu wyzłacana, na brzegach floresy bite z tymże herbem 1; [taca] srebrna pozłocista, ampułki dwie srebrne pozłociste; dzwonek jeden srebrny; cereusz jeden z łańcuszkiem srebrnym, cały wyzłacany. Pro quibus itaque, per manus rmi Kosicki receptis, Rmum Capitulum gratias debitas egit.

[1134] s. 295. Litterae ad ilmum eppum Culmensem dirigendae. Dirigendas litteras intuitu apparatus commodati ad ilmum episcopum Culmensem Capitulum censuit.

D. 26 Septembris, in capitulo partiali ordinario:

[1135] s. 296. Litterae dirigendae ad ilmum eppum Culmensem. Quoniam ilmus episcopus Culmensis inulterius pastorale et apparatum fatis olim celmi principis Komorowski retinendum apud se affectat, proinde rescribendas ad eundem litteras permissivas retinendi ad tempus res easdem censuit.

36 Zabostów Duży i Maty wsie w par. kolegiackiej i Kompina.

89 Dzierżawca tym byt jeden z cztonków kapituty. 
Dieb. 8-14 Decembris, in capitulo generali Conceptionis:

[1136] s. 299. Lectio statutorum et decretorum. Relectis statutis et decretis tam reformationum, quam generalis et partialium capitulorum, eadem decreta partialia Perillustres Capitulares pro rato susceperunt.

[1137] s. 303-304 (10 Dec.). Bulla Romana innovationis villarum Stomków et Dąbrowice ad Decanatum Eoviciensem. Por. $\mathrm{nr}$ [1034].

[1138] s. 310 (14 Dec.). Revidendus liber fundationum connotandarum. Ad revisionem libri connotandarum fundationum deputatur ex praesenti capitulo pilris, canonicus Kontowski.

\section{8}

Diebus 24 Maii - 3 Iunii, in capitulo generali Pentecostes:

[1139] s. 314 (25 Maii). Lectio siatutorum et recapitulatio. Relectis statutis et decretis reformationum ac capituli generalis et partialium capitulorum, eadem decreta Perillustres Capitulares ratihabuerunt.

[1140] s. 320 (28 Maii). Aurum Komorovianum. Committitur ilri Vicecustodi divenditio auri Komoroviani, quo potuerit meliori modo.

[1141] s. 323, 326 (30 Maii, 1 Iun.). [Procuratores in annum sequentem electi: bonorum A. Zajączkowski, causarum S. Szeliski].

[1142] s. 325 (31 Maii). Inventarium ecclesiae. Ad conscribendum inventarium rerum ecclesiasticarum tam anteriorum inventariis comprehensarum, quam noviter accessarum deputatur ex praesenti capitulo pilris canonicus Kontowski.

[1143] s. 325. Postulatum Patrum Scholarum Piarum. Postulationi Patrum Scholarum Piarum ${ }^{40}$ pro commodatione rerum ecclesiasticarum, pro actu canonisationis $\mathrm{s}$. patris eorum Iosephi Calasanctii supplicantium, Capitulum annuendo, idem negotium ilri Vicecusitodi Ecclesiae suae Collegiatae praesentis commisit, ut quidquid illi visum et possibile ad commodandum fuerit, praevio regestro rerum commodatarum, extradat.

[1144] s. 326-327 (1 Iun.). Platea Glinki. Quoniam incolae inhabitantes plateam Glinki, iurisdictioni Capituli subiectam, documenta et privilegia deperdisse allegant, proinde relinquitur vigor partiali capitulo tradendi iisdem incolis, in recognitionem dominii Capitulo pendentis [s. 327] dimensurandas areas easdem in cubitos et ex cubito constituendum proportionaliter censum terragicum per pilrem causarum Procuratorem, Capitulum censuit. Quotiescumque autem pactum emendi et vendendi iidem incolae plateae memoratae de areis per se possessis inter se habuerint (quod ipsis etiam praesenti conceditur) in actis villanis capitularibus recognoscere, rdus quoque Notarius Capituli submissionem pro solvendo praedicto censu inscriptioni venditivae annotare tenebitur - -

[1145] s. 328 (3 Iun.). Donativum rdo Capituli Notario. Pro addita opera in negotiis Capituli Rmum Capitulum rdo Capituli sui Notario florenos 200 assignat.

Die $30^{\mathrm{n}}$ Iulii, in capitulo partiali ordinario:

[1146] s. 332. Pastorale ab ilmo eppo Culmensi. Ilmus Bajer episcopus

n 29 blęd. akta.

so Pijarzy byli $w$ Łowiczu od $r .1668$. 
Culmensis commodatum a Capitulo pastorale retromisit, cappam et apparatum ac gremiale, ex quo notabiliter deteriorata (ut testantur litterae eius) retinuit. Verum nova ornnia praemissa comparare et restituere, aliaque plura beneficia huic ecclesiae praestare pollicitus. Litteras proinde pro pollicitis beneficiis ad eundem dirigendas Capitulum censuit, scriptumque pro pastorali datum in manus pilris Archidiaconi ${ }^{41}$ ad transmittendum consignavit.

D. 3 Septembris, in capitulo partiali ordinario:

[1147] s. 336-337. Installatio pilris rmi [Gabrielis] Turski ${ }^{42}$ in Coadiutoriam Praepositurae Łoviciensis.

D. 26 Septembris, in capitulo partiali extraordinario:

[1148] s. 340. Libri ad Psalterium comparandi. Quoniam libri ad decantandum Psalterium penitus dissaepti et destructi capitulo praesenti constat, proinde Capitulum commisit pilri Procuratori, ut eosdem libros coëmat.

Dieb. 8-22 Decembris, in capitulo generali Conceptionis:

[1149] s. 344. Recapitulatio. Facta recapitulatione statutorum decretorumque tam reformationum, quam immediati capituli generalis partialiumque capitulorum, eadem decreta Perillustres Capitulares ratihabuerunt.

[1150] s. 344 (10 Dec.). Inventarium rerum ecclesiasticarum et regestrum librorum Bibliothecae Capitularis. Pilris Ioannes Kontowski canonicus loci praesentis, ex anteacto capitulo generali Festorum Pentecosten ad conscribendum regestrum rerum ecclesiasticarum deputatus, in praesenti capitulo produxit idem regestrum, manu sui conscriptum, et in eodem libro, ex speciali sua gratia librum ad id comparatum, inductum. Insuper in eodem libro ex speciali sua gratia praesentavit regestratos libros Bibliothecae Capitularis, per se descriptos et per classes compositos et ordinatos. Quae regestra seu potius inventaria, manu pilris Praesidentis ${ }^{43}$ capituli subscripta, in Archivo Capituli conservanda Capitulum mandavit, pilrique suprascripto Canonico gratias debitas pro suscepto labore egit.

[1151] s. 345. Imago Beatissimae in Altari Maiori. Imago Bmae Virginis Mariae in Altari Maiori in longitudine et latitudine sua multum spatio designato deficit, ut itaque ilris ${ }^{\circ}$ Vicecustos captato tempore eandem divendere, alia autem imago comparari possit, capitulum praesens dat suam facultatem.

[1152] s. 345. Liber fundationum connotandarum. Ad revisionem libri fundationum connotandarum deputatur pilris Eukaszewicz ${ }^{44}$.

[1153] s. 345. Revisio Archivi et summariorum eiusdem. Ad revisionem Archivi deputantur pilres Żeliński et Łukaszewicz.

[1154] s. 347 (12 Dec.). Aurum Komorovianum. Reassumitur anterioris capituli generalis Fest. Pentecosten decretum, committiturque ilri Vicecustodi loci praesentis venditio auri Komoroviani relative ad capitulum.

- Priris akta.

41 Prat. Marcinkowski - jak przyp. 14

42 Gabriel Józef Turski $h$. Rogala, m.in. prat. koad. prepozyt low. od r. 1768, prepozyt $w$ l. $1776-1790$.

43 Jak przyp. 41.

44 Bartlomiej Eukaszewicz m.in. kan. low. w l. 1765-1780. 
[1155] s. 353 (19 Dec.). Apparatus apud ilmum eppum Culmensem. Reassumitur anterius decretum capituli immediati generalis innovanturque litterae pro deteriorato apparatu eidem ilmo episcopo Culmensi commodato, novum comparare determinantes cum ceteris beneficiis eidem ecclesiae praesenti praestari litteris iisdem declaratis.

[1156] s. 354 (21 Dec.). Tubae musicales. Comparatae sumptu Capituli tubae, ut non deteriorentur per privatos usus musicorum, in Sacristia in cistula occlusa conservabuntur.A qua rdus Vicecustos clavem habebit, recipiet et extradet attendetque, ut pro devotione tantum Ecclesiae Collegiatae iisdem utantur.

[1157] s. 356 (22 Dec.). Electio thesaurarii Confoederationis S. Ioannis. Spect. Połatyński consul Civitatis praesentis in thesaurarium Altaris Sancti Ioannis Nepomuceni eligitur et constituitur. Cui pilres ad recipiendum $a b$ exsecutoribus spect. Barszcz calculum Deputati collectam pecuniam et libros reddent.

\section{9}

Diebus $16^{\mathrm{P}}$ Maii - 3 Iunii, in capitulo generali Pentecostes:

[1158] s. 363 (17 Maii). Recapitulatio. Relectis statutis, decretis reformationum, tum decretis immediati capituli generalis atque partialium capitulorum, eadem decreta Perillustres Capitulares ratihabuerunt.

[1159] s. 364 (18 $^{\mathrm{q}}$ Maii). Cultus Divinus. Ad revidendas reliquias Ecclesiae Collegiatae, et praesertim S. Victoriae, sigillaque iisdem reliquiis appensa deputatur pilris Tarnowski, cum relatione Capitulo facienda - -

[1160] s. 364. Deputati ad revisionem libri fundationum. Pilres iidem Tarnowski et Szeliski ad revisionem libri fundationum annotandarum deputantur.

[1161] s. 365 ( $19^{\mathrm{r}}$ Maii). Aurum Komorovianum. Divenditio auri Komoroviani ob calamitatem temporis praesentis ${ }^{45}$ ad ulterius suspenditur, opportune tamen divendatur.

[1162] s. 365. Tubae musicales. Reassumitur decretum anterioris capituli generalis iniungiturque ilri Vicecustodi, ut tubae musicales noviter emptae serventur in Sacristia et ad nullos usus privatos accipi permittantur.

[1163] s. 366. Apparatus apud ilmum eppum Culmensem. Apparatus apud ilmum episcopum Culmensem haerentis capitulum praesens mentionem fecit.

[1164] s. 369 (26 Maii). Donativum rdi Notarii. Quoniam adpraesens massa exhausta, proinde 200 florenos eidem dono assignatos ex proventibus vindicandis sibi repetet. Expensas porrectas eidem pilris Procurator refundet.

[1165] s. 370, 371 (29 Maii, 3 Iun.). [Procuratores electi in annum sequentem: bonorum I. Kontowski, causarum (iurium) S. Szeliski].

[1166] s. 370 (30 Maii). Torquis aurea Wężykoviana. Divenditio tor-

p 26 5tęd. akta.

q 16 akta.

r 17 akta.

13 Mowa o potyczkach z konfederatami barskimi. 
quis aureae Wężykovianae cum cruce committitur pilri canonico Łukaszewicz, una cum auro Komoroviano, cui et ubi potuerit, curanda.

[1167] s. 370. Moneta anteriorum massarum reducenda. Monetam anteriorem massae, in variis tinphonibus ac alia moneta exstantem, pilris canonicus Łukaszewicz curabit omni meliori modo reducendam et prodendam.

Die 24 Iulii, in capitulo partiali extraordinario:

[1168] s. 374. Obitus ilmi [Christophori] Dobiński [suffr. Gnesn.] decani loci praesentis.

Dieb. 8-17 Decembris, in capitulo generali Conceptionis:

[1169] s. 382 (9 Dec.). Recapitulatio. Lectis statutis decretisque reformationum, tum et decretis generalis anteacti et partialium capitulorum, eadem decreta Perillustres Capitulares ratihabuerunt.

[1170] s. 384 (11 Dec.). Litterae recommendatoriae rdi Notarii ad Celmum Principem. Cum obventurus speratur vacans fundus canonicatus post ascensum pilris canonici Kaszowski ad Decanatum Lanciciensem, recommendandum rdum Capituli sui Notarium ad eundem canonicatum per litteras dirigendas Celsissimo Principi ${ }^{40}$ Capitulum censuit.

[1171] s. 384. Aurum Komorovianum et torquis Wężykoviana. Auri Komoroviani et torquis Wezzykoviani divenditionis modus relinquitur cum pleno igore partiali capitulo.

[1172] s. 385 (12 Dec.). Apparatus apud ilmum eppum Culmensem. Annotatur pro memoria apparatus ilmo Bajer episcopo Culmensi commodatus litteris ad Capitulum directis restitui, seu ob deteriorationem eius novum comparari determinatus.

\section{0}

Diebus 5-23 Iunii, in capitulo generali Pentecostes:

[1173] s. 392 (6 Iun.). Lectio statutorum et recapitulatio. Relectis statutis et decretis tam reformationum, quam immediati capituli generalis. et partialium capitulorum, eadem decreta Capitulum ratihabuit.

[1174] s. 393 (7 Iun.). Revisio libri fundationum. Ad revisionem libri connotandarum fundationum deputatur ex praesenti capitulo pilris canonicus Kontowski, cum relatione Capitulo facienda.

[1175] s. 393-394 (8 Iun.). Fiat inventarium status Curiae post mortem cuiuslibet pilris Capitularis. Ut conservationi curiarum per quemlibet praelatum et canonicum Capitulo provideatur, post cessum vel decessum cuiusvis ad conscri[s. 394]bendum statum curiae eiusdem deputandum, et descriptionem reparationis sive desolationis perficiendam, Capitulo praestandam et in Archivo Capituli conservandam Capitulum censuit.

[1176] s. 394 (9 Iun.). Aurum Komorovianum et torquis Wężykoviana. Reassumitur decretum anterioris capituli generalis Festi Immac. Conceptionis BVM 1769, obliganturque pilres anteacto capitulo destinati, ut quantocius modum divendendi auri Komoroviani et torquis Wężykovianae adinveniant.

${ }^{46}$ Gabriel Jan Podoski h. Junosza, dr ob. prawa, m.in. arcybp gniezn. i prymas: w l. $1767-1777$. 
[1177] s. 395. Apparatus apud itmum eppum Culmensem. Apparatus ilmo episcopo Culmensi accommodati et ob deteriorationem eiusdem in novo restitui determinati praesens capitulum mentionem facit.

[1178] s. 395 (11 Iun.). Monetae antiquioris commutatio. Reassumitur decretum anterioris capituli generalis obligaturque pilris canonicus Łukaszewicz una cum p. canonico Kontowski, ut monetam antiquiorem in summa trium millium tinphonum prutenicorum, in massa Capituli adusque degentem, commutari faciant.

[1.179] s. 398, 402 (16, 23 Iun.). [Procuratores in annum sequentem electi: bonorum I. Kontowski, causarum S. Szeliski].

[1180] s. 402 (23 Iun.). Pyxis reformanda. Quoniam pilris canonicus Zajączkowski suo sumptu deaurationem pyxidis vetustate deterioratae offert, proinde capitulum praesens opportuno tempore reformandam eandem pyxidem determinat et p. Zajączkowski pro testato beneficio debitas deponit gratias.

Die 30 Iunii, in capitulo partiali ordinario:

[1181] s. 404. Restituitur residentia Sanctuariis. Hypocaustum, in quo olim pilris canonicus Zajączkowski de consensu Capituli ad vitae suae tempora permanserat, ad dispositionem suam Rmum Capitulum recipit et rehabet. In eademque residentia unum hypocaustum pro schola, alterum pro Sanctuariis praesentibus disponit.

D. 14 Iulii, in capitulo partiali ordinario:

[1182] s. 407-408. Deputatio ad conficiendum inventarium curiae derelictae fatis olim pilris Zajączkowski. Pilres Wężyk et Kontowski ad curiam ad Ecclesiam S. Ioannis Baptistae sitam et iacentem, fatis olim p. Adami Zajączkowski canonici loci praesentis, illius ultimi et immediati possessoris derelictam, deputantur per praesentes, cum relatione Capi [s. 408] tulo suo cum confecto eodem inventario facienda.

Dieb. 8-19 Decembris, in capitulo generali Conceptionis:

[1183] s. 415 (10 Dec.). Lectio statutorum et recapitulatio. Relectis statutis et decretis factaque recapitulatione decretorum tam anteacti generalis, quam et partialium capitulorum, eadem decreta Perillustres Capitulares ratihabuerunt.

[1184] s. 416. Inventarium ecclesiae. Pilris bonorum Procurator verificabit praeteritum inventarium et noviter res accessas connotabit.

[1185] s. 416. Revisio libri fundationum. Pilris Rybiński ${ }^{47}$ librum fundationum revidebit et Capitulo referet.

[1186] s. 419 (12 Dec.). Apparatus apud ilmum eppum Culmensem. Reassumuntur anteriora decreta in puncto commodatorum ilmo episcopo Culmensi ex ecclesia praesenti apparamentorum.

[1187] s. 421 (15 Dec.). Aurum Komorovianum. Pilbus ad Celmum Principem Delegandis datur facultas divendendi aurum Komorovianum omni meliori modo.

[1188] s. 422. Relatio pilrium ad conscribendum inventarium curiae fatis olim p. Zajaczkowski Deputatorum. Pilres ad conscribendum inventarium curiae fatis olim pilris Zajączkowski derelictae Deputati produxerunt in praesenti capitulo idem inventarium per se descriptum, quod

47 Filip Jakub Rybinski h. Radwan, m.in. kan. low. w l. 1769-1791, surogat low. 
taliter productum in Archivo Capituli conservandum Capitulum censuit et pilbus Deputatis gratias egit.

\section{1}

Die 19 Februarii, in capitulo partiali extraordinario:

[1189] s. 423. Aurum Komorovianum. Aurum Komorovianum a multo tempore decretis capitularibus ad divendendum dispositum, cum pilris bonorum Procurator maiori pretios unam quam talero uno divendi non posse, et sic ad ultimum unum ex mercatoribus nonnisi promisisse refert, proinde Capitulum et super eodem valore et pretio consentit et divendendum eidem $\mathrm{p}$. Procuratori permittit.

Diebus 21-29 Maii, in capitulo generali Pentecostes:

[1190] s. 427 (22 Maii). Recapitulatio. Facta recapitulatione decretorum tam anteacti generalis, quam et partialium capitulorum, relectisque statutis et decretis reformationum, eadem decreta capitularia Perillustres Capitulares ratihabuerunt per praesentes.

[1191] s. 427 ( $23^{\mathrm{t}}$ Maii). Deputatio ad revisionem libri fundationum. Ad revisionem libri connotandarum fundationum deputatur pilris $\mathrm{Eu-}$ kaszewicz.

[1192] s. 428 (24 "Maii). Apparatus apud ilmum eppum Culmensem. Ratione apparatus apud ilmum episcopum Culmensem Capitulum per praesentes mentionem facit.

[1193] s. 430 (27 ${ }^{\vee}$ Maii). Inventarium ecclesiasticum. Quoniam pilris Kontowski canonicus et procurator bonorum, ad conscribendum inventarium ecclesiasticum deputatus, multis ${ }^{w}$ adpraesens distentus est negotiis, proinde relinquitur vigor partiali capitulo recipiendi relationem et revidendi regestra conscripti seu verificati eiusdem inventarii.

[1194] s. 431 (28* Maii). [Procuratores electi in annum sequentem: bonorum I. Kontowski, causarum S. Szeliski].

[1195] s. 432 (29 Maii). Innovatio privilegii incorporationis Makowa ad Decanatum [Eoviciensem] et beneplacitum Apostolicum. [Bina documenta ad Archivum]. Por. nr [1137].

[1196] s. 432-433. Relatio pilris ad revisionem libri fundationum Deputati. Pilris canonicus Eukaszewicz retulit, qualiter librum fundationum [s. 433] connotandarum revidit, fundationes cantatas praeter fundationem Prażmovianam in cursu suo decantatas praevenit. Nonnullos tamen altaristas, ob non solutionem in praesenti tempore censuum, non salariatos cessasse easdem, retulit. Eapropter, ne propria sua auctoritate id audere videantur, ad ilmum episcopum Bolinensem auditorem generalem Consistorii praesentis ${ }^{48}$ pilrem canonicum Rybiński expostulavit, ut pro et cum eis pro reductione sive dispensatione tantisper absolutionis earundem missarum ad solutionem censuum instare dignetur.

s $W$ aktach brak następnego wyrazu.

t 22 bięd. akta.

u 23 akta.

$\checkmark 25$ akta.

w $W$ podstawie wyd. stowo wystepuje 2 razy.

$\times 26$ bięd. akta.

8 Antonin Korneliusz Przedwojewski h. Odrowąż, kapucyn, m.in. biskup tyt. bolineński, audytor prym. Podoskiego, kan. low. w l. 1769-1793. 
[1197] s. 433. Donum gratuitum rdo Capituli Notario. Quoniam rdus Capituli Notarius annis tribus per florenos ducentos, pro dono sibi gratuito assignatos, non recepit, proinde Capitulum ex vindicatis in futurum per se censibus recipiendum sibi idem triennale donum permisit.

D. 10 Iunii, in capitulo partiali ordinario:

[1198] s. 433-434. Deputatio ad colligenda iura et decreta ad ordinationem fundationum et obligationum Altaris S. Ioannis Nepomuceni.

D. 17 Iulii, in capitulo partiali extraordinario:

[1199] s. 438. Postulatum rdi Notarii. Bituminis pro reparatione camini in domo notariali, quod et quantum necessitas postulaverit, extraditionem capitulum praesens ad postulationem rdi Notarii permisit.

D. [24] Augusti, in capitulo partiali ordinario:

[1200] s. 439. Deputantur ad custodiendas res pilris Janicki. Quoniam pilris Janicki, improvisa valetudine desperata et incerta, factus sine viribus destitutus decumbit, proinde ne res per quempiam discerpentur, deputantur ad observandas easdem p. Kontowski canonicus et rdus Capituli sui Notarius.

D. 28 Septembris, in capitulo partiali ordinario:

[1201] s. 447-448. Plenipotentes ad tuendam causam testamentorum approbandorum constituuntur.

Dieb. 8-13 Decembris, in capitulo generali Conceptionis:

[1202] s. 452 (9 Dec.). Lectio statutorum et recapitulatio. Relectis statutis et decretis tam anteacti generalis et partialium capitulorum, eadem decreta partialia ratihabuit Capitulum per praesentes.

[1203] s. 452. [Deputatio] ad revisionem libri fundationum. Ad revisionem libri fundationum absolvendarum et connotandarum deputatur pilris Eukaszewicz.

[1204] s. 453 (10 Dec.). Ordo Perillustrium in stallis servandus.

[1205] s. 454. Apparatus apud Celmum Principem et ilmum eppum Culmensem. Apparatum Celmo Principi iuxta reversum et annotationem in regestris ecclesiasticis commodatum, tum apud ilmum episcopum Culmensem exstantem et litteris restitui determinatio pro memoria connotare Capitulum demandavit in actis suis, captato tempore requirendos.

[1206] s. 458 (13 Dec.). Revisio libri fundationum. Quoniam pilris Eukaszewicz ad revisionem libri fundationum deputatus ob aegram sui valetudinem praesens adesse capitulo nequit, proinde relinquitur relatio in capitulo facienda partiali.

[1207] s. 358-459. Disponitur tempus pro gestandis mantoletis.

\section{2}

Die 11 Ianuarii, in capitulo partiali ordinario:

[1208] s. 460. Postulatum incarceratorum. Ad postulatum militum Confoederatorum, sub aresto exercitus Moschovitici degentium, numerum centum quinquaginta personarum excedentium, subsidium charitativum a Capitulo exigentium, praesens capitulum ex massa sua capitulari florenos quinquaginta, ex censibus Wężykovianis flor. viginti, ex censibus Montis Pietatis flor. triginta assignavit. Pro reliqua contributione caritatis secundum posse et pietatem cuiusvis capitularis personae 
et aliarum ad idem opus charitativum accedere volentium rdum Capituli sui Notarium deputavit, et eidem distribuenda praemissa commisit per praesentes.

D. 15 Februarii, in capitulo partiali ordinario:

[1209] s. 462. Moneta massae argentea. Quoniam tempore praesenti in moneta argentea falsitas apparet, proinde obviando alicui in eadem decessui, anticipate minori clero solvendum quartuale praesens Capitulum decrevit. Dummodo quoque advenerit quartuale, non exspectato dimidio, solvendas sibi refectiones idem capitulum determinavit.

Diebus 9-20 Iunii, in capitulo generali Pentecostes:

[1210] s. 468 (11 Iun.). Lectio statutorum et recapitulatio. Lectis statutis et decretis reformationum necnon decretorum anterioris generalis capituli et subsequentium partialium capitulorum, ulterius Capitulum procedere mandavit.

[1211] s. 469-470. Deputatio ad conscribendum inventarium rerum ecclesiasticarum. Pilres Żeliński et Tarnowski deputantur ad revisionem et [s. 470] conscriptionem inventarii rerum ecclesiasticarum.

[1212] s. 471. Apparatus apud Cels. Principem et ilmum eppum Culmensem. Reassumuntur pro memoria solita apparatus tam apud ilmum episcopum Culmensem, quam apud Cellmum Principem commodi via exstantes.

[1213] s. 471. Deputatio ad revisionem libri fundationum. Ad revisionem libri fundationum connotandarum deputatur pilris Tarnowski, cum relatione Capitulo suo facienda.

[1214] s. 473 (16 Iun.). Lotrix ecclesiastica. Lotrici ecclesiasticae spectato tempore praesenti ad praeteritam pensionem per florenos duos pro quartuali quolibet Capitulum auget, ita ut quolibet quartuali viginti flor. percipiat atque tritici coretum unum pro anno dandum permittit.

[1215] s. 473. Deputantur ad revisionem bullarum et erectionis [Altaris] S. Ioannis [Nepomuceni].

[1216] s. 476-477 (19 Iun.). Relatio pilris ad revisionem libri fundationum Deputati. Pilris canonicus Tarnowski, ad revisionem libri fundationum deputatus [s. 477] retulit in praesenti capitulo omnes missas cantatas in eodem libro fundationum annotatas fuisse; privatas quoque missas nonnullos rdos altaristas non connotasse. Monendos proinde eosdem rdos altaristas, ut etiam fundationes easdem suas connotent. Inter quas fundationes quoniam etiam obligationes Altaris Sancti Liborii, ad fundum canonicatus $\mathrm{S}$. Ioannis spectantes, non sunt anotatae, proide rmus Custos ${ }^{49}$ munus tractandi cum ilmo episcopo Bolinensi, fundi eiusdem praesentaneo possessore (ut etiam substitutum suum ad connotandas easdem obligationes adigat) in se assumpsit. Quo demum spectat obligationes in Capella Boczkoviana ${ }^{50}$ ex fundatione Awedykoviana ${ }^{31}$ absolvi debitas, quoniam ob retentas provisiones a summis pro iisdem missis provenientes, et inde curatis villanis ${ }^{52}$ non solutas, easdem missae non absolvuntur. Proinde utilitatem missarum earundem commodo populi villae eiusdem remotae ab ecclesia prospiciendo, pilxi futuro

49 Prat, Szaniawski - jak przyp. 33.

so Boczki wieś kapitulna w par. kolegiackiej.

51 Kan. Awedyk - jak przyp. 41 w księdze XI.

58 Duszpasterze wiejscy w par. Icolegiaclciej. 
bonorum Procuratori Capitulum commendavit, ut ex massa intercedat fundationem eandem.

[1217] s. 478. [Procuratores in annum sequentem electi: bonorum I. Kontowski, causarum B. Łukaszewicz].

[1218] s. 479 (20 Iun.). Donum gratuitum rdo Notario. Rdo Capituli sui Notario ex gratia sua speciali praesens capitulum florenos 264, circa dispersionem Capituli receptos, condonavit.

D. 12 Septembris, in capitulo partiali ordinario:

[1219] s. 486. Instrumenta fabricae bloch nuncupata. Quoniam pilris rmus Kosicki metrop. Gnesn. canonicus, loci praesentis decanus favore ecclesiae praesentis instrumentum fabricae bloch nuncupatum condonare litteris suis est testatus, hinc Capitulum referendas ei gratias per litteras pro promissis censuit, et ad postulationem pro necessitate eius commodandum ad quamvis requisitionem determinavit.

D. 3 Octobris, in capitulo partiali ordinario:

[1220] s. 489-490. Desideriorum quoque Celsissimi ad Capitulum series verborum talis - - $[s .490]-\ldots$ Reliqua hoc in negotio ipsi actui circa visitationem Collegiatae Łoviciensis commodo tempore a nobis instituendam ${ }^{53}$

Dieb. 8-12 Decembris, in capitulo generali Conceptionis:

[1221] s. 493 (9 Dec.). Lectio statutorum et recapitulatio. Quoniam statuta capitularia ad manus non habentur, ideo relectis decretis reformationum atque capitulorum tam anteacti generalis, quam et partialium, ulterius procedere Capitulum decrevit.

[1222] s. 494 (10 Dec.). Deputatio ad revisionem libri fundationum. Deputatur ad revisionem libri connotandarum fundationum pilris Zeliński.

[1223] s. 494. Apparatus apud Cels. Principem et ilmum eppum Culmensem. Apparatus apud Celmum Principem et apud ilmum episcopum Culmensem mentio actis praesentibus connotatur.

[1224] s. 495. Resolutio circa delegationem Pilrium Capitularium. Statuit praesens capitulum, ut quoties contigerit in quocumque negotio Capituli Perillustrium personarum Capitularium deputatio, fiat per $\mathrm{Ca}$ pitulum congregatum et decretum actis insertum.

\section{3}

23 Ianuarii, in capitulo partiali ordinario:

[1225] s. 499-501. Resolutio pro dispergendis.

D. 27 Martii, in capitulo partiali ordinario:

[1226] s. 501. Martyrologium novae editionis. Martyrologium novae editionis, in Bibliotheca Capitulari adusque conservatum, ad usum chori Capitulum dandum decrevit, vetus vero Martyrologium cum notis asservandum in Bibliotheca censuit.

D. 22 Maii, in capitulo partiali ordinario:

[1227] s. 507-518. Installatio ilmi [Ioannis] Karski [suffr. Gnesn.] in Coadiutoriam Decanatus [Łoviciensis].

Diebus 1-26 Iunii, in capitulo generali Pentecostes:

${ }^{83}$ Do wizytacji kolegiaty przez Podoskiego nie doszlo. 
[1228] s. 518 (2 Iun.). Lectio statutorum et decretorum reformationum. Recapitulatio. Lectione statutorum, ex causis certis Capitulo notis interrupta, decreta reformationum relecta sunt. Relectis decretis tam immediati generalis, quam et partialium capitulorum, eadem praesens capitulum ratihabuit.

[1229] s. 519. Revisio Sacristiae. Ad revisionem supellectilis ecclesiae deputantur pilres Rybiński et Jaśkiewicz ${ }^{54}$.

[1230] s. 519. Deputatio ad revisionem libri fundationum. Ad revisionem libri fundationum deputantur pilres Rybiński et Jaśkiewicz.

[1231] s. 519. Apparatus apud Cels. Principem et ilmum eppum Culmensem. Ratione apparatus apud Celmum Principem exstantis capitulum praesens mentionem facit. Ad ilmum quoque episcopum Culmensem in simili negotio apparatus eidem concessi dirigendas litteras Capitulum decrevit - -

[1232] s. 522 (9 Iun.). Relatio pilrium ad librum fundationum Deputatorum. Retulerunt pilres ad revisionem libri fundationum Deputati, qualiter plures defectus in eodem libro reperiantur. Proinde monenda Collegia, ut librum eundem accuratius scribant, censuit Capitulum.

[1233] s. 523-524. Relatio pilrium ad revisionem rerum ecclesiasticarum Deputatorum. Pilres ad revisionem rerum ecclesiasticarum et argenteriarum Deputati, functi officio deputationis suae, produxerunt in praesenti capitulo regestrum rerum earundem omnium adpraesens reperibilium, per se conscriptum et subscriptum. Quo relecto, Capitulum exhibita pilbus Deputatis pro suscepto labore gratiarum actione, idem regestrum etiam pilris Rmi Capituli [s. 524] sui Praesidentis ${ }^{55}$ subscribendum et in Archivo Capituli sui asservandum decrevit.

[1234] s. 527, 529 (18, 26 Iun.). [Procuratores electi in annum sequentem: bonorum I. Kontowski, causarum B. Łukaszewicz].

[1235] s. 529 (26 Iun.). Providetur capitulis brevius terminandis. Quoniam per rationem calculi proventuum bonorum saepius capitula protrahi solent, per idque perillustres capitulares dispendium temporis sui patiuntur. Proinde praesens capitulum praecavet praesentibus, ut pilres ad calculum deputati regestra parata et étiam summaria eorum, per p. procuratorem bonorum descripta, reperiant calculumque eundem ante inchoationem capituli generalis perficere curent. Quibus etiam pilbus delegatis congruum commodum intra tempus calculi praesens capitulum praecavet per praesentes. In librum quoque rationum nemo, quam ipsemet pilris bonorum procurator, perceptam summarum inducere audeat. Iam vero pilres ad calculum delegati regestra nova conficiant et in eadem manu sua remanenta inducant.

D. 16 Octobris, in capitulo partiali ordinario:

[1236] s. 534. Delegatio pro Comitiis Succamer. Gostinen. Delegationem pilris rmi Custodis pro Comitiis Succamerarialibus Gostinensibus, in nuperna conferentia capituli extraordinarii factam, praesens capitulum ratihabet.

Dieb. 8-14 Decembris, in capitulo generali Conceptionis:

[1237] s. 537-538 (9 Dec.). Lectio statutorum et decretorum reform.

54 Mikotaj Jaskiewicz m.in. kan. łow. w l. 1771-1779.

55 Prat. kust. Szaniawski - jak przyp. 33. 
Relectis statutis et decretis reformationum, tum decretis capituli generalis [s. 538] et partialium capitulorum, eadem praesens capitulum ratihabuit.

[1238] s. 538. Liber fundationum. Pilris Szeliski librum fundationum absolvendarum revidebit et de continentis eius Capitulum informabit.

[1239] s. 538. Revisio Sacristiae. Ex rationibus animum permoventibus revisio Sacristiae ad futurum generale capitulum Pentecosten differtur.

[1240] s. 538 (10 Dec.). Apparatus apud Cels. Principem et ilmum episcopum Culmensem. Reassumuntur decreta anteactorum capitulorum.

[1241] s. 539-540 (11 Dec.). Platea Glinki. Ex rationibus per pilrem Procuratorem massae expositis potissimum, si Deo favente tempora feliciora subvenient, ut domus commoda pro Ministris ecclesiae et aliis utilitatibus ecclesiae possit in areis eiusdem plateae capitularis ex.strui - -

[1242] s. 541 (14 Dec.). Relatio Deputati y ad librum fundationum. Quoniam pilris ad revisionem libri fundationum Deputatus refert defectuose plurimum connotatas fuisse fundationes, proinde ante omnia capitulum praesens p. canonicum Szeliski deputat, ut idem cogat altaristas et omnem clerum, quatenus inscribant suas fundationales missas in librum fundationum.

\section{4}

Die 9 Ianuarii, in capitulo partiali ordinario:

[1243] s. 542. Inventarium chori musicalis. Illatum in praesenti capitulo negotium intuitu conscriptionis inventarii chori musicalis tam videlicet instrumentorum, quam et artium figuralium ad Missas et Vesperas differtur ad futurum capitulum generale Sacri Pentecosten.

D. 5 Februarii, in capitulo partiali ordinario:

[1244] s. 545. Plenipotentes constituuntur pro Iudiciis Lanciciensibus. Diebus 23 Maii - 8 Iunii, in capitulo generali Pentecostes:

[1245] s. 548 ( $24^{z}$ Maii). Lectio statutorum et recapitulatio. Relectis statutis et decretis reformationum, factaque recapitulatione decretorum tam immediati generalis, quam et subsequentium capitulorum partialium, eadem decreta Capitulum ratihabuit.

[1246] s. 549 (26 Maii). Revisio curiarum. Revisionem curiarum praesens capitulum decernit per electas sibi ad id personas capitulares faciendam.

[1247] s. 549. Revisio Sacristiae. Ad revisionem Sacristiae deputatur pilris Kamieński ${ }^{50}$, cum relatione futuro capitulo facienda.

[1248] s. 549. Apparatus apud ilmum eppum Culmen. Dirigendas litteras ad ilmum episcopum Culmensem pro restitutione seu potius compensatione commodati apparatus Capitulum censuit.

[1249] s. 549. Apparatus apud Cels. Principem. Apparatum Celmo Principi commodatum pro memoria actis suis praesens annotari fecit capitulum.

y Deputatorum akta.

z 14 błęd. akta.

56 Tomasz Kamieński $h$. Jastrzębiec, m.in. kan. łow. w l. 1770-1807. 
[1250] s. 550. Liber fundationum. Ad revisionem libri fundationum deputatur pilris Rybiński.

[1251] s. 553 (3 Iun.). Expensa in negotio fundationis Komorovianae. Quoniam thesaurus Komorovianus adpraesens est exhaustus, adeo ut proventus fundationis eiusdem Komorovianae impensis massae vindicati fuerint et praebendarii ex massa salariati. Proinde dummodo proventus idem ad hesaurum venerit, repetendam eandem expensam massae tam intercedendo fundationem eandem, quam pro vindicandis proventibus erogatam Capitulum censuit.

[1252] s. 555 (6 Iun.). [Procuratores in annum sequentem electi: bonorum (massae) I. Kontowski, causarum B. Eukaszewicz].

[1253] s. 556-557 (7 Iun.). Relatio pilris ad revidendum librum fundationum Deputati. Reassumitur anterius decretum et quandoquidem pilris rmus Rybiński [s. 557] ad revidendum librum eundem deputatus, defectus plures in eodem libro comperisse refert: proinde monendos per eundem p. Deputatum omnes, quod obligatio connotationis fundationum suarum stringit, ut easdem fundationes sufficientius omnino in libro eodem connotent.

[1254] s. 558. Residentia notarialis. Commendatur reparatio residentiae notarialis pilri bonorum Procuratori capto tempore.

[1255] s. 558. Inventarium chori musicalis. Inventarium chori musicalis commendatur pilbus Kontowski et Rybinski.

D. 18 Iunii, in capitulo partiali ordinario:

[1256] s. 562. Plenipotentes constituuntur ad causas in Iudiciis Terrestribus et Castrensibus Gostinensibus.

D. 20 Augusti, in capitulo partiali ordinario:

[1257] s. 563. Obitus canonici hon. et secretarii Wyszyński. Die 18 mensis Augusti 1774 pilris Felicianus Wyszyński canonicus honorarius Capituli febre et languore stomachi correptus, annorum circiter sexaginta, post praestitis multis annis Capitulo labores et obsequia, supremum diem hic obiit.

[1258] s. 563. Exsecutores dativi a Capitulo post fata ilris Wyszyński. Ad conficiendum inventarium rerum derelictarum post fata ilris Feliciani Wyszyński, cum titulo exsecutorum, ad disponendum de iisdem assignantur et deputantur pilres dni Łukaszewicz et Jaśkiewicz, facultatem iisdem omnimodam tribuendi decreti praesentis vigore.

D. 27 Augusti, in capitulo partiali ordinario:

[1259] s. 566. Sancitum Reipublicae ratione solvendorum censuum pro semiquattuor.

[1260] s. 566. Illatum ilmi Przedwojewski ratione episcopalis argenteriae. Instantiae ilmi Przedwojewski episcopi Bolinensis, Eoviciensis canonici, ut argenteriam episcopalem, videlicet calicem cum patena, ampullas cum disco, lavatorium cum disco, discos ad insignia episcopalia, buseum, campanulam, pacificale, omnia inaurata, ut iusto pretio taxandam emere et solvere possit deferendo, capitulum praesens assensit.

[1261] s. 566. Argentum ecclesiae divendendum. Necessitatibus fabricae ecclesiae subveniendo, cum interea alius non occurrat modus, et massa bonorum sit extenuata, capitulum praesens decrevit, quatenus argentum Capituli, quod nulli usui et decori altarium ecclesiae servit, 
iusto pretio, praevio tamen Celmi Lociordinarii super haec consensu, divendatur.

D. 12 Septembris, in capitulo partiali extraordinario:

[1262] s. 567. Domus Notarii capitularis violenter occupata. Quoniam Rdi Vicarii domum Notarii Capituli vi et violenter occuparunt, Capitulumque eadem domo spoliarunt, ideo pro compescendo tam temerario ausu, poenisque exemplaribus motoribus infligendis, eosdem Vicarios ad Officium Consistorii citandos decrevit, causamque praesentem pilri Procuratori massae commisit.

D. 22 Octobris, in capitulo partiali ordinario:

[1263] s. 570. Assumitur in substitutum Notarii Capituli adm. rdus Rębalski. Post obitum ilris Wyszyński Notarii Capituli, ex rationibus iustis adinterim, in substitutum adm. rev. Rębalski praebendarium Sanctae Crucis ${ }^{57}$ Capitulum assumpsit. Cui post praestitum solitum iuramentum acta concredita.

[1264] s. 570-582. Installatio pilris Kaszowski ad Coadiutoriam Archidiaconatus Łoviciensis.

Diebus 8-16 Decembris, in capitulo generali Conceptionis:

[1265] s. 585 (9 Dec.). Lectio statutorum et recapitulatio. Relectis statutis et decretis, factaque recapitulatione decretorum tam anteacti generalis, quam et partialium capitulorum, eadem decreta Domini Capitulares ratihabuerunt.

[1266] s. 586 (10 Dec.). Liber fundationum. Ad revisionem connotandarum fundationum deputatur pilris Szeliski.

[1267] s. 586. Deputatio ad revisionem Sacristiae. Quoniam immediate elapsi capituli generalis decreto assignata revisio Sacristiae ob certas causas per Delegatum non est expedita, proinde capitulum praesens eandem revisionem tempore aestivo expediendam committit pilbus Szeliski et Jaśkiewicz canonicis et ad eandem conficiendam assumendum Notarium substitutum Capituli sui censet, salva relatione in futuro generali capitulo facienda. Qui pilres Deputati etiam munditiem et decorem Sacristiae Canonicalis adm. rdo Vicecustodi demandabunt et mandata haec, ut exsequantur, curabunt plena data facultate decreti praesentis vigore.

[1268] s. 586. Apparatus apud Cels. Principem et ilmum eppum Culmen. Apparatus Celmo Principi accommodatus pro memoria hisce in actis connotatur. Quoad idem reassumitur decretum capituli generalis immediate elapsi et litteras dirigendas pro restitutione eiusdem apparatus ad ilmum episcopum Culmensem Capitulum praesentibus decernit.

[1269] s. 586. Residentia notarialis. Reassumitur decretum capituli generalis Festorum Pentecosten.

[1270] s. 588 (12 Dec.). Reductio monetae. Quoniam novella lex Regni ordinavit, novat reductionem rei monetariae, ideo praesens capitulum disponit pilri bonorum Procuratori, ut eandem exacte in omnibus solutionibus refectionum, anniversariorum, pensionum etc. a data altefatae legis publicatae observet.

[1271] s. 589 (14 Dec.). Relatio pilris Deputati ad librum fundationum.

s7 Ks. Rębalski notariusz-substytut kapituty pomiędzy kan. Wyszyńskim a kan. Nikorowiczem. 
Retulit pilris Deputatus librum fundationum exquisite per se revisum. In quo, cum plurimi defectus in annotandis absolutionibus fundationum advertuntur, capitulum praesens censuit, ut eaedem fundationes abhinc omnino ab omnibus obligatis accuratius connotentur.

D. 20 Decembris, in capitulo partiali extraordinario:

[1272] s. 591. Assumptio Vicecustodis. Post fata immediate secuta adm. rdi Iacobi Jaramowski psalteristae et vicecustodis huius Insignis Ecclesiae Collegiatae Eoviciensis, in vicecustodem adm. rdum Iacobum itidem Jaramowski, defuncti ex fratre nepotem similiterque huius ecclesiae psalteristam ${ }^{58}$ praesens capitulum unanimiter elegit et assumpsit. Cui curam Sacristiae atque Thesauri et Asservatorii ecclesiastici, regimen aedituorum ecclesiae et omnia munia vicecustodis fideliter exsequendi praecommisit, salvis nihilominus ulterioribus dispositionibus $\mathrm{Ca}-$ pituli constituendis eidem fusius exponendis decreti praesentis vigore.

\section{5}

Diebus 6 aa -10 Iunii, in capitulo generali Pentecostes:

[1273] s. 597. Lectio statutorum et recapitulatio. Relectis statutis et decretis reformationum, factaque recapitulatione decretorum tam anteacti generalis, quam et partialium capitulorum, eadem decreta Domini Capitulares ratihabuerunt.

[1274] s. 598 (7 Iun.). Liber fundationum. Ad revisionem libri fundationum deputatur pilris Szeliski.

[1275] s. 598. Relatio pilrium Deputatorum ad revisionem Sacristiae. Pilres Szeliski et Jaśkiewicz, deputati ad revisionem et conscriptionem inventarii et supellectilis ecclesiasticae, retulerunt suam diligentiam in commissis adhibitam atque reposuerunt in mensa Capituli librum novum compactum eiusmodi supellectilis in auro, argento, stanno, aere, cupro, cappis, casulis, dalmaticis, albis, corporalibus, purificatoriis, cingulis utriusque Sacristiae specifice et graphice conscriptum. Ubi incontinenti comportarunt omnem argenteriam usui publico amplius non servientem. Capitulum praesens gratitudinem debitam pro praestito obsequio et peracta functione, debitam humanitatem praestando, iisdem pilbus Dominis commisit, ut tam maiores partes, quam etiam minutissima fragmenta argenti in unam vel plures partes, adhibito artis huius perito, qui per Procuratorem pensionari mandatur, conflari faciant et in Thesauro ecclesiae recondi. Aurum in partibus, quale invenitur in seorsivo scriniolo, ad ulteriorem sui Capituli dispositionem asservari. Anulos vero, quales inveniuntur, iuxta taxam divendi, pecuniam in massa $\mathrm{Ca}-$ pituli reponi faciant. Postquam autem conflatum argentum et anuli divenditi fuerint, datur vigor partiali capitulo in eiusmodi libro hoc novo inventarii exsecuta inserendi et productum inscribendi.

[1276] s. 599 (8 Iun.). Apparatus apud ilmum eppum Culm. Reassumitur decretum anteacti capituli immediate elapsi et litteras dirigendas ad eundem pro restitutione eiusdem apparatus praesens capitulum statuit, ad quas dirigendas obligatur rmus Custos.

aa 14 błęd. akta.

so Jakub Jaramowski mlodszy wybrany na wicekustosza. 
[1277] s. 599. Apparatus apud Cels. Principem. Item apparatus apud Celmum Principem modcrnum hucusque exsistens pro memoria actis praesentibus annotatur.

[1278] s. 599. Relatio pitris Rybinstci ad inentarium chori musicalis conficiendum deputati. Idem Perillustris retulit Capitulo suo, quomodo inventarium eiusdem chori musicalis confecerat. Et Capitulum suum decrevit, ut cantores seu musici ad comprobationem iuratoriam supra realitatem comportatorum instrumentorum singulorum et omnium, tum et libellorum musicalium, et praecipue honoratus Rybicki organarius ${ }^{59}$, uti ecclesiae huic antiquius inserviens, per p. Deputatum stringantur. Instrumenta vero et libelli musicales per pilrem Praefectum capellistarum ${ }^{\text {io }}$ sigillentur et subscribantur, praevia relatione partiali capitulo reservata.

[1279] s. 600. Notarius Capituli. In praesenti qapitulo obligatur pilris rmus Jaśkiewicz, ut ad rdum Nikorowicz ${ }^{61}$ Varsaviam dirigat litteras, eundem pro functione notariatus eiusdem invitet et Capitulum suum specimen capacitalis ad exsecuendam hanc functionem sibi reservat.

[1280] s. 600 (9 Iun.). Inventarium Bibliothecae. Pro conscribendo inventario Bibliothecae curabit futurus Notarius Capituli comparari seorsivum librum, in eundemque hinc inventarium Bibliothecae, praevia verificatione, munde et accurate inscribet.

[1281] s. 600. Relatio pilris, Deputati ad librum fundationum. Pilris Szeliski deputatus retulit capitulo praesenti, quornodo liber fundationum non adeo adhuc accurate conscribitur. Ut autem accuratissime abhinc omnes fundationes connotentur, obligat Capitulum suum p. rmum Weżyk, ut qualibet septimana per mensem unum connotationes fundationales revideat et accuratiori conscriptioni absolvendarum fundationum attendat. Quo vero attinet fundationes nonnullas, quae non absolvantur, aut stipendium pro eis non solvícur, cognitio summarum fundationalium, scilicet ubinam hae summae locatae exsistant et utrum ab eis census Capitulo suo pendantur, plenarie ad concludendum et acquirendum hoc negotium praecommittitur pilri Procuratori bonorum, praevia relatione capitulo partiali reservata.

[1282] s. 603 (10 Iun.). [Procuratores electi in annum sequentem: massae seu bonoruri I. Kontowski, causarum B. Eukaszewicz].

[1283] s. 603-604. Deputatio ad suscipiendum iuramentum ab adm. rdo Vicecustode. [s, 604] Exsecutio huiusce iuramenti a rdo Vicecustode pilri massae Procuratori, praevia relatione futuro capitulo, reservatur.

Die 1 Iulii, in capitulo partiali ordinario:

[1284] s. 605. Beneficium psalteriatus ven. F. Nikorowicz confertur. Psalteriatum in Capella Tarnoviana tituli Smae Trinitatis Ecclesiae Collegiatae praesentis, morte et obitu adm. rdi Iacobi Jaramowski vicecustodis illius ultimi at immediati possessoris vacantem, capitulum praesens ven. Francisco Nicorowicz notario suo conferendo, eundem pro praesentatione et institutione, ad quem de iure, remisit.

[1285] s. 605. Altaria S. Barbarae ven. Nikorowicz confertur. Alta-

59 Rybicki diugoletni organista kolegiacki.

* Prefe kiem kapeli kolegiaclicj bywa jeden $z$ kanoników.

61 Ks. Franciszek Nikorowicz niebawem not, kap. 
riam Sanctae Barbarae in Ecclesia Collegiata praesenti, post mortem et obitum ilris adm. rdi Feliciani Wyszyński anteacti notarii capitularis, capitulum praesens ven. Francisco Nikorowicz notario sui Capituli contulit.

[1286] s. 605-606. Susceptio in secretarium Capituli ven. Nikorowicz et iuramentum. Post mortem et obitum rdi Feliciani Wyszyński anteacti notarii et secretarii capitularis, praesens capitulum ad electionem in locum eius notarii condescendendo unanimi votorum consensu ad praemissam functionem ven. Franciscum Nikorowicz assumpsit. Qui taliter receptus iuramentum in capitulo praesenti in eam rotam praestitit:

Ego Franciscus Nikorowicz iuro Deo Omnipotenti, quod assumptus in secretarium Capituli, Archi[s. 606]vum Capituli custodiam, omnia accurate scriptis mandabo, secreta Capituli per omnia servabo, praesentias Perillustrium Dominorum fideliter connotabo et omnia, quae munus secretarii concernunt, diligenter obibo. Praestito itaque in manibus pilris canonici Zeliński iuramento praeinserto, eidem novo electo et assumpto Notario acta Capituli tradidit, assignando eidem pro annua pensione: primo florenos quadringentos more antiquo cum obligatione duarum in hebdomada missarum - unius ad Altare Corporis Christi, alterius ad Altare Sanctae Crucis; deinde alios florenos quadringentos doni gratuiti; item decimas post agros cmenthonales Płyćwia et Swięte, fructumque ex agro uno Civitatis Antiquae Eoviciensis, ac consolationum solito more, quas Perillustres Capitulares sub tempus capitulorum generalium percipere solent, eidem Notario medietatem, ac solitas alias obventiones notarios respicientes. Et pro intromittendo ab in domum no tarialem capiendamque eius possessionem pilrem rmum Jaśkiewicz canonicum designavit praesentium vigore.

D. 8 Iulii, in capitulo partiali ordinario:

[1287] s. 607. Litterae ab ilmo eppo Culmensi. Responsum ad litteras Capituli praesentis ab ilmo Bajer episcopo Culmensi receptum et in hodierno capitulo relectum, ratione apparatus e Sacristia huius ecclesiae per eundem commodati, praesens capitulum cum aliis litteris ab eodem ilmo Episcopo ad se directis in Archivo suo conservari mandavit, ac epistolam gratiarum actoriam pro assecuratione, quod se non solum eundem apparatum redditurum, verum etiam alium proprium cum certa summa per ultimam voluntatem legaturum promiserat, pilris rmus $\mathrm{Cu}-$ stos praesidens sui Capituli conscribere munus in se suscepit.

D. 12 Augusti, in capitulo partiali ordinario:

[1288] s. 609. Negotia ex generalibus capitulis remissa. Quoniam multa negotia ex generalibus capitulis crebro ad partialia capitula remittuntur, in quibus per oblivionem nihil de eiusmodi negotiis tractatur, proinde abhinc rdus Notarius tempore partialium capitulorum ea in memoriam revocabit.

D. 2 Septembris, in capitulo partiali ordinario:

[1289] s. 610. Deputatio Varsaviam. Quoniam Congressus Episcoporum Varsaviae proxime celebrandus totalem summam sescentorum millium florenorum polon. subsidii charitativi, constitutione anni 1775 laudatam ac per statum spiritualem Regni Poloniae et Magni Ducatus

ab intermittendo akta. 
Lithvaniae ad Thesaurum Reipublicae quotannis pendendam, est dispartiturus: proinde praesens capitulum necessarium duxit pilres canonicos Żeliński et Kontowski Varsaviam deputare, qui de dispositionibus huiusce Congressus Capitulum informarent.

[1290] s. 611-614. Ordinatio Stalli Custodialis et praesentiarum Coadiutorum. „Gabriel Ioannes Junosza comes in Srzeńsko a Podosie Podoski Dei et Apostolicae Sedis gratia archiepiscopus Gnesnensis, legatus natus, Regni Poloniae et M. Ducatus Lithvaniae primas primusque princeps, abbas commendatarius Tyniecensis et Paradisiensis, praepositus generalis Miechoviensis, Ordinum Aquilae Albae et $\mathrm{S}$. Andreae eques universis et singulis, quorum interest aut quomodolibet in posterum interesse poterit. Significamus et ad certam notitiam deducimus devolutam fuisse ad nos quaestionem ac controversiam inter pilrem adm. rdum Stanislaum Kaszowski Archicollegiatae Lanciciensis decanum uti et tamquam pilris adm. rai Iosephi Jaksa Marcinkowski Insignis Collegiatae Eoviciensis archidiaconem coadiutorem ab una et pilrem rmum Thomam Szaniawski cancellarium Metrop. Gnesnensem, dictae Insignis Collegiatae Łoviciensis custodem de et super stallo et loco sedendi in choro ac capitulo ex altera; totum denique Venerabile Capitulum Insignis Collegiatae Łoviciensis ratione participationis distributionum quotidianarum ex tertia partibus. Utque mernoratae superius quaestionis et controversiae finem imponeremus, pro ea qua fungimur ordinaria potestate, requisiti fuimus postulato Ven. Capituli Eoviciensis, porrecto nobis per ipsius plenipotentem pilrem rmum dnum Thomam Szaniawski cancellarium Ecclesiae Metrop. Gnesnensis et custodem Ins. Collegiatae Eoviciensis. Postulatum porro istud erat tenoris sequentis: Infrascriptus a Capitulo Eoviciensi delegatus plenipotentiarius Celmo et Rmo Primati Regni, archiepiscopo metropolitano Gnesnensi, pastori et protectori suo nomine Capituli humillime postulor, quatenus categorias binas inter pilrem Kaszowski decanum Lanciciensem, coadiutorem archidiaconum Eoviciensem ab una et Custodem eiusdem collegiatae ratione stalli et loci in capitulo [s. 612] parte ab altera; tum alteram categoriam inter eundem Coadiutorem ratione distributionis quotidianarum praesentiarum in absentia sui Coadiuti praetensarum decidere et hanc decisionem vim statuti habere, declarare dignetur. Post quod quidem postulatum his verbis conceptum nobisque porrectum, requisivimus coram nobis produci authentica documenta tam pro parte Custodis et Capituli Eoviciensis, quam pro parte pilris rdi Archidiaconi Eoviciensis eiusque Coadiutoris. Ad talem nostram requisitionem pilris rdus dnus Godaczewski ${ }^{82}$, agens vi plenipotentiae sibi datae ad hocce negotium inchoandum et terminandum a pilri rdo dno Kaszowski coadiutore Archidiaconatus Eoviciensis, porrexit nobis inter alia erectionem dicti archidiaconatus Łoviciensis factam a Ioanne de Łasko archiepiscopo Gnesnensi, praedecessore nostro. In qua erectione ad praesens negotium terminandum invenimus ordinationem his verbis conceptam: Perpendentes amplitudinem Archidiaconatus Lanciciensis, erigendum duximus archidiaconalem dignitatem in Ecclesia Collegiata Eoviciensi. In qua ecclesia per olim praedecessores nostros erecta et fundata tres praelatos, scilicet

62 Ks. Godaczewski $z$ archidiecezji. 
praepositum, decanum et custodem, canonicos vero numero 10 etc. His praemissis de ordine trium praelatorum, in ulteriori traciatu eiusdem erectionis idern Ioannes archiepiscopus ordinat, quatenus futurus archidiaconus Eoviciensis hubeat pro fundo canonicatum et praebenalam in Ecclesia Eoviciensi, quam tum temporis possidebat Stanislaus de Zawada canonicus toviciensis. Tinit denum talem ordinationom his verbis: Decernentes et volentes, quatenus archidiaconus pro tempore exsistens dicti Archidiaconatus ₹oviciensis (sicut praefertur) per nos erecti, titulo archidiaconatus in dicta Ecclesia Collegiata Loviciensi superpelliceo et dalmu'io stalloque in choro ac tum canonicatum et praebendam praedictos, quorum possessionem absque alia praesentatione tenebit sibi vigore praesentis privilegii, quamprimum illos per cessum vel decessum memorati domini Stanislai, vel quamvis aliam dimissionem aut quovis alio modo [s. 613] (ut praedictum est) vacare contigerit, libere intrare, apprehendere et manutenere possit et valeat. Cum ex tali erectione Archidiaconatus Eoviciensis luculenter pateat tertium obtinuisse locum et stallum custodem Eoviciensem in Ecclesia Insignis Collegiatae Eovi. ciensis, antequom dignitas archidiaconalis in eadern ecclesia fuit erecta, certum sit etian archidiaconum Eoviciensem successisse in fundum et praebenclam Stanislai de Zawada canonici. Clare etiam patet, quod iuxta ordinationem erectionis Archidiaconatus Eoviciensis superpelliceo, dal. mutio, stallo in choro nonisi per cessum vel decessum memorati dni Stanislai apprehendere et manutenere potuisset. Continua etiam praxis in aliis ecclesiis cathedralibus et collegiatis doceat iuxta ordinem vocationis seu erectionis dignitatum ecclesiasticarum manuteneri et possideri stalla. Certum est etiam cusiodem Koviciensem semper fuisse possessorem stalli tertii. Porro si aliquando contigerat, annuente custode, tertium stallum ab archidiacono fuisse occupatum, praeiudicium inde nullum poterit promanare ordinationi stallorum secundum tempus, quo unaquaeque praelatura fuerat erecta. Resolventes igitur quaestionem de stallo et loco in capitulo inter Custodem et Archidiaconum Łoviciensem decernimus et statuinus, ut iuxta sonantiam erectionis Archidiaconatus Custos possideat tertium stallurn et tertium locum in capitulo, Archidiaconus vero, cum originaliter successerat in locum canonici Stanislai de Zawada, idem stallum et locum in capitulo obtineat. Quod spectat alteram categoriam eiusdem pilris Kaszowshi coadiutoris archidiaconi Eoviciensis cum toto V. Capitulo eiusdem ecclesiae super praetensa participatione distributionum quotidianarum eo tempore, quo eius Coadiutus abest, ipse vero coadiutor Divinis adest. -- _ $[s, 614] \ldots$ [Responsum negativum]. Et ita etiam quoad alios coadiutores statuimus, ordinamus, pronuntiamus ac sententiamus praesentemque nostram ordinationem, decisionem et resolutionem vin et robur perpetuae firmitatis habere volumus et mandamus. In quorum fidera praesentes, manu nostra. subscriptas, sigillo nostro communiri iussimus. Datum Gedani, die 8 mensis Augusti anno Domini 1775. Cabriel Ioannes archiepiscopus et primas mp. (Locus sigilli). Yosephus Dodionar regens Cancellariae Suae Celsitudinis Primatialis mp.". 1775 die Mercurii 30 mensis Augusti in Officio Vicariatus Generalis Gnesnensis Eovicii productum et actis ingrossatum. Ita est JC. Głowacki actuarjus mp.

[1291] s. 614-615. Installatio rdi Notarii ad canonicatum honora- 
rium. [s. 615] Coram pilbus rinis Canonicis capituli praesentis comparens personaliter adm. rdus Franciscus Nikorowicz actorum Cavituli eiusdem notarius, exhibitis literis creationis suae in canonicun honorarium, sibi a Celsissimo Principe, Domino N.C. Dei ct Apostolicae Sedis gratia archiepiscopo Gnesnensi - - Gedani die 10 mensis Augusti anno praesenti datis et benigniter impertitis, virtute et auctoritate corundem petiit se ad realem et actualem dicti canonicatus honorarii possessionem admitti et investiri, stallumque in choro et locum in processionibus aliaque quaevis sibi competentia committi et assignari. Quibus capitulum praesens visis lectisque litteris, postulatum eius grato animo suscipiendo in actualem possessionem dicti canonicatus honorarii inducendum esse duxit et ad installationem pilrem canonicum İukaszewicz deputavit. Qui pilris ad praemissa Deputatus eidem adm. rdo Francisco Nikorowicz notario Capituli praesentis ultimum a cornu Fpistolae stallum, in processionibus competentem locum assignavit, cum plenitudineque iuris contulit. In quorum reali et actuali possesione manutentus est manutene-. turque praesentium vigore.

D. 23 Septembris, in capitulo partiali ordinario:

[1292] s. 615-616. Celebratio festorum sublatorum.

D. 21 Novembris, in capitulo partiali ordinario:

[1293] s. 618. Iiquidatio proventuum ex Collegio Episcoporum iniuncta.

Dieb. 8-12 Decembris, in capitulo generali Conceptionis:

[1294] s. 619 (9 Dec.). Lectio statutorum et recapitulatio. Relectis statutis et decretis reformationum, tum decretorum anteacti capituli generalis et subsequentium partialium capitulorum, eadem Perillustres Capitulares ratihabuerunt.

[1295] s. 619. Apparatus apud Cels. Principem et eppum Culmen. Apparatus Celmo Principi et episcopo Culmensi ex Sacristia Collegiatae praesentis accommodati, propter memoriam, hisce in actis connotantur.

[1296] s. 620. Deputatus ad revisioneriu libri connot. fundationum. Deputatur ad revidendum librum connotandarum fundationum pilris canonicus Smelisli, cum relatione Capitulo facienda.

[1297] s. 620 (11 Dec.). Relatio ad revisionem libri connot. fundationum Deputati. Retulit pilris canonicus Szeliski, ad revidendum librum absilvendarum fundationum deputatus, multo accuratius quam antea annotari absolvi solitas obligationes missarum, adinvenisse tamen nonnullos defectus, qui facile suppleri possunt. Pro qua relatione gratias eidem retulit praesens capitulum.

[1298] s. 622 (12 Dec.). Mutratio pecuniae ex massa. Quoniam mutuatio pecuniae ex massa sive praenumeratae in vim deserviendorum plurimum perturbat Capitulum et procuratorem massae, ac negotia in Capitulo principaliora supprimit massa, quoque et nunc est notabiliter extenuata, proinde capitulum praesens prohibet eiusmodi cuicuam Perillustrium Dominorum pecuniae et praenumeratae concessionem.

[1299] s. 625. Litterae ad ilmum eppum Kijoviensem. Litteras consignandas ad ilmum Ossoliński episcopum Kijoviensem ${ }^{63}$, quatenus summum

${ }^{63}$ Franciszel Salezy Kandyd Ossolinski $h$. Topór, dr teol., franciszłanin, zm. jako biskup kijowski $w 1783$ r. 
decem millium florenorum polon., sibi a Capitulo accommodatam, pro Festo SS. Trium Regum anni proxime sequentis Capitulo exsolvat, decrevit per praesentes.

\section{6}

Die 9 Martii, in capitulo partiali ordinario:

[1300] s. 628. Litterae ad pilrem rmum Decanum. Epistolam gratiarum actoriam ad pilrem rmum Kosicki canonicum Gnesnensem, decanum loci praesentis Perillustres Capitulares pro oblatis sibi quattuor scriniis vitri censuerunt.

D. 11 Martii, in capitulo partiali extraordinario:

[1301] s. 629. Obitus ilmi [episcopi Dominici] Kiełczewski praepositi Eoviciensis.

D. 30 Martii, in capitulo partiali ordinario:

[1302] s. 631. Contributio fumalis [vulgo podymne].

D. 13 Aprilis, in capitulo partiali ordinario:

[1303] s. 633. Processus antecedens Iubilaeum Magnum.

D. $27^{\text {ac }}$ Aprilis, in capitulo partiali ordinario:

[1304] s. 633-634. Proventus et obligationes Collegiorum [pro subsidio charitativo].

Diebus 28 Maii - 8 Iunii, in capitulo generali Pentecostes:

[1305] s. 634. Lectio statutorum et recapitulatio. Relectis statutis et decretis reformationum, ad recapitulationem decretorum tam anteacti capituli generalis, quam subsequentium partialium Perillustres Capitulares processerunt, quae pariter relecta ratihabuerunt.

[1306] s. 635 (29 Maii). Liber fundationum. Ad revidendum librum connotandarum fundationum absolvi solitarum deputatur pilris Szeliski, cum relatione Capitulo facienda.

[1307] s. 635. Apparatus apud Cels. Principem et ilmum eppum Culmen. Apparatus ecclesiae praesentis apud Celmum Principem feliciter modernum et episcopum Culmensem reperibiles, propter memoriam, hisce in actis annotentur.

[1308] s. 636 (30 Maii). Litterae ad ilmum eppum Kijovien. Litteras ad ilmum episcopum Kijoviensem dirigendas, intuitu solutionis summae 10 millium flor. polon. ab eodem Capitulo suo provenientium, Capitulum statuit per praesentes.

[1309] s. 637 (3 Iun.). Relatio revisionis libri fundationum. Retulit pilris canonicus Szeliski, ad revisionem libri connotandarum fundationum deputatus, omnes missas fundationales, quae absolvuntur, comotatas esse, nonnullas autem fundationes, videlicet Leszczynianam, Obartuszkovianam, Travinianam, Sancti Liborii, non annotari. Proinde commendatur futuro pilri massae Procuratori, ut inquirat rationem huius negligentiae, et ut exactius missae fundationales absolvantur et absolutae connotentur, iniungitur.

[1310] s. 637. Inventarium supellectilis ecclesiasticae. Complendi inventarium supellectilis ecclesiasticae, et relationem a pilbus ex anteacto

ac 8 blęd. akta. 
capitulo generali ad id Deputatis recipiendi partiale capitulum virtute praesentium habebit vigorem et potestatem.

[1311] s. 640 (8 Iun.). [Procuratores in annum sequentem electi: bonorum I. Kontowski, causarum B. Eukaszewicz].

[1312] s. 640. Eleemosyna pro erubescentibus mendicare. Pilres ad Montem Pietatis Deputati ${ }^{\text {BA }}$ census a summa Potociana reperibiles emendicare erubescentibus distribuant.

[1313] s. 640-641. Tabellae proventuum et obligationum collegiatae praesentis. Pilres domini ad praescriptum Ilmi Collegii Episcoporum ad conficiendas tabellas proventuum et obligationum tam Capitularium ex bonis, decimis et summis, quam omnium et singulorum Collegiorum et Beneficiatorum collegiatae praesentis Deputati, Consistorio praesenti Eoviciensi inchoaturo [s. 641] porrigendas, easdem capitulariter produxerunt. Quibus capitulum praesens visis et lectis, pilbus Deputatis gratias egit et in recompensam laboris in conficiendis iisdem tabellis perpessi p. canonico Żelińsk $\dot{i}$ spatio sex hebdomadarum praesentiam connotandam, rdo vero Notario florenos trecentos dendos censuit per praesentes.

D. 3 Augusti, in capitulo partiali ordinario:

[1314] s. 642. Introductio Iubilaei Magni.

D. 9 Augusti, in capitulo partiali extraordinario: nis.

[1315] s. 643. Ordo devotionis in collegiata praesenti tempore Missio-

D. 17 Augusti, in capitulo partiali ordinario:

[1316] s. 643. Purgatio caminorum.

D. 20 Augusti, in capitulo partiali extraordinario: nij.

[1317] s. 644. Votiva de Sancto Spiritu pro successu Comitiorum [Reg-

D. 28 Septembris, in capitulo partiali ordinario:

[1318] s. 645. Devotio Sacri Iubilaei.

[1319] s. 645. Dies Medicorum ${ }^{65} 30$ superadditi.

D. 12 Octobris, in capitulo partiali ordinario:

[1320] s. 646. Conductio missionariorum, pro iisdem residentia et victus.

D. 26 Octobris, in capitulo partiali ordinario:

[1321] s. 647. Missio crastina die incipiens et deputatio pilris Rybinski canonici.

D. 9 Novembris, in capitulo partiali ordinario:

[1322] s. 647. Cultus Divinus [in collegiata tempore Iubilaei].

[1323] s. 647. Viales et eleemosyna patribus missionariis.

D. 16 Novembris, in capitulo partiali ordinario:

[1324] s. 649-650. Pro iubilaeo futuro memoria.

Dieb. 8-11 Decembris, in capitulo generali Conceptionis:

[1325] s. 652 (9 Dec.). Lectio statutorum et recapitulatio decretorum. Relectis statutis et decretis reformationum, tum capituli anteacti generalis et subsequentium partialium, Perillustres Domini eadem ratihabuerunt.

${ }_{64}$ Kanonicy Wę̇̇yk $i$ Zeleński - jak przyp. 53 i 58 w księdze XI.

f5 Owe dni wolne od rezudencji do XVII w. nazyzuano "vindemiae”, póniej „dies amicorum”, a obecnie „,dies medicorum”. 
[1326] s. 652. Liber connotandarum fundationum. Ad revidendum librum connotandarum missarum, vi variarum fundationum per clerum collegiatae praesentis absolvi debitarum, deputatur pilris canonicus Kamieński.

[1327]. s. 653. Apparatus. Ratione apparatuum tam per Celmum Prin-cipem, quam et ilmum episcopum Culmensem, a Capitulo accommodatorum, reassumuntur anteriorum capitulorum generalium decreta.

[1328] s. 653. Supellex ecclesiastica. Ad conficiendum inventarium supellectilis ecclesiasticae deputantur pilres Szeliski et Jaśkievicz canonici.

[1329] s. 653. Summa $10 \mathrm{~m}$ /illium] flor. polon. apud ilmum cppum Kijovien. Quoniam ilmus episcopus Kijoviensis summam decem millium florenorum polon., ad scriptum manuale sibi a Capitulo commendatam, pro futuro festo S. Ioannis Baptistae in anno sequenti 1777 Capitulo reddere appromiserat, proinde intuitu solutionis eiusdem summae pro supradicto termino litteras dirigendas ad eundem Capitulum decrevit.

\section{7?}

Die 4 Ianuarii, in capitulo partiali ordinario:

[1330] s. 660-661. Percepta annualis pecunia ex bonis capitularibus.

D. 1 Februarii, in capitulo partiali ordinario:

[1331] s. 664-665. Eleemosyna tempore Iubilaei collecta.

D. 5 Aprilis, in capitulo partiali ordinario:

[1332] s. 667. Litterae innotescentes Capitulum de termino dispartitionis quotae totalis pro subsidio charitativo pendendae.

D. 26 Aprilis, in capitulo partiali ordinario:

[1333] s. 668. Deputatio ad Cels. Principem Nominatum ${ }^{66} \mathrm{cum}$ gratulatione.

[1334] s. 668-669. Census de Szreńsk, quota pro sebo ex Arce Łovic., tum apparatus commodati repetendi. Ad tractandum cum pilri rmo Wiażewicz canonico Gnesnensi et Eoviciensi, commissario ${ }^{17}$ olim cels. principis Podoski archieppi Gnesn. immediati defuncti, ratione appromissae solutionis census a summis in bonis [s. 669] Szreńsk haerentibus, tum quotae pro sebo ex Arce Łoviciensi pendi debitae, necnon restitutionis ap-paratuum et calicum ex Sacrario Ecclesiae Collegiatae praesentis celmo olim Principi commodatorum ad scriptum reversale, pilrem canonicum Kamieński, pro tempore Suae Celsitudinis capellanum [et] p. rmum Wę.żyk can. Posnaniensem et Łovic. capitulum praesens deputavit.

D. 28 Aprilis, in capitulo partiali extroordinario:

[1335] s. 669. Litterae significantes obitum cels, archieppi ${ }_{6}$ nesnensis [Podoski, 5 Apr. Marsiliae defuncti].

Diebus 20 Maii - 2 Iunii, in capitulo generali Pentecostes:

[1336] s. 670. Lectio statutorum et recapitulatio decretorum. Relectis statutis et decretis reformationum, tum anteacti capituli generalis, quam

${ }_{66}$ Antoni Kazimierz Osirowsici h. Grzymała, m.in. arcybp gniezn. i prymas 10 l. $1777-1784$.

67 Wackaw Wiażewicz h. Leliwa, dr teol. i ob. prawa, eks-jezuita, m.in. kan. ใolv. $w$ l. 1771-1781. 
subsequentium capitulorum partialium, eadem decreta praesens capituIum ratihabuit.

[1337] s. 670. Litterae ad eppum Kijovien. Rogatur praesentibus pilris canonicus Szeliski, ut litteris ad ilmum Ossoliński episcopum Kijoviensem, a Capitulo suo rescribendis, solutionis summae tam originalis, quam censualis exposcat.

[1338] s. 671 (24 Maii). Notificabit dnum Praesidentem de agitando capitulo Notarius. Obligatur praesentibus ilris Capituli Notarius, ut semper notificet pilrem rmum Capituli Praesidentem de loco et tempore inchoandi capituli. Pro partialibus sive septimanalibus capitulis ante horam nonam pulsum campanae maioris fieri curabit, pro generalibus $a b-$ sque pulsu hora nona Perillustres Domini conveniant.

[1339] s. 671. Celebratio missarum conventualium festis sollemnior.

[1340] s. 671. Deputatio ad librum fundationum. Ad revidendum librum absolvendarum obligationum sive missarum deputatur pilris canonicus Kamieński, cum relatione in capitulo partiali facienda.

[1341] s. 672. Iuramentum Vicecustodis. Ad auscultandum iuramentum vicecustodis collegiatae praesentis adm. rdi Iacobi Jaramowski pilris canonicus Kontowski bonorum procuratos, anterioris capituli generalis decreto deputatus, retulit eundem in praesentia sui solitum iuramentum praestitisse.

[1342] s. 672. Apparatus apud eppum Culmen. Apparatus apud ilmum Bajer episcopum Culmensem ex Sacrario collegiatae praesentis accommodatus, ob memoriam, hic in actis connotatur.

[1343] s. 672-673. Summae originales et censuales, tum apparatus apud olim cels. principem Podoski AG. Ad vindicandas summas originales et censuales per celmum olim principem Ioannem Gabrielem Podoski archiepiscopum Gnesnensem - - super bonis omnibus, potissimum Szreńsk suis haereditariis, Capitulo praesenti inscriptas; tum quotam pro sebo, vigore privilegiorum ad Ecclesiam Collegiatam Eoviciensem pendi solitam, durante cels. Principis dominio in Thesauro suo retentam; necnon apparatus ex Sacristia collegiatae praesentis ad capellam dictae suae Celsitudinis commodatos; tum summam pro calce ad aedificandam Domum Invalidorum Presbyterorum, sub protectione Capituli exsistentium, coëmpta et per eundem [s. 673] Celmum in exstructionem braxatorii et praedii Łoviciensis conversa et nondum exsoluta, iuxta seorsivos calculos liquidatas; et documenta sibi ex Archivo Capitulari extradita et extradenda repetenda deputatur ilmus Antoninus Przedwiojewski episcopus Bolinensis, canonicus loci praesentis. Cui plenaria facultas et omnimoda potestas praemissa recipiendi, summas levandi, de receptis vel levatis etiam officiose quietandi et, si opus fuerit, in quovis iudicio Regni Maioris Minorisve subsellii intuitu praemissorum iure agendi, decreta obtinendi, publicationes et exsecutiones ac traditiones bonorum urgendi, iuramenta attestandi etc. et omne, quod negotium poposcerit, exsequendi datur et committitur, pro quorum omnium ratihabitione Capitulum cavet per praesentes.

[1344] s. 676 (31 Maii). Relatio Deputatorum ad revidendam supellectilem ecclesiae. Pilres canonici Szeliski et Jaśkiewicz, ad revidendam supellectilem ecclesiasticam deputati, produxerunt inventarium dictae su- 
pellectilis accurate descriptum. Cuius postquam ad tenorem statutorum alterum exemplar conscribetur, datur vigor partiali capitulo eadem inventaria manu pilris Praesidentis subscribendi, ac cum peristromatis, ne deteriorentur, disponendi.

[1345] s. 678 [2 Iun.]. De expensis extraordinariis.

[1346] s. 680. Sit in bonis mensura regia.

[1347] s. 680. [Procuratores electi in annum sequentem: bonorum I. Kontowski, causarum B. Łukaszewicz].

[1348] s. 680-681. Subsidium charitatiovum a Clero Minori.

D. [7] Iunii, in capitulo partiali ordinario:

[1349] s. 681-682. Peristromata accommodanda. Pilris bonorum Procurator retulit se esse requisitum a Curia Cels. Principis Nominati super accommodatione peristromatorum ad tegendas parietes hypocaustorum primatialium in Domo Congregationis Missionis, in quibus Cels. Princ. Nominatus ad [s. 682] tempus residebit. Proinde capitulum praesens eadem extendendi et accommodandi adm. rdo Vicecustodi facultatem dedit, et scriptum reversale cum specificatione qualitatis et quantitatis eorundem, a quo intererit, recipiendi munus praecommittit. Ibidem sella artificia Gedanensia, pelle deaurata tecta, numero quinque ex Capitulari Stuba ad tempus accommodata, propter memoriam his in actis annotantur.

D. 28 Iunii, in capitulo partiali ordinario:

[1350] s. 685. Obitus pilris Marcinkowski archidiaconi Łoviciensis.

D. 5 Iulii, in capitulo partiali ordinario:

[1351] s. 685-686. Apparatus post obitum Praepositi Capitulo oblati. [s. 686] Casulam, infulam auro textas et tobaleam albam ab exsecutoribus olim ilmi [Dominici] Kiełczewski suffraganei Chelmensis, praepositi loci praesentis Capitulo Eoviciensi oblatas, inventario supellectilis ecclesiasticae ascribendas Capitulum censuit.

D. 30 Augusti, in capitulo partiali ordinario:

[1352] s. 693. Salutatio imminens Celmi Principis [circa ingressum ad collegiatam].

D. 18 Octobris, in capitulo partiali ordinario:

[1353] s. 702. Crux argentea Cels. Principi commodata. Scriptum reversale, datum Skiernieviciis d. 12 Octobris a. 1777 manu Celmi Principis feliciter moderni subscriptum et eigillo communitum, super crucem argenteam portatilem, ex quinque frustis compositam, cum effigie Christi Crucifixi a capitulo praesenti per manus adm. rdi Iacobi Jaramowski vicecustodis Suae Celsitudini ad certum tempus accommodatam, capitulum praesens circa inventarium supellectilis ecclesiasticae conservari mandavit.

Dieb. 8-13 Decembris, in capitulo generali Conceptionis:

[1354] s. 711. Lectio statutorum. Relectis statutis et decretis reformationum limitatum capitulum ad diem crastinam.

[1355] s. 712 (9 Dec.). Recapitulatio decretorum. Relectis decretis anteacti capituli generalis Festorum Pentecosten, tum subsequentium partialium, eademmet Perillustres Capitulares ratihabuerunt.

[1356] s. 712. Litterae ad ilmum eppum Kijovien. Quoniam ilmus Ossoliński episcopus Kijoviensis appromissam exsolutionem summae 
10 millium flor. polon. sibi ad scriptum manuale accommodatam non effectuavit, iterum intuitu exsolutionis ad eundem epistolam consignandam Capitulum censuit per certum latorem ad manus eius transmittendam.

[1357] s. 712. Liber fundationum. Ad revidendum librum absolvi solitarum missarum fundationalium deputatur pilris canonicus Kamieński, cum relatione Capitulo facienda.

[1358] s. 713. Apparatus apud ilmun eppum Culmen. Intuitu apparatus sacri, post obitum celmi olim principis Komorowski ecclesiae praesenti destinati, ad ilmum episcopum Culmensem litteras dirigendas $\mathrm{Ca}$ pitulum censuit.

[1359] s. 713 (10 Dec.). Relatio [eppi Przedwojewski] in negotio cum successoribus celmi olim Podoski $A G$ et cum gnoso Lenk.

[1360] s. 719 (12 Dec.). Relatio Deputatorum ad conscribendum inventarium ecclesiae. Pilres dni Szeliski et Jaśkiewicz canonici, ad conscribendam supellectilem ecclesiasticam deputati, produxerunt inventarium eiusdem supellectilis, sed nondum completum. Proinde capitulum praesens ad complendum eundem hos obligavit et completum in capitulo partiali subscribendum decrevit.

[1361] s. 722 (13 Dec.). Relatio Deputati ad librum fundationum. Pilris canonicus Kamieński, ad verificandum librum absolvendarum fundationum in collegiata praesenti deputatus, retulit quomodo onnes missas fundationales absolvantur exceptis missis ex fundatione rdi Trawiński.

\section{8}

Die 21 Martii, in capitulo partiali ordinario:

[1362] s. 727. Mausoleum Celmi Primatis [Ostrowski, desideratio].

D. 25 Aprilis, in capitulo partiali ordinario:

[1363] s. 729. Deputatio ad receptionem apparatuum sacrorum. Ad recipiendos apparatus Ecclesiae Collegiatae praesentis, cels. olim principi Podoski archiepiscopo Gnesnensi et primati accommodatos, deputatur pilris rmus Adalbertus Wężyk ecclesiarum cathedr. Posnaniensis, collegiatarum Eoviciensis canonicus, Eascensis decanus, Cui datur facultas dictos apparatus iuxta regestrum originale, sibi per copiam authenticam datam, specificatos recipiendi de manibus pilris rmi Wiażewicz canonici Gnesn. et Łovicien., tamquam olim cels. Primatis plenipotentiarii, de receptis quietandi.

D. 23 Maii, in capitulo partiali ordinario:

[1364] s. 731. Capella musices Skiernievicios mittenda.

[1365] s. 731. Summa 10 millium flor. polon. apud ilmum eppum Kijovien. Retulit pilris canonicus Eukaszewicz causarum procurator, quomodo ilmum Ossoliński episcopum Kijoviensem adiverit, solutionemque summae originalis 10000 flor. polon. nomine Capituli ab eodem ilmo episcopo requisiverit. Qui se pro die 3 Iulii anni currentis soluturum pro certo, sive per se sive per suum plenipotentem, assecuravit.

D. 5 Iunii, in capitulo partiali extraordinario:

D. 6 Iunii, in capitulo partiali ordinario: 
[1367] inter p. 732 et 733. [Testamentum eiusdem Kosicki, polonice, sedecim pp.].

Diebus 9-13 Iunii, in capitulo generali Pentecostes:

[1368] s. 734. Lectio statutorum et recapitulatio decretorum. Relectis; statutis et decretis reformationum, tum decretis anteacti capituli generalis et subsequentium partialium, eademmet decreta ratihabita.

[1369] s. 734 (10 Iun.). Inventarium ecclesiasticum. Argenteriam ecclesiasticam, ob metum calamitatis in Regno, servatam et in producto regestro per pilres Szzeliski et Jaśkiewicz canonicos, ad complendum inventarium ecclesiae ex immediate anteacto capitulo generali deputatos specificatam, inde eximendi et in librum supellectilis ecclesiasticae inducendi praesens capitulum iisdem deputatis dat facultatem per praesentes.

[1370] s. 734-735. Deputatio ad conscribendum inventarium curide decanalis. Ad conscribendum inventarium curiae decanalis, post obitum pilris [s. 735] rmi olim Kosicki decani Łoviciensis, deputantur p. Zeliński et Notarius Capituli.

[1371] s. 735. Ingrossatio testamentorum. Pilres Domini Capitulares studendo bono ordini decreverunt, quatenus testamenta ultimae voluntatis post obitum dominorum capitularium circa ecclesiam decedentium, in acta capitularia inducantur, salvo honorario Notarii pro labore circa praemissa praestando.

[1372] s. 736-737. Apparatus apud ilmum eppum Culmen. Ilmus Bajer episcopus Culmensis, litteris suis ad pilrem rmum olim Paulum Kosicki decanum loci praesentis directis, enuntiavit apparatus apud se retentos, post obitum celmi principis Komorowski archieppi Gnesnensis et ad Ecclesiam Collegiatam Łoviciensem dispositos et pertinentes, velle sine mora reddere et remittere. Et quoniam Gedanum pro festo S. Dominici se condescensurum pro certo affirmavit, hinc capitulum praesens pi]rem canonicum Rybinski deputavit ad ilmum Garnysz referendarium Regni,'suffraganeum Pomeraniae ${ }^{68}$, quatenus ipse suum surrogatum iudicem Gedanensem p. Lipiński ${ }^{69}$ obligare dignetur ad recipiendos dictos apparatus de manibus ilmi eppi Culmensis [s. 737] eosdemque per occasionem opportunam Eovicium remittendos: Litteras quoque ad ilmum eppum Culmensem consignandas Capitulum statuit cum denuntiatione, quod dictos apparatus pilris Lipinski ad habeat in commissis suscipere et suo Capitulo remittere.

[1373] s. 74.0 (12 Iun.). Liber fundationum. Ad revidendum librum absolvendarum obligationum missarum deputatur pilris canonicus'Kamieński, cum relatione Capitulo facienda.

[1374] s. 744 (13 Iun.). Ad conficienda inventaria praediorum capitulärium deputatio. Ad conficienda et conscribenda inventaria praediorum et villarum tam ad mensam Capituli pertinentium, quam advocatiarum sub inspectione et regimine Capituli exsistentium deputantur, praeter pilrem futurum bonorum Procuratorem, ilmus Przedwojewski episcopus

ad Lipnicki akta.

68 Maciej Grzegorz Garnysz h. Poraj, dr ob. prawa, aktual. referendarz kor., sufr, pomorski $w$ diec. wtoct. $i$ audytor prym. Ostrowskiego, potem biskup chetmski $i$ podkanclerzy.

${ }_{89}$ Oficjat pomor. Antoni Marcin Szur Lipinski zmart już w 1774 r., o czym kapitula nie wiedziata. 
Bolinensis et p. Kamieński, qui inventarium advocatiae Skaratki ${ }^{70}$ ante festum imminens $\mathrm{S}$. Ioannis Baptistae confici curabunt.

[1375] s. 744-745. Notarius pioventualis conducendus. Mensura Varsaviensis Regia sit unica in bonis. Quantum credendum colonis in tabernis. Minuendo labores Procuratoribus bonorum mensae Capituli, providendoque accuratae annotationi regestrorum oeconomicorum, statuit $\mathrm{Ca}-$ pitulum, ut Notarius proventualis conducatur, qui officia ex munere sibi incumbentia obibit, claves tamen a granaris neque pecunias a tabernatoribus recipiet. -- -

[1376] s. 745. [Procuratores in annum sequentem electi: bonorum B. Łukaszewicz, causarum S. Szeliski].

[1377] s. 746. Ordo devotionis tempore missionis.

7o Skaratki wieś w par, Domaniewice k. Eowicza. 